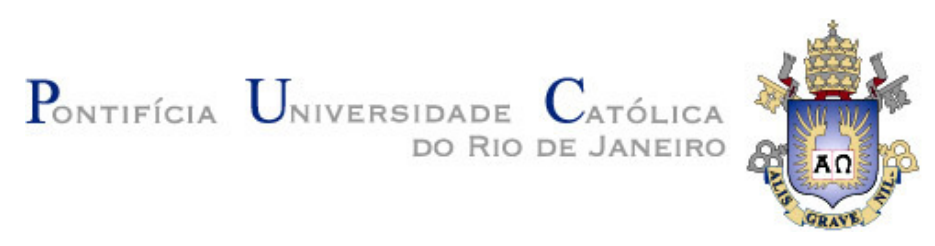

Juliana Barros Carvalho

\title{
Desenvolvimento de Sistemas de Detecção de Gases na Região do Infravermelho
}

Tese apresentada como requisito parcial para obtenção do título de Doutor pelo Programa de PósGraduação em Engenharia Elétrica da PUC-Rio.

Orientador: Prof. Marbey Manhães Mosso

Co-orientador: Dra. Sully Mejía Quintero

Rio de Janeiro

23 de Setembro de 2016 
Desenvolvimento de Sistemas de Detecção de Gases na Região do Infravermelho

Tese apresentada como requisito parcial para obtenção do grau de Doutor pelo Programa de Pós-Graduação em Engenharia Elétrica do Departamento de Engenharia Elétrica do Centro Técnico Científico da PUC-Rio. Aprovada pela Comissão Examinadora abaixo assinada.

Prof. Marbey Manhães Mosso Orientador Centro de Estudos em Telecomunicações - PUC-Rio

Dra. Sully Milena Mejia Quintero Co-orientadora Departamento de Engenharia Mecânica - PUC-Rio

Profa. Maria Cristina Ribeiro Carvalho Centro de Estudos em Telecomunicações- PUC-Rio

Dr. Giancarlo Vilela de Faria Departamento de Engenharia Mecânica - PUC-Rio

Profa. Maria Aparecida Gonçalves Martinez CEFET/RJ

Prof. Ricardo Marques Ribeiro UFF

Dr. Luiz Alberto de Andrade Comando-Geral de Tecnologia Aeroespacial

Prof. Márcio da Silveira Carvalho Coordenador Setorial do Centro Técnico Científico - PUC-Rio 
Todos os direitos reservados. É proibida a reprodução total ou parcial do trabalho sem autorização da universidade, da autora e do orientador.

\section{Juliana Barros Carvalho}

Graduou-se em Licenciatura em Física pela Universidade Federal Rural do Rio Janeiro (UFRRJ) em 2009. Mestrado em Engenharia Elétrica pela Pontifícia Universidade Católica do Rio de Janeiro (PUC-Rio). A atual linha de pesquisa é em Eletromagnetismo Aplicado, Dispositivos de Microondas e Sistemas de Comunicações Ópticas.

Ficha Catalográfica

\section{Carvalho, Juliana Barros}

Desenvolvimento de sistemas de detecção de gases na região do infravermelho / Juliana Barros Carvalho ; orientador: Marbey Manhães Mosso ; co-orientador: Sully Mejía Quintero. 2016.

116 f. ; $30 \mathrm{~cm}$

Tese (doutorado)-Pontifícia Universidade Católica do Rio de Janeiro, Departamento de Engenharia Elétrica, 2016.

Inclui bibliografia

1. Engenharia Elétrica - Teses. 2. Gases. 3. Absorção. 4. Detecção. 5. Fibras ópticas. 6. Gás carbônico. I. Mosso, Marbey Manhães. II. Mejía Quintero, Sully. III. Pontifícia Universidade Católica do Rio de Janeiro. Departamento de Engenharia Elétrica. IV. Título. 


\section{Agradecimentos}

À Deus, pela grande oportunidade de concretizar esta etapa e constante presença em todos os momentos da minha vida, dando-me força e sabedoria.

Ao meu orientador professor Marbey Manhães Mosso pelo imenso estímulo, dedicação, compreensão e confiança para a realização deste trabalho.

À pesquisadora Sully Quintero pela co-orientação com grande acompanhamento e aprendizado.

Ao Eng. Giancarlo Vilela pela inserção no grupo de projeto do prof. Marcos Sebastião e Luiz Carlos Guedes, que com muitas contribuições possibilitaram o desenvolvimento de grande parte deste trabalho de tese.

Ao CNPq, CAPES, Petrobrás e à PUC-Rio pelos auxílios concedidos, sem os quais este trabalho não se realizaria.

Aos meus amados pais, agradeço fortemente pela educação, valores, atenção, amparo, confiança e amor incondicional.

Ao meu irmão Fabrício, por me presentear com minha sobrinha Helena que tem praticamente a idade desta tese e é grande inspiração. E agora, com o Teo, que nascerá quase que com esta, marcando mais uma etapa da vida.

A toda minha maravilhosa família: meus adoráveis avós, tios e primos, pelo incentivo que veio a reforçar a fé em mim mesma. Agradeço imensamente por sempre acompanharem meus passos, compreenderem minha ausência e pelos desmedidos gestos de carinho e amor visando sempre a minha felicidade.

Aos professores do CETUC/PUC-Rio pelos valiosos conhecimentos transmitidos ao longo das disciplinas, que muito contribuíram para minha formação neste curso. 
Aos meus amigos do CETUC e LSFO pela agradável convivência e apoio em todos os dias.

Às eficientes secretárias do CETUC e do DEE pelos esclarecimentos e auxílio à minha condição de estudante.

À querida bibliotecária Ana Beatriz pelo excelente trabalho e amizade formada.

A todos os funcionários do CETUC e LSFO em razão do bom convívio cotidiano.

Aos amigos da vida pela compreensão da ausência, ombros e vibrações sempre positivas. 


\section{Resumo}

Carvalho, Juliana Barros; Mosso, Marbey Manhães. Desenvolvimento de Sistemas de Detecção de Gases na Região do Infravermelho. Rio de Janeiro, 2016. 116 p. Tese de Doutorado - Departamento de Engenharia Elétrica, Pontifícia Universidade Católica do Rio de Janeiro.

O presente trabalho aborda o desenvolvimento de sistemas de detecção de gases na região do infravermelho. Conceitos fundamentais sobre a teoria eletromagnética da luz e como o sinal luminoso pode ser absorvido por gases é apresentado na etapa inicial. Em seguida, são apresentados novos métodos de detecção utilizando fibras ópticas através de simulações eletromagnéticas destas fibras e por observações de medições em laboratório. O software utilizado é o Optiwave. Um sistema de interrogação baseado em um laser em anel é desenvolvido para o comprimento de onda em $2000 \mathrm{~nm}$. São aplicados dispositivos ópticos, fibras padrão, fibras micro estruturadas como elementos constituintes de sistemas de detecção de gases. Adicionalmente, um método de detecção coerente homodina e um subsistema capaz de detectar variações do índice de refração até pelo menos a sexta casa decimal são introduzidos, discutidos e propostos como novas técnicas a serem utilizadas na detecção e medição de gases. O desenvolvimento das técnicas aqui propostas tem ainda por finalidade segurança industrial e ambiental, avaliação de riscos de explosões, e no controle de vazamentos, emissões e poluição atmosférica.

\section{Palavras-chave}

Gases; absorção; detecção; fibras ópticas; gás carbônico; laser; infravermelho; comprimento de onda; índice de refração; rede de Bragg; célula de gás; cavidades ressonantes. 


\section{Abstract}

Carvalho, Juliana Barros; Mosso, Marbey Manhães (Advisor). Development of Gas Detection Systems in the Infrared Region. Rio de Janeiro, 2016. 116 p. Ph.D. Thesis - Departamento de Engenharia Elétrica, Pontifícia Universidade Católica do Rio de Janeiro.

This thesis discusses the development of gas detection systems in the infrared region. Fundamental concepts on the electromagnetic theory of light and how the light signal can be absorbed by gases is shown in the initial stage. Then, the possibility of new optical fiber detection methods is presented using electromagnetic simulations and laboratory observations activities. The software used is the Optiwave. A scanning system based on laser ring is designed for the wavelength of $2000 \mathrm{~nm}$. In this step, the study of Bragg gratings is explored. Other systems using optical devices, Micro structured optical fibers, coherent homodyne systems are presented and realized. Besides, a subsystem able to detect at least $10^{-}$ ${ }^{6}$ variations of the refraction index is introduced and evaluated as a gas detection application. All procedures presented can also be activated in industrial security, environment and atmospheric pollution evaluation, gas leakage, and gas blasts risks.

\section{Keywords}

Gases; absorption; detection; optical fibers; carbon dioxide; laser; infrared; wavelength; refractive index; fiber Bragg grating; gas cell; resonant cavities. 


\section{Sumário}

1 Introdução

2 Conceitos Fundamentais $\quad 24$

2.1 Teoria Eletromagnética da Luz 24

2.2 Fibras Ópticas $\quad 28$

- Janelas de transmissão: 32

2.3 Células ópticas de gás 34

2.4 Non-dispersive sensors $\quad 34$

2.5 Espectroscopia de Correlação 36

$\begin{array}{lll}2.6 & \text { Espectrofotometria } & 37\end{array}$

2.7 Cavity ringdown spectroscopy (CRDS) 38

2.8 Detecção Fotoacústica 38

2.9 Fibras ópticas microestruturadas 39

2.9.1 Fibras ópticas preparadas para interação entre a luz guiada

e a luz existente na região exterior 42

2.10 Absorção e detecção óptica de gases 44

2.10.1 Analisador de concentração de $\mathrm{CO}_{2} \quad 47$

2.11 Comentários e conclusões do Capítulo 48

3 Novos métodos para detecção de gases 49

3.1 Caracterização de fibras ópticas por simulações eletromagnéticas 49

3.1.1 Validação das simulações para fibras ópticas padrão SMF-28 50

3.1.2 Simulações para validação da fase sensora de fibras ópticas de diferentes diâmetros de núcleos e fatores de absorção na casca de vidro 55

3.1.3 Simulação de fibra óptica cujas cascas possuem índices de refração igual ao da água $(n=1,33)$ e do $\operatorname{ar}(n=1) \quad 58$

3.2 Caracterização de fibras ópticas microestruradas 62 
3.2.2 Aquisição de fibra óptica microestruturada comercial (HC-2000 Thorlabs)

3.3 Desenvolvimento de um sistema de interrogação baseado num laser em anel para detecção de gás carbônico 76

3.3.1 Descrição do sistema de com aplicação da FBG

3.3.2 Ambiente de $\mathrm{CO}_{2}$ : Calibração do sistema - Validação da atenuação do sinal transmitido na célula de gás quando o percentual de concentração é variado

3.4 Caracterização da FBG no LSFO/DEM/PUC-Rio 87

3.5 Comentários e conclusões do Capítulo 94

4 Ampliação da sensibilidade na detecção de gases 96

4.1 Sensores utilizando deteç̧ão simplificada de intensidade 96

4.2 Detecção de variações extremamente reduzidas do índice de refração 106

4.3 Comentários e conclusões do Capítulo 108

5 Comentários finais e conclusões 110

6 Referências bibliográficas 113 


\section{Lista de Figuras}

Figura 1 - Distribuição do espectro de energia eletromagnética do Sol no topo da atmosfera e na superfície terrestre observada ao nível do mar. As áreas indicadas com setas representam as absorções devido aos diversos gases presentes numa atmosfera limpa [5]. 20

Figura 2 - Representação gráfica do espectro eletromagnético. .20

Figura 3 - Sistema de medição do espectro de sinal em $1550 \mathrm{~nm}$ propagante numa fibra óptica convencional. (Imagem a partir do software Optiwave) .22

Figura 4 - Modelo de vórtices para o éter proposto por Maxwell [11] ......26

Figura 5 - Seção transversal e perfil do índice de refração de uma fibra óptica índice degrau e índice gradual [7]

Figura 6 - Atenuação e dispersão de um sinal luminoso em fibras ópticas - relação das amplitudes de entrada e saída.

Figura 7 - Propagação da luz confinada por reflexão interna total na fibra óptica.

Figura 8 - Coeficiente de atenuação considerando transmissões

em uma fibra óptica monomodo [17].

Figura 9 - Células de fluxo (fibra óptica monomodo). [19]

Figura 10 - Ilustração do princípio de medição NDIR: espectro de absorção de $\mathrm{CO}_{2}$ e diagrama esquemático de um simples sensor de gases [24]. .35

Figura 11 - Exemplo de espectroscopia de correlação usando um LED UV como fonte, ilustrando os espectros de emissão fonte, absorção do gás, e recebimento de luz para os dois detectores [21].

Figura 12 - Fibras ópticas microestruturadas adequadas para sensoriamento químico. (a) Sílica-Ar núcleo oco (b) Fibra de núcleo com buracos [7] (c) Fibra de núcleo com ranhura, utilizada para detecção de fluorescência 
distribuída [19] (d) PCF núcleo oco [20].

Figura 13 - Fibras de cristal fotônico de núcleo de vidro

(propagação do sinal luminoso no núcleo) e de núcleo oco

(propagação no ar). [24]

Figura 14 - Processo de perfuração em fibra óptica utilizando

um laser de fs. [20].

Figura 15 - Técnicas proporcionando a interação entre a luz guiada pela fibra óptica e medidas na região exterior:

(a) a luz acoplada fora da fibra; campos evanescentes em:

(b) uma região cônica, (c) uma região com corrosão, (d) uma

região polida de um lado, (e) grades de acoplamento da luz dentro e fora do revestimento; (f) a difusão de alguns gases no núcleo da fibra [26].

Figura 16 - Detecção do efeito fotoacústico de célula fechada [21]. 38

Figura 17 - Feixe de luz com intensidade lo incidindo sobre a região que contém os átomos capazes de absorver. Após passar pela região, o feixe terá uma nova intensidade I.

Figura 18 - Espectros de absorção para cinco gases: amônia, dióxido de carbono, monóxido de carbono, metano e vapor d'água [24]. .46

Figura 19 - Filtro óptico analisador de $\mathrm{CO}_{2}$ modelo $410 \mathrm{i}$

(Thermo Scientific) [23]. .48

Figura 20 - Tela Profile Design OptiBPM indicando a inserção de absorção na ordem de $10^{-6}$ no índice de refração da casca da fibra óptica simulada.

Figura 21 - Perfil da fibra óptica monomodo SMF-28 padrão

aplicada em telecomunicações, com comprimento $1 \mathrm{~cm}$, diâmetro

e índices de refração do núcleo e revestimento respectivamente

$8 \mu \mathrm{m}$ e $125 \mu \mathrm{m}, 1,45205$ e 1,46681.

Figura 22 - Perfil do sinal gaussiano para o modo de propagação

calculado em ambas situações com e sem fator de absorção na casca da fibra óptica caracterizada.

Figura 23 - Fibra óptica ideal monomodo padrão de 
telecomunicações em 1550 nm, com diâmetros e índices de refração do núcleo e da casca de 8 e 125 um, 1,45205 e 1,44681, respectivamente. Análise em $1 \mathrm{~cm}$ de comprimento de guia.

Figura 24 - Atenuação da potência por comprimento de fibra óptica quando o fator de absorção na casa é na ordem de $10^{-5}$. 54 Figura 25 - Simulação no software Optisystem de um sistema de fibra monomodo, 8 um e $1550 \mathrm{~nm}$, com comprimento de $1 \mathrm{~m}$, caracterizada no software BPM. Em (a) tem-se a relação da potência com o comprimento do guia e em (b) pode-se verificar análise do espectro do sinal do laser em $1550 \mathrm{~nm}$. Ambas análises sem grandes perdas, conforme esperado, vez que o comprimento de transmissão é curto. .55

Figura 26 - Gráfico plotado a partir da Tabela 1 para fibras ópticas cujos núcleos são de diferentes diâmetros (8, 20, 40 e $60 \mu \mathrm{m}$ ) e mesmo índice de refração igual a 1,45205. O índice de refração da casca em sílica é igual a 1,44681, com inserção dos índices imaginários (na ordem de $10^{-6}$ a $10^{-3}$ ) que representam o fator de atenuação entre esta região e o ambiente externo.

Figura 27 - Resultados de simulação para uma fibra óptica com núcleo de diâmetro igual a $40 \mu \mathrm{m}$, sendo os índices de refração na casca: (a) água $(n=1,33)$ e $(b)$ ar $(n=1)$. Os gráficos $(a)$ e (b) indicam a relação da atenuação $(\mathrm{dB} / \mathrm{m})$ com o comprimento de fibra, considerando diferentes fatores de absorção na ordem de $10^{-6}$ a $10^{-3}$. Em (c) é plotada a relação da atenuação ao longo do comprimento da fibra em função do coeficiente de extinção (fator de absorção). 60

Figura 28 - llustração do sistema a ser montado para teste de fibras ópticas como sensores de $\mathrm{CO}_{2}$ por absorção do campo evanescente.

Figura 29 - Fotografia em microscópio eletrônico da seção transversal das fibras microesturadas. 
Figura 30 - Sistema microposicionado para medida do campo próximo com uma câmera CCD 65

Figura 31 - Fotografia da intensidade luminosa do campo próximo das fibras óptica microestruturadas FOM1 e FOM2, respectivamente.

Figura 32 - Esquema de teste de transmissão do sinal óptico

nas fibras fabricadas pela ACREO .66

Figura 33 - Resultados experimentais obtidos com o OSA, referentes às medidas dos sensores com FOM1 e FOM2, respectivamente.

Figura 34 - Espectro de transmissão da fibra óptica FOM3

para duas fontes ASE centradas em $1500 \mathrm{~nm}$ e $2000 \mathrm{~nm}$.

Figura 35 - Espectro referente ao gás acetileno medido na saída da FOM3. .73

Figura 36 - Imagens adquiridas no datasheet da nova fibra óptica microestruturada modelo HC-2000 NKT, a ser aplicada no desenvolvimento de sensores de $\mathrm{CO}_{2}$. .74

Figura 37 - Características de transmissão da fibra HC-2000 [34] .74

Figura 38 - Resultados do teste realizado na fibra HC-2000 Thorlabs com injeção de $\mathrm{CO}_{2}$ (concentração 1300 ppm):

(a) comparação entre a medida da intensidade de luz antes e depois da injeção do gás; (b) Linhas de absorção do gás e luz propagando na Fibra HC-2000 .75

Figura 39 - Ilustração de um acoplador óptico de 3 dB quando há inserção de sinal óptico em um dos terminais.

Figura 40 - llustração de uma rede de Bragg iluminada por uma fonte de banda larga.

Figura 41 - Esquema da montagem utilizada para gravação de redes de Bragg pelo método interferométrico. .79

Figura 42 - Ilustração esquemática do deslocamento vertical da FBG colada na viga.

Figura 43 - Montagem experimental para a sintonização do laser em anel. 
Figura 44 - Sistema de interrogação para a construção de um laser em anel - Montagem da FBG como elemento de um sistema sensor de gás $\mathrm{CO}_{2}$. Na recepção, pode ser utilizado um fotodetector com um osciloscópio ou um OSA, como indicado com o computador.

Figura 45 - Esquema montado para sistema com fonte ASE realimentada com rede Bragg - linhas de $\mathrm{CO}_{2}$ com a célula padrão.

Figura 46 - Descrição: (a) Linhas de absorção de $\mathrm{CO}_{2}$ para baixas concentração do gás (b) relação do aumento da atenuação com o aumento da concentração de gás.

@ 2003 nm para uma célula com caminho óptico de comprimento $78 \mathrm{~cm}$.

Figura 47 - Células de gás fabricante Wavelenght

References com diferentes parâmetros, sendo por ordem:

(a) célula de referência, (b) célula de fluxo e (c) célula aberta.

Figura 48 - Transmissão do sinal da fonte ASE pelas células

de gás individualmente e quando conectadas em série.

Figura 49 - FBG realimentando fonte ASE. Atenuação de

$50 \mathrm{~dB}$ é necessária para evitar danificar o OSA na aquisição

dos dados.

Figura 50 - Gráfico indicando a FWHM do $\lambda_{\text {Bragg }}$ dentro das

linhas de absorção de CO2 pela base de dados do HITRAN.

Figura 51 - Sinal resultante da fonte ASE e entregue ao sistema,

a partir da realimentação pelo $\lambda_{\text {Bragg }}$

Figura 52 - Deslocamento do comprimento de onda a partir da

deformação causada na FBG

Figura 53 - Motor montado no LSFO para deformação da viga

onde está colada a FBG. O motor realiza a rotação do disco

permitindo que a viga seja deformada na vertical para cima

e para baixo.

Figura 54 - Bancada de teste do sistema de detecção de $\mathrm{CO}_{2}$

montado no LSFO. 
Figura 55 - Deslocamento do comprimento de onda a partir da deformação causada na FBG. .93

Figura 56 - Resultados obtidos com osciloscópio. Os vales na curva em azul indicam os pontos em que a FBG passou pelas linhas de absorção de $\mathrm{CO}_{2}$. Para o instante em $7 \mathrm{~s}, \lambda=1955 \mathrm{~nm}$, $\Delta \lambda=2 \mathrm{~nm}$.

Figura 57 - Sistema simples de uma fonte laser operando

em um determinado $\lambda$ s entregando uma potência $P_{s}$ para um fotodetector. 96

Figura 58 - Sistema sensor utilizando detecção coerente e modulação.

Figura 59 - Diagrama em bloco do sistema de de detecção coerente homodina e foto da montagem. 100

Figura 60 - Potência elétrica associada às potências ópticas

de -3,8 e -13,8 dBm (modulado em $500 \mathrm{MHz}$ ). 101

Figura 61 - Gráfico demonstrativo da relação de aumento da potência elétrica em $5 \mathrm{~dB}$ para cada $2 \mathrm{~dB}$ óptico.

Figura 62 - Célula de referência de $\mathrm{C}_{2} \mathrm{H}_{2}$ : (a) Imagem do

dispositivo, (b) espectro de transmissão - linhas de absorção

em função do comprimento de onda. 104

Figura 63 - Gráfico da transmitância dos gases $\mathrm{C}_{2} \mathrm{H}_{2}$ e $\mathrm{CO}_{2}$ na região de comprimento de onda referente a 1500 a 2000 nm, para um mesmo percentual de concentração igual a 0,1\% 105

Figura 64 - Configuração básica de um oscilador. 106

Figura 65 - Malha de realimentação óptica. 106

Figura 66 - Associação da cavidade Fabry-Perot com um filtro óptico para selecionar o modo próximo a $\lambda_{1}$ 107

Figura 67 - Sistema para detecção e calibração $\left(\lambda_{1 \mathrm{~A}}-\lambda_{1 \mathrm{~B}} \approx 0\right)$. 107 


\section{Lista de Tabelas}

Tabela 1 - Características de uma fibra óptica SMF-28.

Tabela 2 - A tabela mostra a atenuação referente às situações em que o índice de refração do núcleo e da casca são 1,45205 e 1,44861, respectivamente, com inserção do termo imaginário (10-6 a $10^{-3}$ ) como fator de absorção na casca, para diferentes núcleos.

Tabela 3 - Dados obtidos por análise espectral para o cálculo da média de $\Delta \mathrm{u}$, considerando FOM1

Tabela 4 - Cálculo do deslocamento de frequência considerando o espectro de FOM1

Tabela 5 - Dados obtidos por análise espectral para o cálculo da média de $\Delta \mathrm{u}$, considerando FOM2.

Tabela 6 - Cálculo do deslocamento de frequência considerando o espectro de FOM2 


\section{Lista de Acrônimos}

ASE: Amplified Spontaneous Emission

CCD: Charge-coupled device

$\mathrm{C}_{2} \mathrm{H}_{2}$ : Gás acetileno

$\mathrm{CO}_{2}$ : Gás dióxido de carbono

DUT: Device Under Test

EDFA: Erbium Doped Fiber Amplifier

FBG: Fiber Bragg Grating

GEE: Gases de efeito estufa

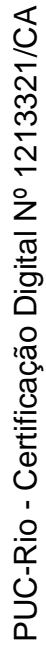

GSOM: Grupo de Sistemas Ópticos e Microondas

HITRAN: HIgh resolution TRANSmission molecular absorption database

HCPCFs: hollow core photonic crystal fibers

IMDD: Intensity Modulation Direct Detection

IrDA: Infrared Data Association

ITU: International Telecommunications Union

LSFO: Laboratório de Sensores a Fibra Óptica

OMM: Organização Meteorológica Mundial

OSA: Analisador de espectro óptico

RF: Radio Frequency

ppm: partes por milhão 


\section{Introdução}

Instituída pela Lei $\mathrm{n}^{\mathrm{o}}$ 12.187, de 2009, a Política Nacional sobre Mudança do Clima (PNMC) oficializa o compromisso voluntário do Brasil perante a Organização das Nações Unidas (ONU) de diminuir as emissões de gases de efeito estufa (GEE). O efeito estufa é um fenômeno natural, porém o aumento de GEE na atmosfera têm potencializado e consequentemente causado aumento da temperatura.

Grande parte destes gases é produzido pelos seres humanos em diversas atividades, principalmente pela queima de combustíveis fósseis, atividades industriais e queimadas. Estas substâncias gasosas absorvem parte da radiação infravermelha emitida principalmente pela superfície terrestre, e dificultam seu escape para o espaço, mantendo a Terra aquecida. Os principais GEE são: dióxido de carbono $\left(\mathrm{CO}_{2}\right)$, metano $\left(\mathrm{CH}_{4}\right)$, óxido nitroso $\left(\mathrm{N}_{2} \mathrm{O}\right)$, perfluorcarbonetos, hexafluoreto de enxofre $\left(\mathrm{SF}_{6}\right)$. Principais atividades geradoras de GEE no mundo são, segundo fonte do World Resources Institute: geração de eletricidade e calor $(24,9 \%)$, indústria $(14,7 \%)$, transporte $(14,3 \%)$, agricultura $(13,8 \%)$, mudanças no uso do solo $(12,2 \%)$, outros combustíveis $(8,6 \%)$, processos industriais $(4,3 \%)$, lixo $(3,2 \%)$, emissões de gases provenientes de equipamentos de pressão (4\%) [1].

Apesar dos muitos gases citados que contribuem para tal efeito, no presente trabalho é tomado como foco o estudo e detecção do gás $\mathrm{CO}_{2}$.

As emissões de gases como o $\mathrm{CO}_{2}$, provenientes da queima de combustíveis fósseis (petróleo, gás e carvão) - ou seja, a quantidade expelida por centrais térmicas, refinarias, fábricas e automóveis - têm crescido globalmente. No período compreendido entre 2003 e 2012, aumentou em média 3,3\% ao ano, segundo dados do Global Carbon Atlas [2]. A quantidade de $\mathrm{CO}_{2}$ é o principal causador do aquecimento global, vez que chegou a 396 partes por milhão (ppm). O aumento foi proporcional a 2,9 ppm, contra uma média de 1,5 ppm por ano desde 1990 e de 2,1 ppm por ano na última década. A esta velocidade, a simbólica marca dos 400 ppm poderá ser excedida neste ano de 2016, conforme já previa a OMM 
(Organização Meteorológica Mundial) no ano passado. Este limite já foi ultrapassado pontualmente em algumas estações de medição de $\mathrm{CO}_{2}$. Os cálculos da OMM são, no entanto, uma média global, com base em dezenas de medições em ambiente terrestre e a partir de navios e aviões [2].

A molécula de gás $\mathrm{CO}_{2}$ apresenta absorções ópticas características associadas aos seus vários modos vibracionais, que são únicos, pois dependem da geometria e das massas dos átomos que a compõem.

As técnicas espectroscópicas de detecção de espécies utilizam basicamente uma propriedade que a matéria apresenta, a de absorver radiação eletromagnética. O espectro de absorção da radiação é único para cada espécie, revelando com precisão os tipos de moléculas presentes em um volume de ar qualquer. A espectroscopia no infravermelho trata das variações de energia molecular associadas às transições vibracionais devido à absorção ou emissão de um fóton, partícula elementar responsável pelo fenômeno eletromagnético, que não é suficientemente energético para causar uma transição eletrônica. A energia de um fóton envolvido neste fenômeno é expressa por: $\mathrm{E}=\mathrm{h} v$, onde $\mathrm{h}$ é a constante de Planck $(6,626 \times 10-34$ J.s $)$ e $v$ é a frequência de transição. Como a radiação eletromagnética pode ser tratada como uma onda, a energia envolvida neste tipo de transição pode ser também expressa por: $\mathrm{E}=\mathrm{h} \frac{c}{\lambda}$, sendo c a velocidade da luz no vácuo e $\lambda$ o comprimento de onda. Em presença de matéria, fótons são freados ou mesmo absorvidos, transferindo energia e momento proporcionais à sua frequência $[3]$.

A radiação eletromagnética é absorvida quando sua frequência é idêntica à da vibração molecular. Os principais gases absorvedores da radiação eletromagnética são vapor d'água $\left(\mathrm{H}_{2} \mathrm{O}\right)$, oxigênio $\left(\mathrm{O}_{2}\right)$, ozônio $\left(\mathrm{O}_{3}\right)$ e gás carbônico $\left(\mathrm{CO}_{2}\right)$. Os gases monóxido de carbono $(\mathrm{CO})$, metano $\left(\mathrm{CH}_{4}\right)$, óxido nítrico (NO) e óxido nitroso $\left(\mathrm{N}_{2} \mathrm{O}\right)$ ocorrem em pequenas quantidades e também exibem espectros de absorção [4]. A Figura 1 ilustra o comentário.

A energia eletromagnética pode ser ordenada de maneira contínua em função do comprimento de onda ou de sua frequência, sendo esta disposição denominada de espectro eletromagnético. Este apresenta subdivisões de acordo com as características de cada região. Cada subdivisão é função do tipo de processo físico que dá origem a energia eletromagnética, do tipo de interação que ocorre 
entre a radiação e o objeto sobre o qual esta incide e da transparência da atmosfera em relação à radiação eletromagnética.

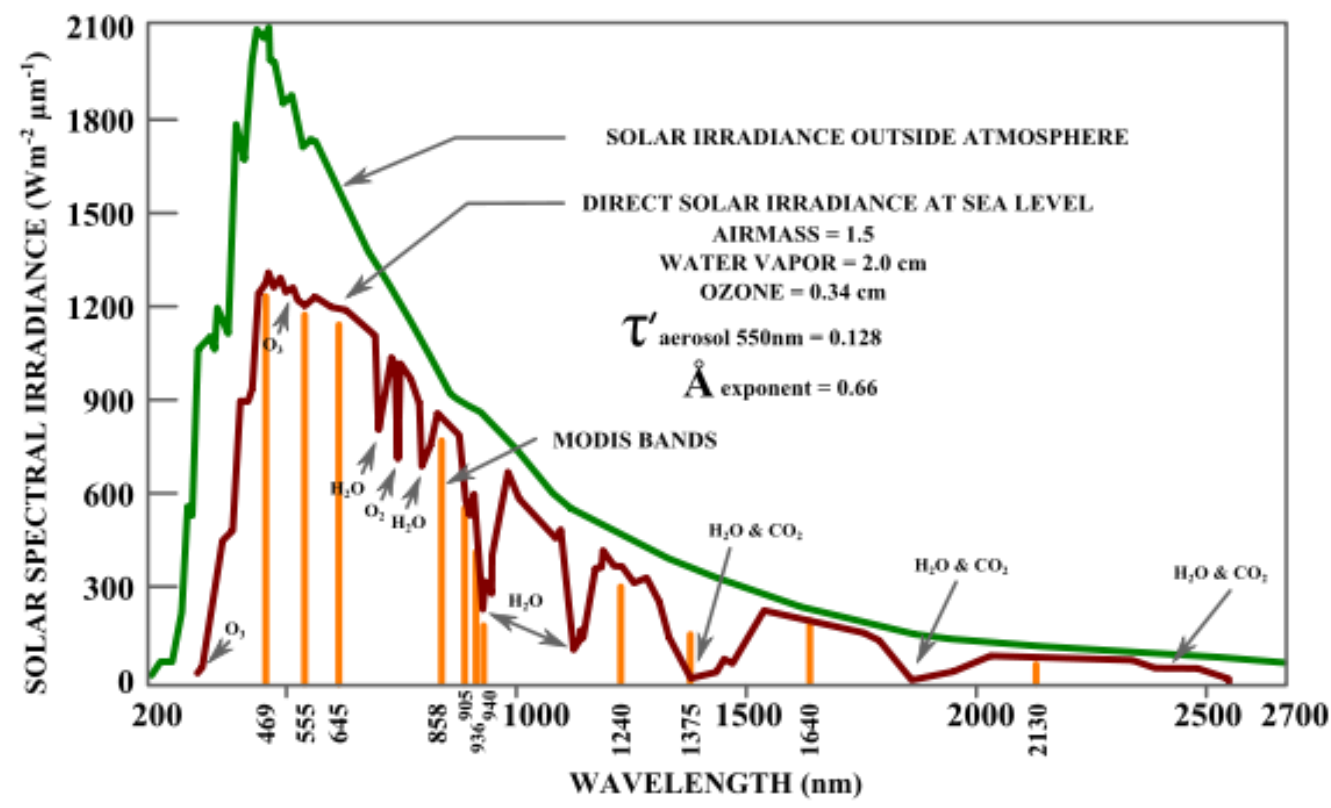

Figura 1 - Distribuição do espectro de energia eletromagnética do Sol no topo da atmosfera e na superfície terrestre observada ao nível do mar. As áreas indicadas com setas representam as absorções devido aos diversos gases presentes numa atmosfera limpa [5].

O espectro eletromagnético se estende desde comprimentos de onda muito curtos associados aos raios cósmicos, até as ondas de rádio de baixa frequência e grandes comprimentos de onda, como mostra a Figura 2 abaixo [6].

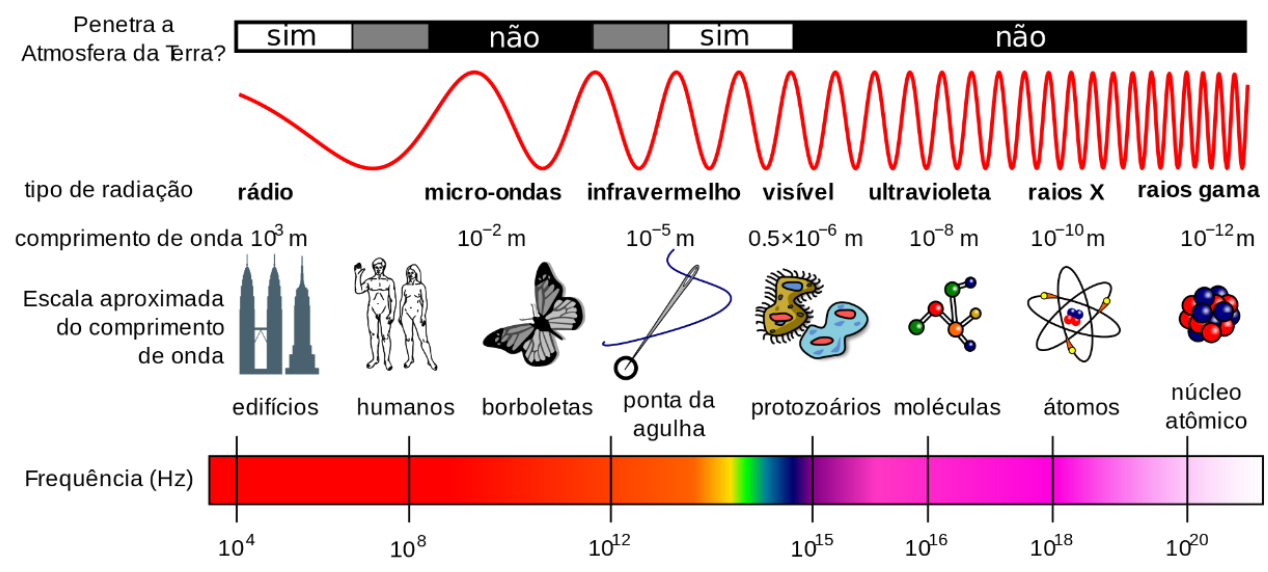

Figura 2 - Representação gráfica do espectro eletromagnético. 
A faixa do infravermelho, região de estudo deste trabalho, é implementada para transferência de dados, de acordo com os protocolos e padrões da IrDA (Infrared Data Association). Esses padrões são projetados para aceitar componentes de baixo custo e reduzir a demanda de energia, e para ativar conexões simplesmente apontando dispositivos de infravermelho um para o outro [7].

Do ponto de vista de aplicação, como também de instrumentação, o espectro no infravermelho é convenientemente dividido em infravermelho próximo (near infrared, NIR, de 780 a $2500 \mathrm{~nm}$ ), médio (mid infrared, MID, de 2500 a $50000 \mathrm{~nm}$ ) e distante (far infrared, FAR, de 50000 a $10^{6} \mathrm{~nm}$ ). De forma geral, as medidas feitas na região do infravermelho NIR ou MID possibilitam o estudo de amostras que podem se encontrar na fase sólida, líquida ou gasosa. Na maioria das vezes, não requerem grande preparo da amostra e dependendo da técnica utilizada para a análise, podendo esta ser não destrutiva e relativamente rápida [3].

A transmissão da luz no infravermelho pode ser feita através de fibras ópticas fabricadas com sílica pura ou dopadas. O desenvolvimento de técnicas de medição óptica realizadas a partir dos anos 70 e o estudo de fibras ópticas que apresentem baixas perdas e alta qualidade para uso em telecomunicações, permitiu o avanço significativo das técnicas de sensoriamento de várias grandezas físicas e químicas, como por exemplo, temperatura, pressão e concentrações químicas, vez que viabilizaram a monitorização de tais grandezas a longas distâncias. Atualmente, as fibras ópticas são largamente utilizadas em diversos setores industriais e área médica [8].

Fibras ópticas são estruturas transparentes, flexíveis, que podem ter muitos formatos, porém o mais comum é com a luz guiada em uma região central, o núcleo, que tem um índice de refração mais elevado do que a casca concêntrica circundante, criando as condições adequadas para a reflexão interna total da luz incidente sobre determinados ângulos de incidência. Geralmente, são compostas por dois materiais dielétricos, projetadas para transmitir potência luminosa injetada pelo emissor de luz, até o fotodetector, evitando a interação da luz guiada com o meio externo [9]. Possuem a vantagem de ter banda passante permitindo altas taxas de transmissão, detecção remota, atenuação muito baixa, imunidade à interferências eletromagnéticas e ruídos, isolamento elétrico e baixo custo. Tais características junto a possibilidade de transmissão de luz no infravermelho justificam, portanto, o interesse da pesquisa com aplicação de fibras ópticas como elementos sensores. 
Entretanto, vez que muitos gases e o especificamente o $\mathrm{CO}_{2}$ apresentam valores de constante dielétrica muito próxima da constante do espaço livre, isto é, $\left(\mathcal{E} \approx \varepsilon_{\mathrm{o}}\right)$, a utilização de fibras será associada a sistemas ópticos capazes de ampliar a sensibilidade de detecção dos sensores frequentemente utilizados. Os testes a serem realizados em laboratório envolvem a medição de um determinado percentual de $\mathrm{CO}_{2}$ concentrado num ambiente, seja puro ou em mistura com o ar. Um sistema de detecção simples é apresentado na Figura 3. Uma fonte laser no comprimento de onda de absorção do gás a ser analisado entrega o sinal óptico ao sistema. Numa câmara contendo o respectivo gás em teste está presente o dispositivo sensor. Um analisador de espectro óptico é utilizado para captura dos dados. Havendo interação entre luz e gás, é possível observar neste equipamento as linhas de absorção que correspondem à análise do sistema desenvolvido.

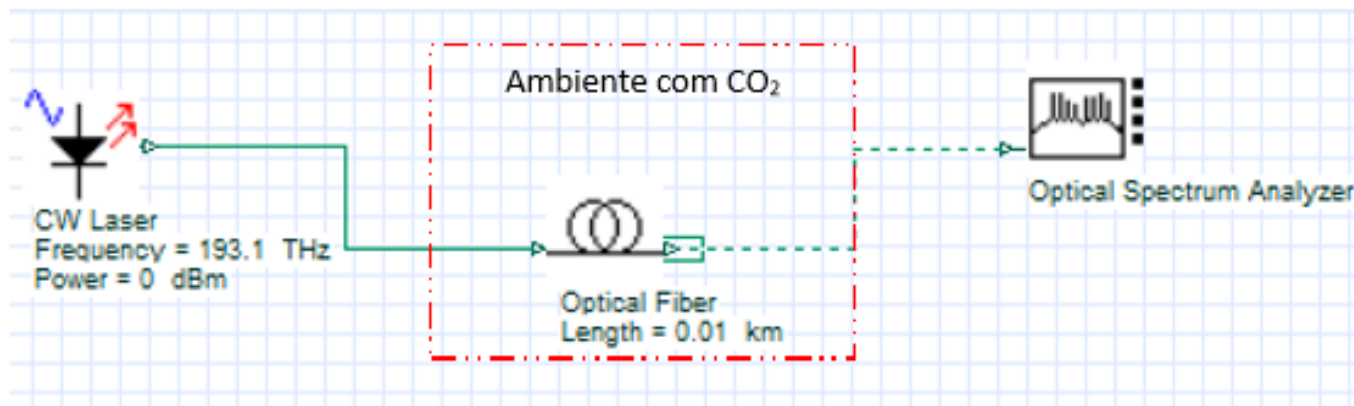

Figura 3 - Sistema de medição do espectro de sinal em 1550 nm propagante numa fibra óptica convencional. (Imagem a partir do software Optiwave)

A tecnologia básica pode ser também aplicada no desenvolvimento de outros sensores para gases, poluentes, inflamáveis, tóxicos, etc., com finalidade de cobrir uma grande demanda nas áreas de segurança industrial e ambiental, avaliação de riscos de explosões, e no controle de vazamentos, emissões e poluição atmosférica [9].

A partir das observações acima apresentadas, os principais objetivos deste trabalho podem assim ser destacados como:

Introdução aos procedimentos básicos utilizados na detecção de gases por meios ópticos;

Estudo e posterior seleção dos tipos de fibras ópticas capazes de permitir a detecção de gases; 
Desenvolvimento de sistemas ópticos utilizando fibras ópticas para a detecção de $\mathrm{CO}_{2}$;

Estudo e avaliação de sistemas de detecção óptica com sensibilidade ampliada, adequados para aplicação com gases.

Nos Capítulos que seguem, o presente trabalho está estruturado da seguinte forma: no Capítulo 2 é descrito inicialmente os fundamentos teóricos necessários para conhecimento da estrutura do sistema de detecção de gases, fibras ópticas e suas propriedades para a propagação de raios luminosos. Ainda neste Capítulo, são abordadas algumas das técnicas existentes para a detecção óptica de $\mathrm{CO}_{2}$. No Capítulo 3, são apresentadas duas metodologias propostas para aplicação em sistemas de detecção de gases por absorção da luz infravermelho. Ainda neste Capítulo, ao longo da abordagem são descritos os resultados referentes às propostas apresentadas e desenvolvidas. No Capítulo 4, métodos de medição significativamente mais sensíveis às variações dos níveis de potência óptica são apresentados, destacando-se um método utilizando a técnica de detecção coerente homodina. Ainda neste capitulo é apresentado um sistema de detecção de variações extremamente reduzidas do índice de refração a partir da aplicação de cavidades de Fabry-Perot. No Capítulo 5 são feitos os comentários finais, conclusões e sugestões de trabalhos futuros associados à presente tese. 


\section{Conceitos Fundamentais}

O presente Capítulo introduz a teoria eletromagnética da luz, as fibras ópticas padrão e suas janelas de transmissão. Em seguida são apresentadas as fibras ópticas do tipo microestruturadas e também as fibras adaptadas para a interação entre a luz guiada e propagante no meio externo (campo evanescente). Ainda neste Capítulo são descritos os principais procedimentos envolvendo a absorção e detecção óptica de gases e um analisador de concentração de $\mathrm{CO}_{2}$ com aplicação no trabalho. Estes elementos são importantes na criação de uma metodologia própria para a detecção de gases através de técnicas ópticas. Um resumo da literatura existente é também apresentado.

\subsection{Teoria Eletromagnética da Luz}

Na metade do século XIX, o estudo da propagação de ondas em um meio elástico (por exemplo, a propagação do som no ar ou outro meio material) era um campo de pesquisas bem desenvolvido e as equações que descrevem este tipo de fenômeno já eram conhecidas. Além disso, o fato de a luz apresentar um comportamento ondulatório, isto é, propagar-se como uma onda em um meio elástico (o éter), também era conhecido e aceito pelos físicos da época. Uma das questões discutidas, era saber como seria essa onda e quais as propriedades do éter [10].

Maxwell percebeu que a elasticidade dos vórtices presente em seu modelo mecânico poderia ser útil para relacionar a óptica com o eletromagnetismo. Após obter as equações de movimento do sistema de vórtices e partículas, Maxwell dedicou-se a determinar a rapidez de propagação de perturbações através dele na forma de ondas. Essas ondas seriam perturbações elétricas e magnéticas que se propagariam através do éter, as chamadas ondas eletromagnéticas [10]. 
Considerou ondas transversais no meio elástico (ondas que se propagam na direção perpendicular à direção de oscilação) cuja velocidade de propagação $(v)$ dependeria da elasticidade do meio $(k)$ e de sua densidade $(\mu)$ e seria expressa por (1):

$$
v=\sqrt{\frac{k}{m}}
$$

De acordo com Maxwell, a constante $k$ é inversamente proporcional à constante dielétrica e m é proporcional à permeabilidade magnética $\mu$ do meio.

Entre 1861 e 1862, Maxwell publicou um segundo trabalho, em quatro partes, no Philosophical Magazine. Nesta série de trabalhos, Maxwell propõe um modelo de partículas elétricas e vórtices no éter, que era considerado na época um meio elástico necessário para a transmissão das interações elétricas e magnéticas. Um dos conceitos novos introduzidos por Maxwell nestes trabalhos era a chamada corrente de deslocamento, proporcional à variação temporal do campo elétrico, e que deveria ser adicionada à corrente elétrica de condução na Lei de Ampére para que o princípio de conservação de carga fosse respeitado [11].

No modelo mecânico que Maxwell concebeu para o campo eletromagnético no éter, os tubos de linhas de força magnética eram concebidos como células tubulares cheias de um fluido em rotação em torno das linhas de força. Para que tubos adjacentes pudessem girar no mesmo sentido, Maxwell imaginou a existência de "rolamentos" esféricos, responsáveis pelas forças elétricas, cujos deslocamentos corresponderiam a correntes elétricas (daí o nome dado por Maxwell à corrente de deslocamento, e que é usado até os dias de hoje) - uma ilustração é mostrada na Figura 4. Maxwell chegou às suas equações aplicando a mecânica dos meios contínuos a este modelo de vórtices para o éter celular [12]. 


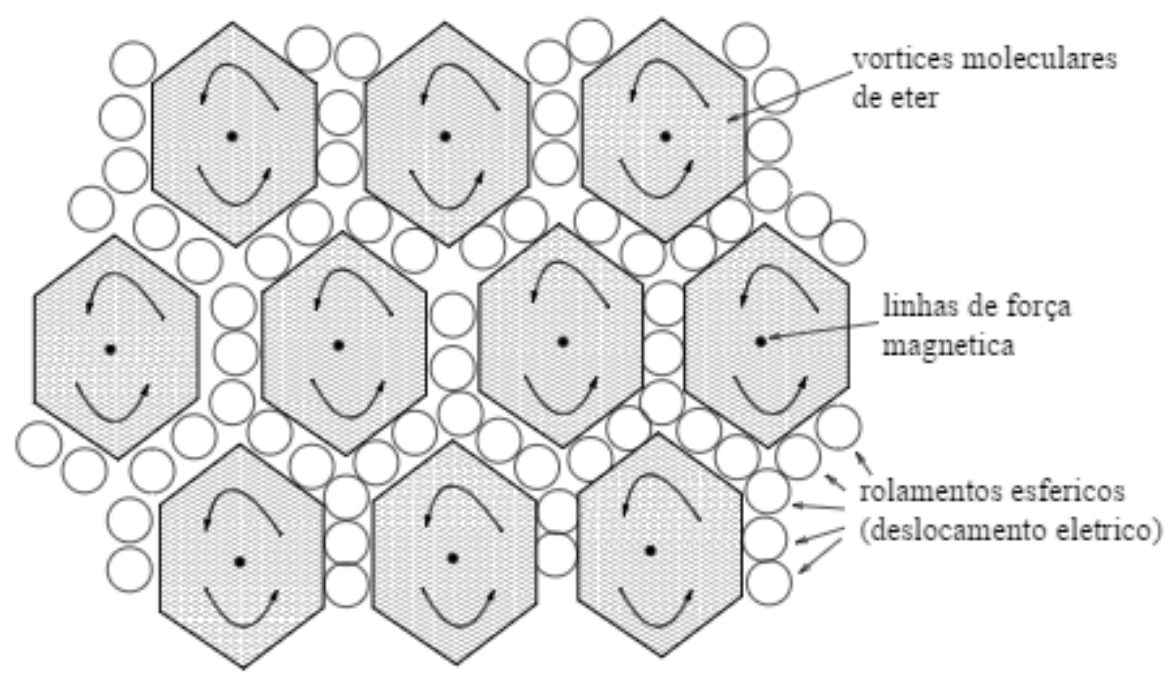

Figura 4 - Modelo de vórtices para o éter proposto por Maxwell [11].

Um resultado importante desse artigo é a hipótese de que o éter permitiria a propagação de vibrações transversais com a mesma velocidade da luz (c). Na época de Maxwell o valor de c era conhecido por meio de observações astronômicas dos satélites de Júpiter (método de Romer) e por experiências de laboratório. Fizeau, em 1848, usando uma roda dentada em rotação rápida e um espelho, obteve: $\mathrm{c}=3,14 \times 10^{8} \mathrm{~m} / \mathrm{s}$. Foucault, em 1850, usando um espelho girante e outro fixo chegou a c $=2,98 \times 10^{8} \mathrm{~m} / \mathrm{s}$. Experiências eletromagnéticas realizadas em 1855 por Kohlrausch e Weber determinaram o valor $3,107 \times 10^{8} \mathrm{~m} / \mathrm{s}$ para a razão entre a unidade eletromagnética absoluta de carga e a unidade eletrostática absoluta de carga. Além disso, a dimensão desta razão é a mesma de velocidade [12]. Em linguagem moderna, esta igualdade é escrita no Sistema Internacional de Unidades como (2):

$$
c=\frac{1}{\sqrt{\mu_{0} \varepsilon_{0}}}
$$

$\mathrm{Na}$ época, os valores da permissividade elétrica $\left(\varepsilon_{\mathrm{o}}\right)$ e da permeabilidade magnética do vácuo $\left(\mu_{\mathrm{o}}\right)$ de vários materiais já eram conhecidos. Maxwell comparou esses resultados com os valores medidos para a velocidade de propagação da luz disponíveis na época, encontrando uma grande concordância 
entre os valores calculados para a velocidade de propagação de uma onda eletromagnética no éter com os valores medidos para a velocidade de propagação da luz. Observando esta concordância, Maxwell concluiu que a luz é uma vibração transversal que se propaga no mesmo meio que os fenômenos elétricos e magnéticos [12].

Em fins de 1861, enquanto trabalhava na parte III do seu artigo, Maxwell, retornando de sua fazenda na Escócia para Londres, leu o trabalho de Kohlrauch e Weber, converteu o resultado num formato compatível com seu trabalho, e concluiu que a luz seria uma onda eletromagnética, resultante das vibrações do éter, como se fosse uma onda mecânica [12].

Maxwell publicaria em 1865 um novo trabalho [13], no qual estruturou de forma mais geral sua teoria unificada dos campos elétrico e magnético, sem o complicado modelo mecânico de vórtices no éter, usado anteriormente. Passa a aceitar que a energia reside no campo eletromagnético, e não nas supostas propriedades elásticas do éter. Além disso, nesse trabalho ele deduz a equação das ondas eletromagnéticas. Em 1873, ele publicou um livro trazendo um apanhado dos seus trabalhos sobre Eletromagnetismo [14]. Originalmente Maxwell havia escrito um conjunto de vinte equações com vinte incógnitas, incluindo algumas equações que atualmente são consideradas auxiliares, como a lei de Ohm e a equação de continuidade de carga. Na forma original, Maxwell havia escrito uma equação para cada componente. As equações de Maxwell foram escritas pela primeira vez na forma vetorial em que as conhecemos atualmente em 1884 por Oliver Heaviside. Nos seus primeiros anos de existência, a teoria de Maxwell ainda era pouco entendida e até mesmo vista com certa desconfiança, principalmente pois algumas das suas predições ainda não haviam sido verificadas experimentalmente. Quem mostrou a existência das ondas eletromagnéticas, que Maxwell interpretava como as vibrações transversais do éter propagando-se à velocidade da luz, foi Heinrich Hertz. Em 1886, Hertz produziu e detectou ondas eletromagnéticas que se propagavam com a velocidade da luz e que possuíam propriedades similares às da luz tais como reflexão, difração, polarização. A teoria de Maxwell e os experimentos de Hertz abriram um importante campo de estudos que propiciou grandes avanços tecnológicos: o estudo da radiação eletromagnética na faixa das ondas de rádio e micro-ondas. A 
descoberta de Hertz foi em seguida aplicada na transmissão de sinais a longa distância [12].

A confirmação da teoria eletromagnética da luz de Maxwell se estendeu para as diferentes modalidades de energia radiante, que se propagam com a mesma velocidade e se diferem pela frequência $(v)$ e comprimento de onda $(\lambda)$, conforme a expressão: $\mathrm{c}=\lambda . v$. A frequência da luz independe do meio no qual ela se propaga é a característica de sua cor. Luz resultante de vibrações de uma só frequência é dita monocromática, e policromática quando composta de ondas de várias frequências (vide Figura 2 apresentada no Capítulo 1. Introdução).

A distinção entre as ondas eletromagnéticas é feita pela frequência ou pelo comprimento de onda. A região de comprimento de onda do espectro eletromagnético usado nas telecomunicações ópticas são definidas pela ITU (International Telecommunications Union) como, banda C (Conventional Wavelength Band, 1530-1565 nm), banda L (Long Wavelength Band, 1565- 1625 $\mathrm{nm}$ ), banda S (Short Wavelength Band, 1450-1530 nm), e bandas mais distantes de ambos os lados da banda C. Atualmente, a única banda utilizada comercialmente para telecomunicações ópticas é a banda C. O constante crescimento de tráfego de dados, voz e internet requerem soluções para expansão da capacidade de transmissão. Expansão para bandas de comprimentos de onda curtos e longos é opção promissora. Para estas bandas, componentes passivos e ativos têm sido desenvolvidos [15].

Para a janela de comprimento de onda em $1500 \mathrm{~nm}$ e com a evolução da tecnologia fotônica são aplicadas fibras ópticas para transmissão de luz baseada no fenômeno da reflexão interna total.

\subsection{Fibras Ópticas}

Uma fibra óptica padrão de $\mathrm{SiO}_{2}$ (dióxido de silício) consiste de um núcleo central cilíndrico envolvido por uma camada denominada de casca (cladding). No processo de fabricação, o índice de refração do núcleo $\left(\mathrm{n}_{1}\right)$ é ligeiramente maior que o índice de refração da casca $\left(\mathrm{n}_{2}\right)$ devido à presença de germânio no núcleo. Existem dois tipos de perfis de índices de refração para as 
fibras ópticas mais comumente encontradas, conhecidos como índice degrau e índice gradual. Nas fibras com índice degrau, o índice de refração entre o núcleo e a casca varia abruptamente, enquanto que nas fibras com índice gradual o índice de refração decresce gradualmente do centro à interface núcleo-casca. A seção transversal e o perfil do índice de refração de uma fibra de índice degrau e gradual são mostrados na Figura 5, onde os raios do núcleo e da casca são definidos por a e b, respectivamente, e no o índice de refração do ar [7].

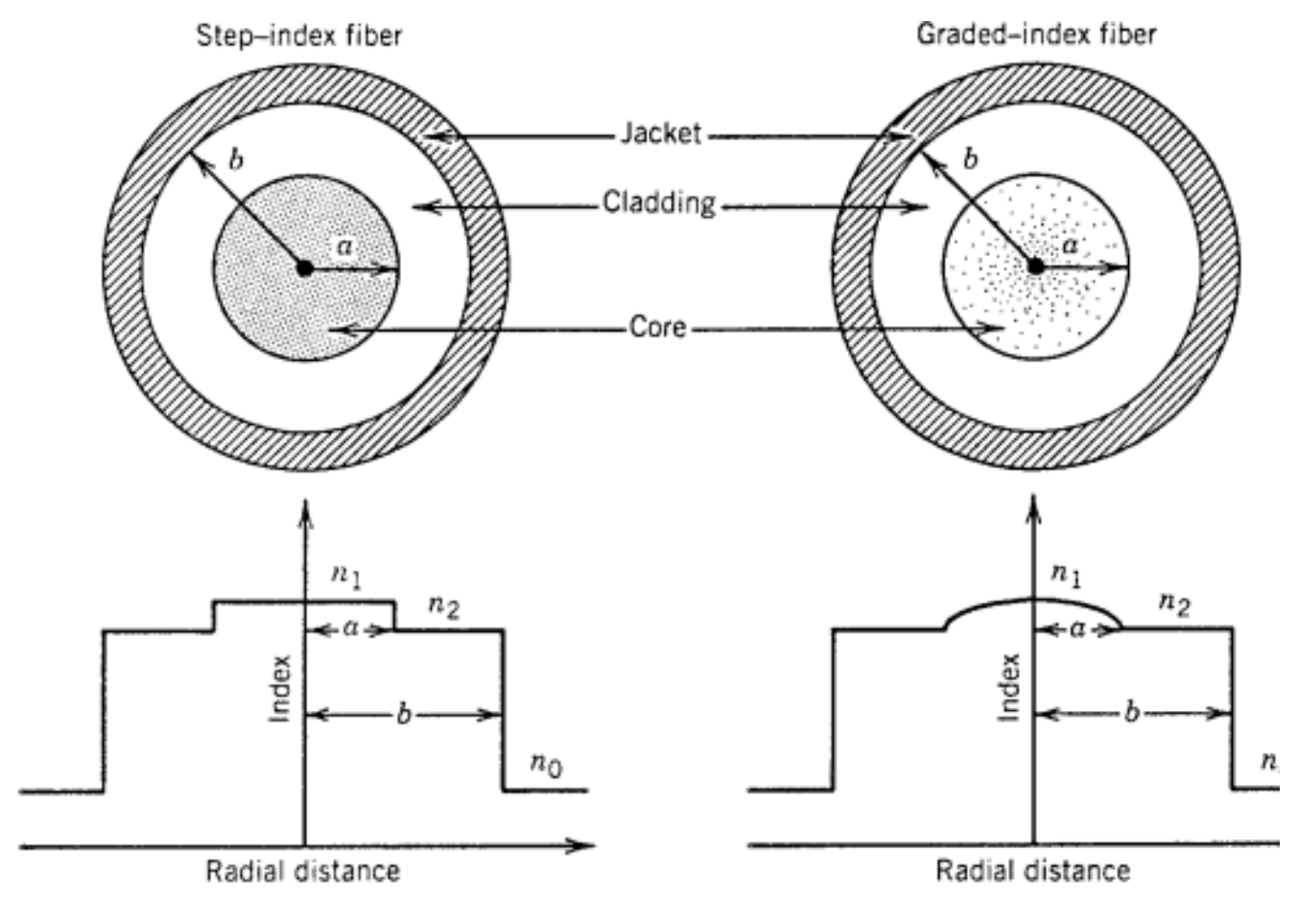

Figura 5 - Seção transversal e perfil do índice de refração de uma fibra óptica índice degrau e índice gradual [7].

Como todo fenômeno eletromagnético, campos ópticos de propagação em fibras são descritos pelas equações de Maxwell, que fornece o tratamento mais completo dos fenômenos ópticos dentro dos limites da óptica clássica [8]. Considerando um material linear, dielétrico e isotrópico sem corrente e cargas livres, estas equações assumem a forma das equações expressas a seguir em (3): 


$$
\nabla \times \overrightarrow{\mathrm{E}}=-\frac{\partial \overrightarrow{\mathrm{B}}}{\partial \mathrm{t}} \quad \nabla \times \overrightarrow{\mathrm{H}}=-\frac{\partial \overrightarrow{\mathrm{D}}}{\partial \mathrm{t}} \quad \nabla \cdot \overrightarrow{\mathrm{D}}=0 \quad \nabla \cdot \overrightarrow{\mathrm{B}}=0
$$

Onde os termos: $\vec{D}=\varepsilon \vec{E}$ e $\vec{B}=\mu \vec{H}$.

Uma relação que define o fenômeno ondulatório dos campos eletromagnéticos pode ser derivada das Equações de Maxwell, obtendo-se (4):

$$
\nabla^{2} \overrightarrow{\mathrm{E}}=\mu \varepsilon \frac{\partial^{2} \overrightarrow{\mathrm{E}}}{\partial \mathrm{t}^{2}} \quad \text { ou } \quad \nabla^{2} \overrightarrow{\mathrm{H}}=\mu \varepsilon \frac{\partial^{2} \overrightarrow{\mathrm{H}}}{\partial \mathrm{t}^{2}}
$$

Que correspondem às equações de onda.

A equação pode ainda ser reescrita como (5):

$$
\nabla^{2} \overrightarrow{\mathrm{E}}+k^{2} \overrightarrow{\mathrm{E}}=0
$$

Sendo $k^{2}=\omega^{2} \mu \varepsilon$ e a relação entre $k$ e $\lambda: k=\omega \sqrt{\mu \varepsilon}=\frac{\omega}{c}=\frac{\omega}{\lambda f}=\frac{2 \pi}{\lambda}$

Esta equação fornece os modos ópticos propagantes de uma fibra óptica com perfil degrau. Devido a geometria das fibras ópticas pode-se determinar a solução da equação de onda por coordenadas cilíndricas.

Os modos de propagação das fibras são híbridos e denotados por $\mathrm{TE}_{\mathrm{mn}}$ ou $\mathrm{TM}_{\mathrm{nm}}$, onde m e n são números quânticos autovalores da equação de onda. A notação usada para denotar o modo de propagação fundamental na fibra é $\mathrm{TM}_{01}$. Este modo somente é encontrado em fibras monomodo. Fibras que suportam outros modos propagantes são as fibras multimodo. A notação $\mathrm{LP}_{\mathrm{mn}}$ é usada para modos propagantes linearmente polarizados [8].

Ao propagar-se, o sinal luminoso sofre vários efeitos que o penalizam, destacando-se a atenuação e a dispersão, conforme ilustrado na Figura 6, onde L é a atenuação ao longo da propagação numa fibra óptica de determinado comprimento $l$. 


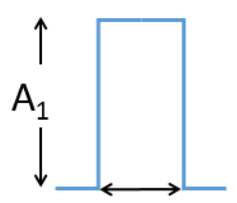

$\mathrm{T}_{0}$

Atenuação: $\mathrm{L}=10 \log \frac{\mathrm{A}_{2}}{\mathrm{~A}_{1}}$

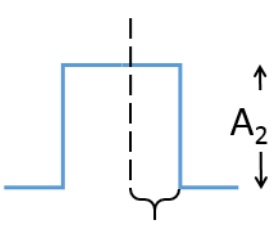

$\Delta \mathrm{T}$

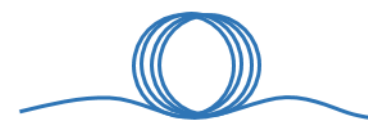

Dispersão: $\mathrm{D}=\frac{\Delta \mathrm{T}}{\mathrm{L} \Delta \lambda}$

Figura 6 - Atenuação e dispersão de um sinal luminoso em fibras ópticas - relação das amplitudes de entrada e saída.

A dispersão está relacionada à dependência do índice de refração com a frequência. Quando uma onda eletromagnética gerada por um pulso interage com os elétrons de um dielétrico, a resposta do meio depende da frequência óptica $(\omega)$. Isto faz com que as diferentes componentes espectrais contidas no pulso se propaguem com diferentes velocidades $\left(\frac{c}{n(\omega)}\right)$, produzindo um considerável alargamento temporal dos pulsos ópticos. O termo $\Delta \lambda$ na equação é a largura espectral da fonte óptica (considerada como uma largura total à metade do valor máximo - full width at half maximum (FWHM)). O parâmetro de dispersão D pode mudar ao longo do enlace de fibra se trechos diferentes apresentarem características distintas [16]. Quando D $=0$ tem-se a propagação no zero de dispersão da fibra óptica.

A geometria representada na Figura 7 mostra um raio de luz incidente fazendo um ângulo $\theta$ com o eixo central no núcleo da fibra óptica. Devido à refração na interface ar/vidro, o raio tende a retornar à normal, onde $\theta_{\mathrm{r}}$ é o ângulo do raio refratado. A relação entre os ângulos de incidência e refratado é descrita pela Lei de Snell (6):

$$
\mathrm{n}_{0} \sin \theta=\mathrm{n}_{1} \sin \theta_{\mathrm{r}}
$$


Entretanto, a refração só é possível para um ângulo tal que satisfaça a condição: $\sin \phi<\frac{\mathrm{n}_{2}}{\mathrm{n}_{1}}$. Os termos $\mathrm{n}_{0}, \mathrm{n}_{1}$ e $\mathrm{n}_{2}$ representam respectivamente os índices de refração do ar, do núcleo e da casca da fibra óptica [17].

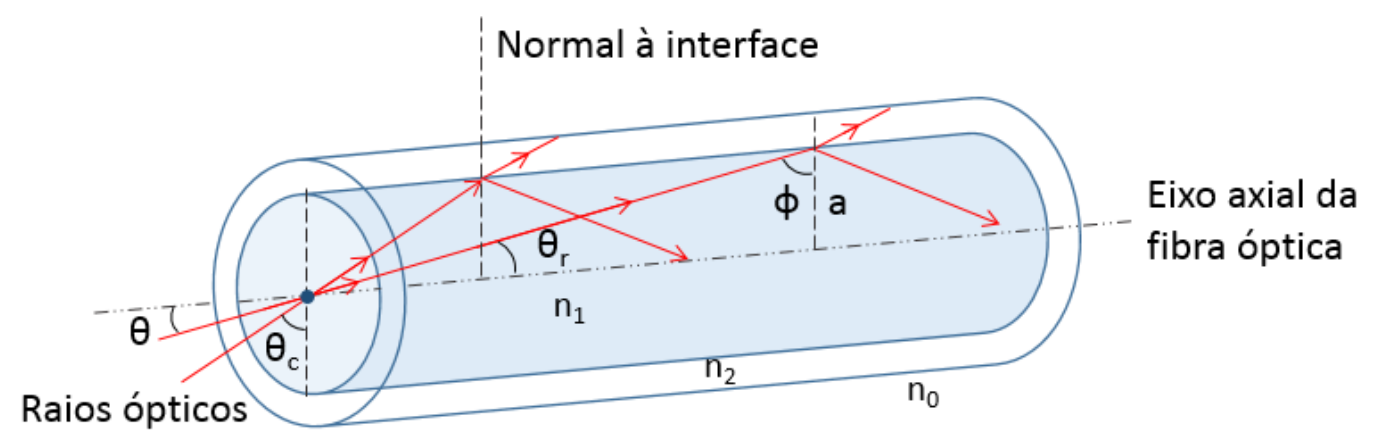

Figura 7 - Propagação da luz confinada por reflexão interna total na fibra óptica.

O ângulo $\theta_{\mathrm{r}}=\frac{\pi}{2}-\phi$ que aparece na figura acima, após aplicação de relações trigonométricas leva à obtenção a expressão dada em (7).

$$
\mathrm{n}_{0} \operatorname{sen} \theta=\mathrm{n}_{1} \cos \phi=\left(\mathrm{n}_{1}^{2}-\mathrm{n}_{2}^{2}\right)^{1 / 2}
$$

É importante observar que um feixe de luz pode ser composto por vários comprimentos de onda, assim em um meio material, para cada comprimento de onda tem-se um índice de refração diferente (prisma). Portanto, para um feixe de luz se tem velocidades de fase diferentes e uma velocidade de grupo para a frente de onda.

\section{- Janelas de transmissão:}

A sílica, material empregado para confecção de fibras ópticas, sofre dopagens para reduzir atenuações (absorção de energia pelas impurezas do vidro) e permitir a transmissão de informação a longas distâncias. Esta dopagem permite 
o controle do índice de refração e da qualidade de transmissão [18]. As menores atenuações ocorrem nas janelas de:

- $820 \mathrm{~nm}$ - atenuação de $2,5 \mathrm{~dB} / \mathrm{km}$

• $1300 \mathrm{~nm}$ - atenuação de $0,5 \mathrm{~dB} / \mathrm{km}$

- $1550 \mathrm{~nm}$ - atenuação de $0,3 \mathrm{~dB} / \mathrm{km}$

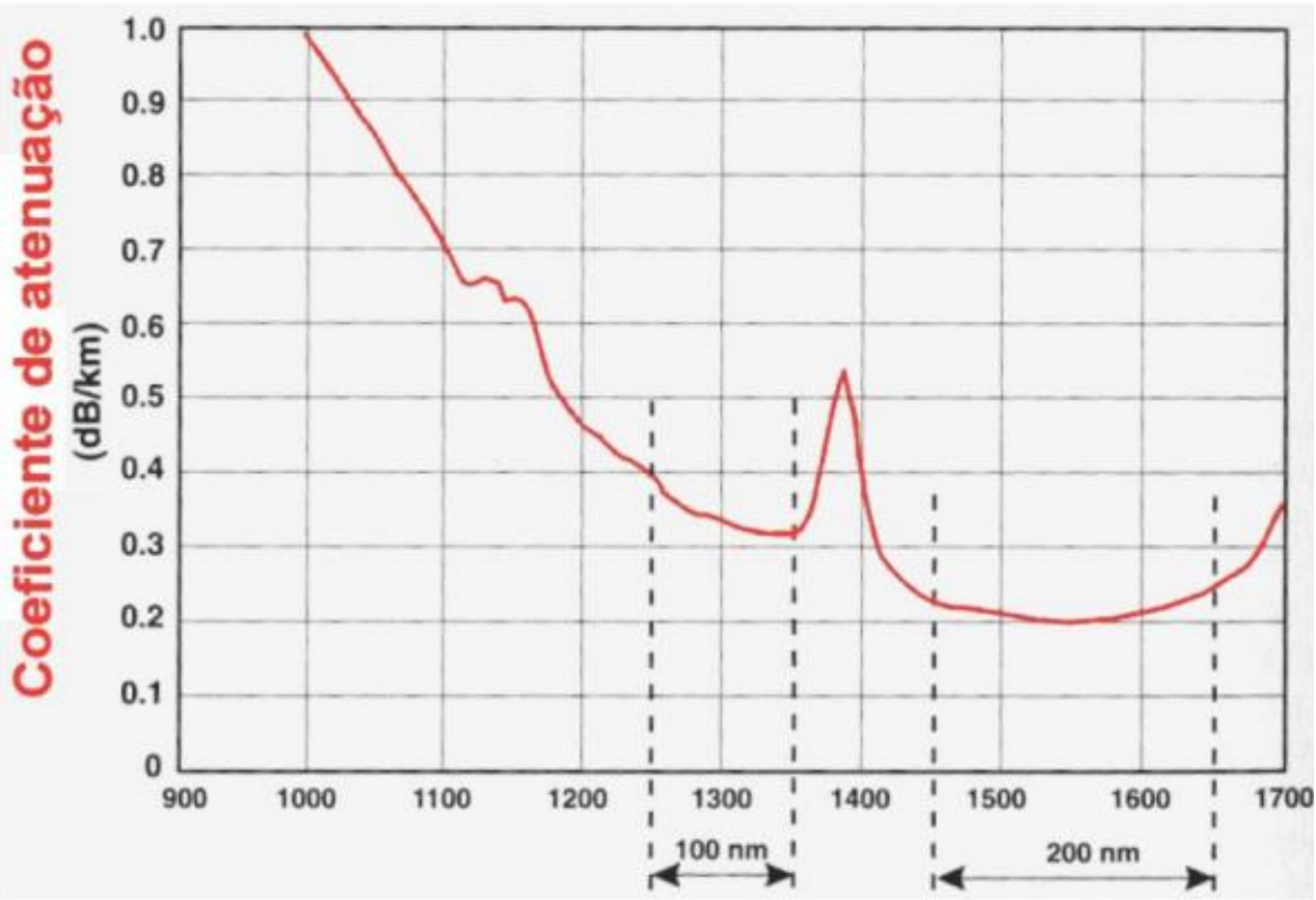

Figura 8 - Coeficiente de atenuação considerando transmissões em uma fibra óptica monomodo [17].

Uma breve discussão de diferentes plataformas tecnológicas, utilizando o princípio de detecção de gases é abordada a seguir. Espectroscopia de correlação, detecção de gás usando espectrofotômetros e cavidades, sendo que ambos podem ser implementados em combinação com outras técnicas espectroscópicas. Em cada caso, são considerados os princípios de operação, tecnologia e limitações significativas. 


\subsection{Células ópticas de gás}

Células ópticas de fluxo de gás são componentes necessários em muitos sistemas de detecção de gás da amostra baseados em laser. Tal dispositivo acoplado a fibra monomodo pode oferecer várias opções para melhor atender a sua aplicação de detecção específica.

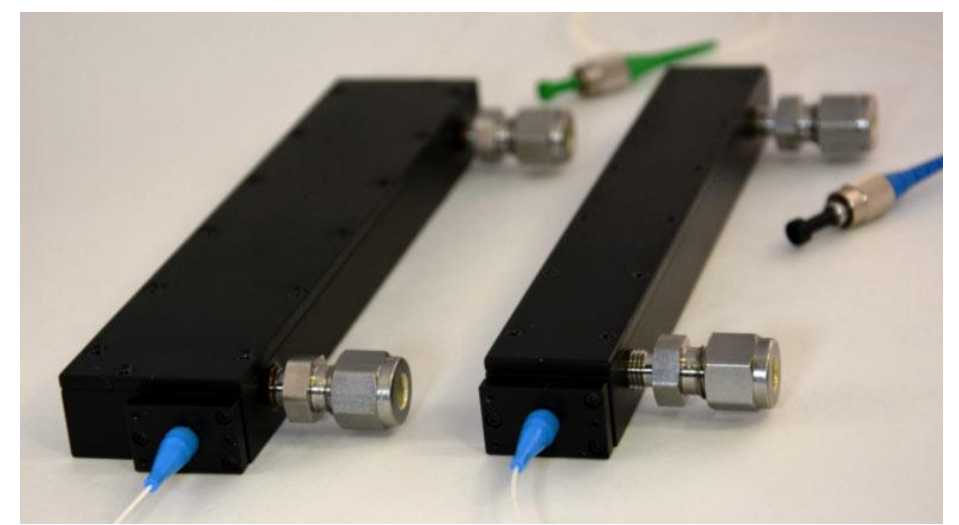

Figura 9 - Células de fluxo (fibra óptica monomodo). [19]

\subsection{Non-dispersive sensors}

Na técnica NDIR (non-dispersive infrared), a ser apresentada a seguir na Figura 10, a intensidade de luz transmitida pela amostra em um determinado comprimento de onda em que a energia é absorvida por esta, é comparada com a intensidade de luz transmitida em outro comprimento de onda onde não haja absorção. A partir da razão entre as intensidades de radiação infravermelha transmitidas nestes dois comprimentos de onda, é possível obter-se a densidade de moléculas do material em análise. 

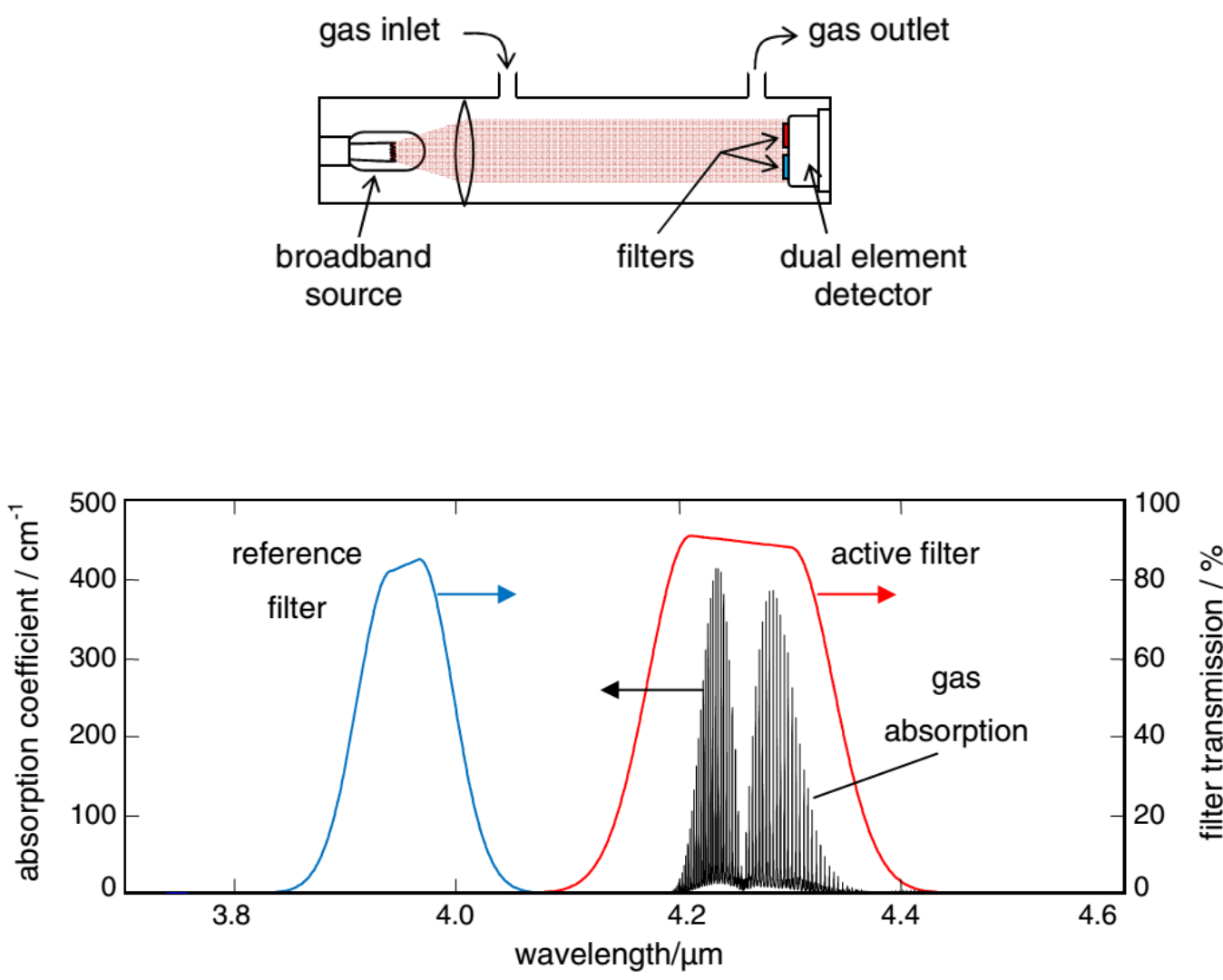

Figura 10 - Ilustração do princípio de medição NDIR: espectro de absorção de $\mathrm{CO}_{2} \mathrm{e}$ diagrama esquemático de um simples sensor de gases [24].

Como as fontes de luz de banda larga, muitas vezes são altamente divergentes, os limites de detecção do mais longo percurso óptico podem ser dependentes da fonte de energia emitida dentro de uma janela espectral definida, e o detector de ruído. Na detecção de ruído, pode ser utilizada uma figura de mérito normalizada, a detectividade específica ( $\left.D^{*}\right)$, equivalente a SNR quando usado em radiação uniforme, normalizado para a área do detector $\mathrm{A}_{\mathrm{d}} \mathrm{e}$ largura de banda de medição $\Delta \mathrm{f}$, conforme (12) [20]:

$$
D^{*}=\frac{\sqrt{A_{d} \Delta_{f}}}{N E P}
$$

Onde NEP é noise equivalente power e $\mathrm{D}^{*}$ expresso $\left(\mathrm{Hz}^{1 / 2} \mathrm{~W}^{-1}\right)$. 
O desempenho dos sistemas NDIR pode ser estimado em termos da variação mínima detectável em potência óptica por $\Delta \mathrm{I} / \mathrm{I}$.

\subsection{Espectroscopia de Correlação}

Espectroscopia de correlação pode ser considerada um desenvolvimento da ténica NDIR, em que o filtro de banda larga é substituído ou aumentado por uma célula de gás de referência contendo uma quantidade conhecida de determinado gás em questão. Com um coeficiente de absorção suficientemente grande na célula, apenas a luz com comprimentos de onda que não são absorvidos pelo gás de destino pode ser identificado pelo detector. A saída do detector de referência é comparada com a de um canal equivalente (ativo) que não contém gás de referência. Ao normalizar as duas intensidades e subtraindo-as, é possível calcular o nível de absorção de luz a comprimentos de onda correspondentes apenas aos absorvidos pelo gás em questão [21].

Um princípio de correlação semelhante pode ser utilizado a partir de um interferômetro de Fabry-Perot (FPI) para fornecer uma referência de gás artificial com linhas de transmissão igualmente espaçados cuja posição espectral pode ser modulada. A técnica pode ser usada apenas para detectar gases com linhas de absorção uniformemente espaçados cuja espaçamento corresponde à faixa espectral livre [21]. 

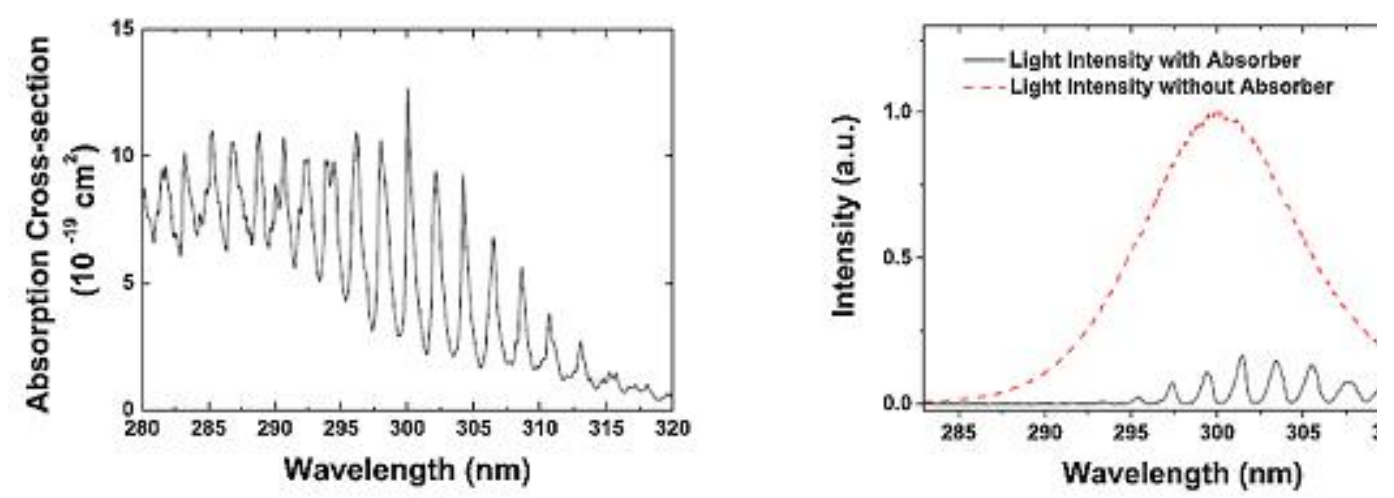

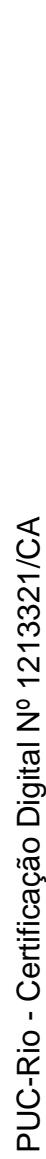

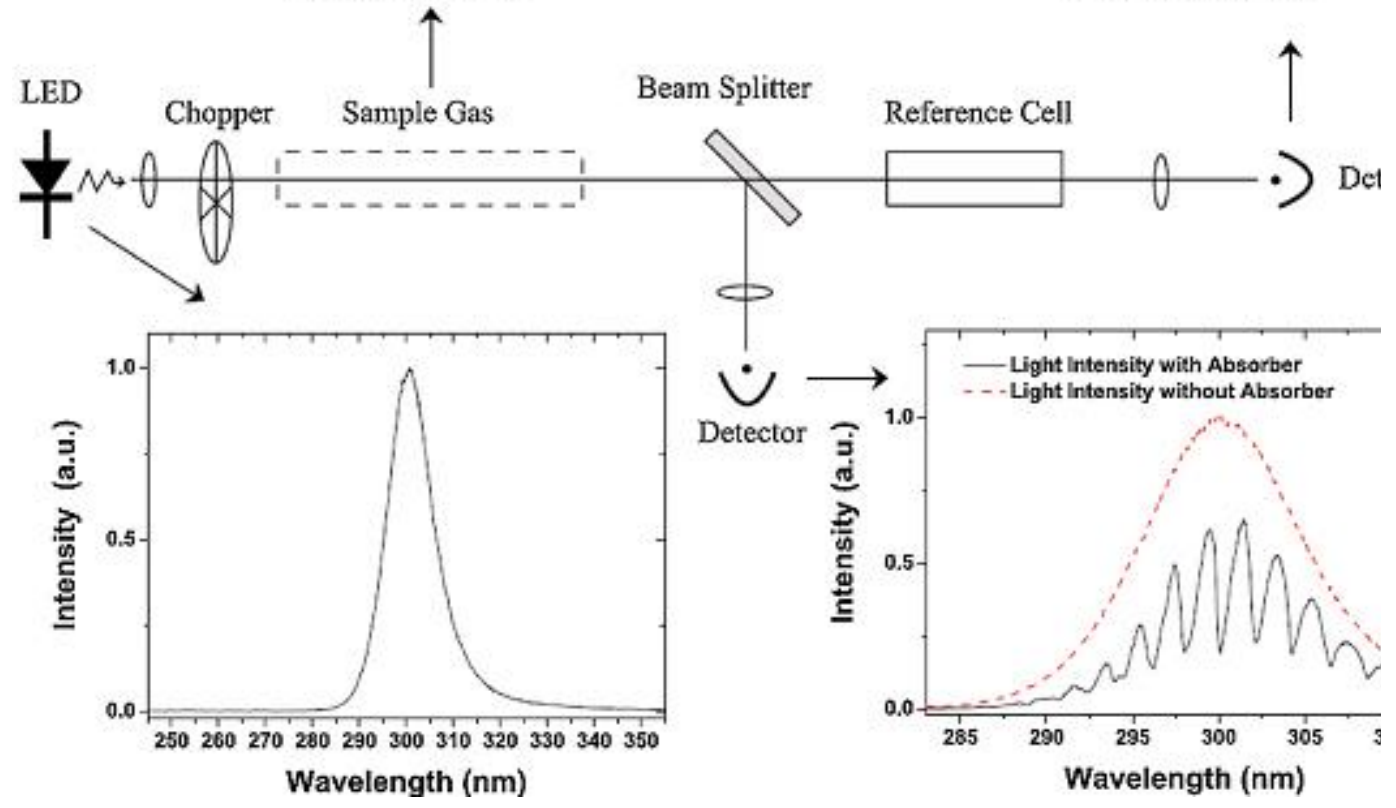

Figura 11 - Exemplo de espectroscopia de correlação usando um LED UV como fonte, ilustrando os espectros de emissão fonte, absorção do gás, e recebimento de luz para os dois detectores [21].

\subsection{Espectrofotometria}

Em contraste com as técnicas não dispersivas descritas acima, espectrofotometria é uma técnica dispersiva no sentido de que o espectro de uma fonte de banda larga é disperso por comprimento de onda. A espectrofotometria é a medida da luz que é absorvida ou emitida por uma espécie química.

Gases múltiplos podem ser detectados desde que as suas linhas de absorção estejam dentro de um intervalo de comprimentos de onda do espectrômetro e regiões possam ser encontrados com pouca ou nenhuma absorção de referência [21]. 


\subsection{Cavity ringdown spectroscopy (CRDS)}

A técnica CRDS foi previamente aplicada para medir refletividade em espelhos. A luz acoplada em uma cavidade de alta finesse acumula e decai exponencialmente à medida que a fonte é ligada e desligada. Medidas de absorção são feitas através do tempo de decaimento exponencial. Fontes de perdas na cavidade incluem espelhos com menos do que $100 \%$ de refletividade, espalhamento e imperfeições em alinhamento (efeitos de banda larga), bem como a absorção espectral, que podem ser diferenciados de acordo com uma linha de base do espectro, ou a medição de referência. O envelope de decaimento exponencial do sinal medido tem a forma geral na equação (13), onde $\tau$ é o tempo de decaimento característico, na ausência de absorção [22].

$$
\mathrm{I}=I_{o} e^{\left(-\frac{t}{\tau}-\alpha c t\right)}
$$

\subsection{Detecção Fotoacústica}

Sensores fotoacústicos diferem na maneira que a luz absorvida é detectada. Em sensores de transmissão tradicionais, monitoriza o nível de luz absorvida por comparação da intensidade da luz, na presença e ausência de absorção de gás [21].

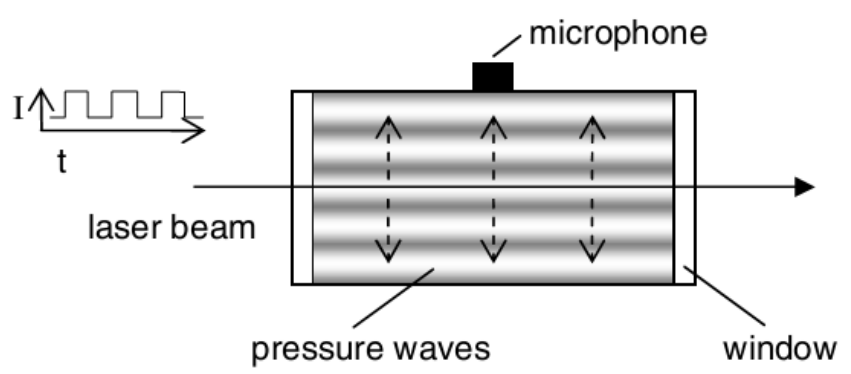

Figura 12 - Detecção do efeito fotoacústico de célula fechada [21]. 
A energia da luz absorvida por uma substância a ser analisada é convertida em calor. Para gases isto geralmente ocorre via colisão molecular induzida por relaxamento não-radiativos de estados excitados. Devido o sinal recebido ser geralmente proporcional à potência de excitação $I_{o}$ e o ruído limitante ser independente de $I_{o}$, o desempenho do sistema é muitas vezes comparado a uma figura de mérito normalizada com base na absorbância mínima detectável $\alpha_{\min }$. Uma desvantagem de sistemas de fotoacústica é que eles são muito sensíveis a ruído de fundo e a vibrações. Isto pode ser uma limitação de desempenho, podendo ainda variar de local para local, sendo difícil de prever. Para outras medidas, este ruído seria reduzido através do aumento da modulação de frequência $f$, como a amplitude de vibrações de fundo é normalmente inversamente proporcional à frequência. No entanto, o sinal fotoacústico resultante da integração da energia absorvida durante cada ciclo de modulação, também é proporcional a $1 / f$, portanto, o resultado geral é nenhuma melhoria nítida na relação sinal-ruído.

\subsection{Fibras ópticas microestruturadas}

A Photonic Crystal fibre (PCF - fibra de cristal fotônico) foi originalmente desenvolvida para aplicações em fotônica e telecomunicações. É uma estrutura periódica de buracos longitudinais ao redor do núcleo. A photonic quantum well (QW) é formado limitando os modos de propagação mais eficientemente do que em fibra convencional, de tal forma que o espaçamento da rede e tamanho do furo possa manter a operação monomodo ao longo de quase toda a transmissão, reduzindo ainda reflexões de Fresnel nas extremidades das fibras. Alguns exemplos de tais fibras estruturadas são apresentados na Figura 13 [23]. 


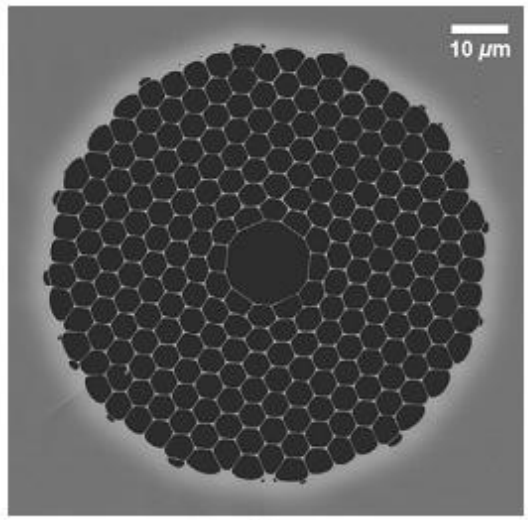

(a)

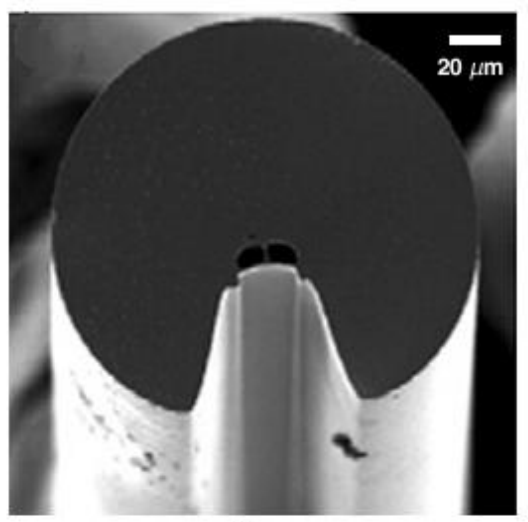

(c)

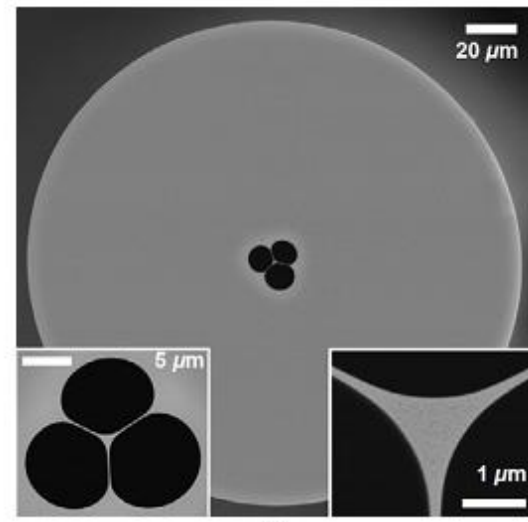

(b)

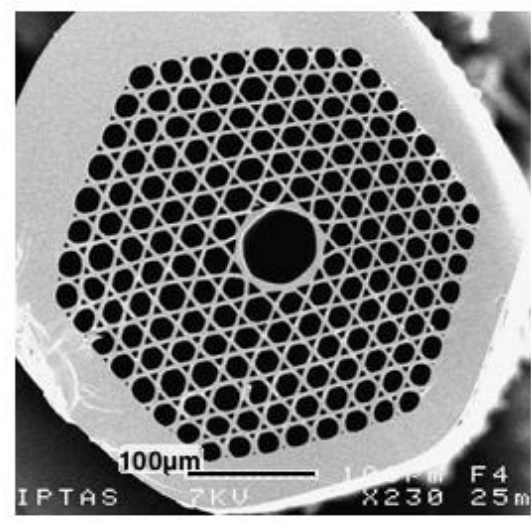

(d)

Figura 13 - Fibras ópticas microestruturadas adequadas para sensoriamento químico. (a) Sílica-Ar núcleo oco (b) Fibra de núcleo com buracos [7] (c) Fibra de núcleo com ranhura, utilizada para detecção de fluorescência distribuída [19] (d) PCF núcleo oco [20].

Numa fibra óptica convencional, a luz é confinada em uma estrutura capilar estreita por uma série de reflexões internas nas paredes de alta refletividade. As perdas podem ser consequentemente altas, mas geralmente podem ser aplicadas a distâncias de alguns metros sem afetar significativamente o desempenho da fibra aplicada como elemento sensor. [24].

Existem dois tipos distintos de fibras de cristal fotônico:

- Núcleo de vidro: o guiamento é por reflexão interna total e o índice de refração da casca varia com o diâmetro modal (e consequentemente com a frequência).

- Núcleo oco: índice de refração do núcleo é menor que o índice da casca, não havendo reflexão total interna. A luz guiada através do ar por reflexão de Bragg (difração). 


\section{Índice de refração:}
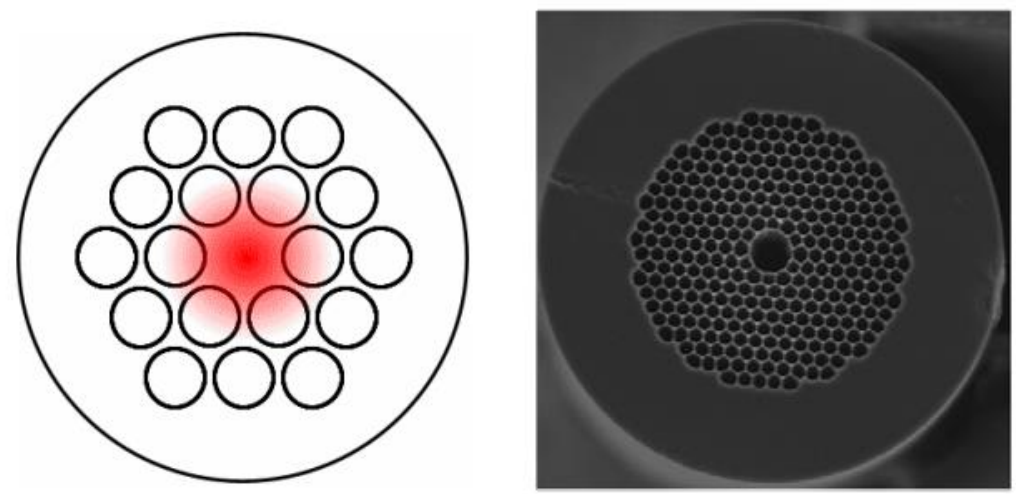

Figura 14 - Fibras de cristal fotônico de núcleo de vidro (propagação do sinal luminoso no núcleo) e de núcleo oco (propagação no ar). [25]

Um dos primeiros sensores a fibra óptica foi apresentado na década de 80 , medindo a pressão externa através de medidas de perda de transmissão óptica em uma fibra devido às pequenas dobras provocadas. Outra aplicação em sensoriamento consistiu em monitorar o sinal óptico devido às múltiplas reflexões da face de duas fibras monomodo separadas por uma distância, consistindo em uma cavidade de Fabry-Perot. Esse dispositivo foi utilizado para medidas de temperatura, vibração mecânica, ondas acústicas, tensão e campo magnético [26].

Na prática, uma das principais dificuldades da engenharia utilizando fibras como células de gás com proporção elevada é o longo tempo necessário para preenchê-las com o gás a ser detectado. As técnicas para melhorar o tempo de preenchimento de amostra incluem o aumento da diferença de pressão através da fibra para conduzir o gás, aumentando o diâmetro da célula, ou pela introdução de orifícios para permitir o fluxo de gás ou de difusão ao longo do comprimento do guia de onda. O tamanho do poro, expresso em unidade nanométrica, deve ser suficientemente elevado para permitir que a difusão do gás deixe de ser reduzida evitando perturbação à luz transmitida. Os furos podem ser feitos usando lasers de femto segundos (fs), e tem a vantagem de serem de fácil manuseio [27]. A Figura 15 mostra o processo de perfuração descrito. 

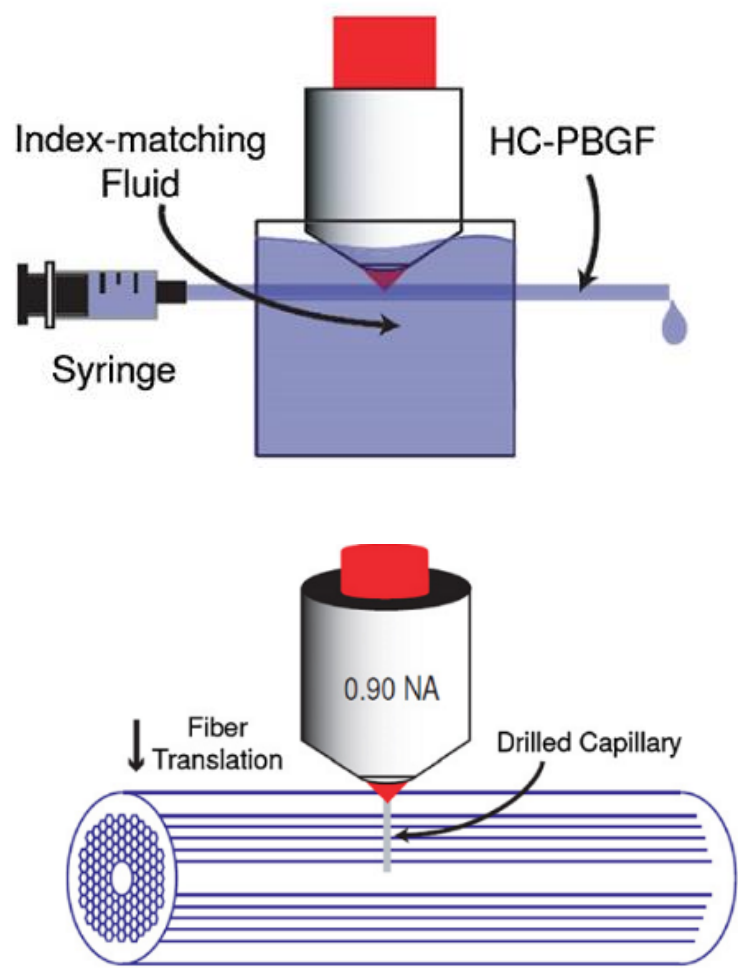

Figura 15 - Processo de perfuração em fibra óptica utilizando um laser de fs. [20]

A vantagem do uso em sensoriamento de fibras PCFs em relação às fibras ópticas padrão é a baixa dependência com a temperatura e na resistência química ao hidrogêncio, o que torna atrativa em aplicações a altas temperaturas e em ambientes ricos do gás. A geometria interna das PCFs pode ser alterada, aumentando a sensibilidade para medidas de pressão, deformação ou índice de refração [28].

\subsubsection{Fibras ópticas preparadas para interação entre a luz guiada e a luz existente na região exterior}

A interação entre a luz guiada pela fibra e a exterior pode ser realizada por uma variedade de alternativas. Para metodologias que envolvam a propagação de campo evanescente, a proporção de luz interagindo com a região circundante analisada é uma função do índice de refração. Consequentemente, estas técnicas são mais comumente utilizadas com amostras líquidas, que 
apresentam índices mais elevados que o do ar [29]. No entanto, há uma série de aplicações da utilização para detecção de gás, e podem ser verificadas na Figura 16. As complexidades adicionais de sistemas de fibra óptica comparados a sistemas no espaço livre, muitas vezes significa que os limites de detecção estão comprometidos por franjas de interferência residuais formadas pelas células de gás, conectores e possíveis emendas na fibra óptica [20].

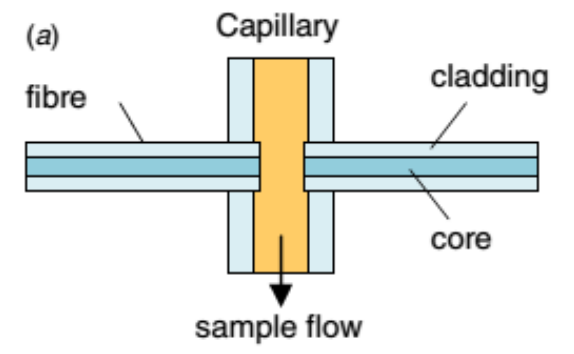

(c)
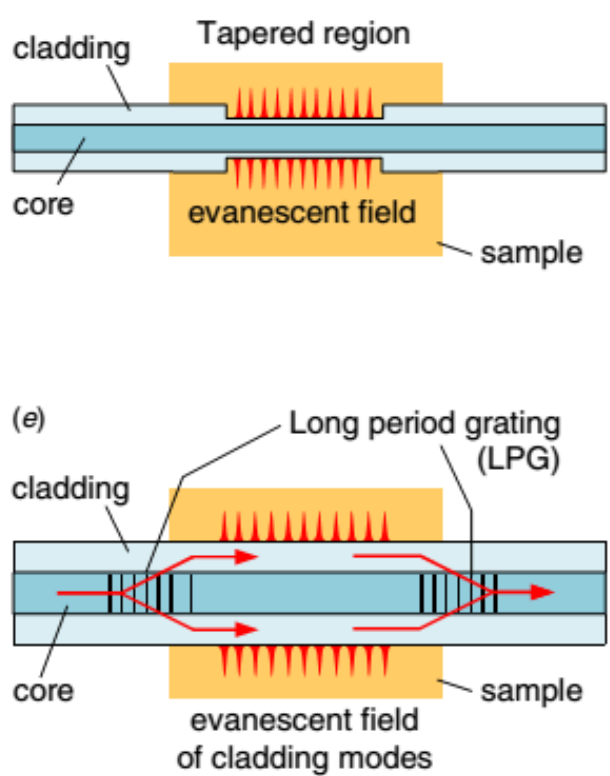

(b)

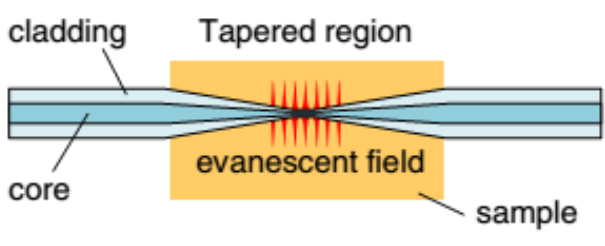

(d)

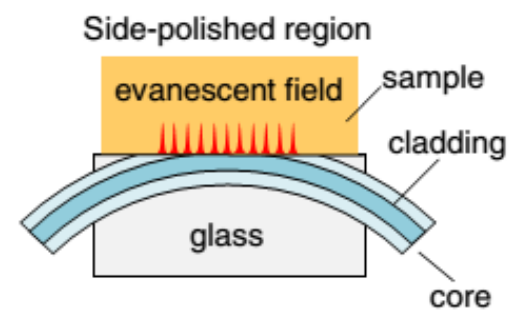

(f) Diffusion region

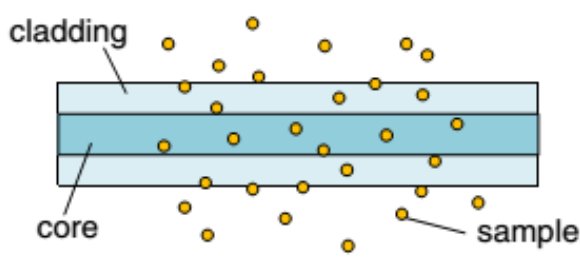

Figura 16 - Técnicas proporcionando a interação entre a luz guiada pela fibra óptica e medidas na região exterior: (a) a luz acoplada fora da fibra; campos evanescentes em: (b) uma região cônica, (c) uma região com corrosão, (d) uma região polida de um lado, (e) grades de acoplamento da luz dentro e fora do revestimento; (f) a difusão de alguns gases no núcleo da fibra [29].

Na utilização de fibras de cristal fotônico de núcleo oco (HCPCFs hollow core photonic crystal fibers), o mecanismo de guiamento é baseado no 
efeito band-gap fotônico, o que torna promissor para aplicações de detecção devido ao confinamento da luz no núcleo oco. No entanto, a banda espectral estreita para a propagação restringe suas aplicações.

\subsection{Absorção e detecção óptica de gases}

Matéria e energia não são consideradas entidades distintas e se interconvertem uma na outra, de acordo com a equação de Einstein (8). Medem-se o comprimento de onda e a frequência (propriedades ondulatórias) de partículas como elétron, próton ou nêutron.

$$
\mathrm{h} v=\mathrm{mc}^{2}
$$

Do mesmo modo, a luz é um conjunto de partículas se deslocando no espaço (fótons) com comprimento de onda e frequência. $\mathrm{O}$ que caracteriza a energia luminosa é a energia dos fótons, determinada pelo comprimento de onda, pois a velocidade dos diversos fótons é a mesma e constante em cada meio. A luz é dita onda eletromagnética porque na Física clássica ela foi descrita como uma oscilação de um campo elétrico e de um campo magnético se propagando no espaço. Essa aproximação permite calcular vários fenômenos ondulatórios e, paradoxalmente, a energia das partículas de luz [30].

A teoria quântica informa que os níveis de energia dos elétrons em átomos neutros são quantizados, isto é, os elétrons assumem estados discretos de energia e só passam de um nível de energia para outro se receberem uma quantidade exata. Essa energia pode ser muito alta, fazendo com que o elétron saia da estrutura atômica e o átomo neutro torne-se um íon. A partir desse limite, que é a energia de ionização, o átomo neutro passa a poder receber qualquer quantidade de energia e não mais "pacotes discretos". Cada elemento químico tem estrutura eletrônica e níveis de energia diferenciados, tem uma energia de ionização característica e absorve uma série diferente de "pacotes discretos" [30]. O que se mede diretamente não é a quantidade de luz absorvida. Esta técnica poderia ser realizada se houvesse 
um detector junto a cada átomo, para ver se este absorveu ou não o fóton. O que se faz normalmente é medir a luz que consegue passar.

Se um feixe de luz com intensidade $\mathrm{I}_{\mathrm{o}}$ é incidido sobre a região que contém os átomos capazes de absorvê-lo, após passar pela região, este feixe terá uma nova intensidade $\mathrm{I}$, menor do que $\mathrm{I}_{0}$, o que significa que uma parte da luz foi absorvida. A nova intensidade é então detectada. A intensidade de I depende da intensidade de $\mathrm{I}_{\mathrm{o}}$, da concentração dos átomos na região, da distância percorrida pelo feixe de luz, do $\lambda$ que incide e, é claro, de que espécie são os átomos. Como I é dependente de $\mathrm{I}_{\mathrm{o}}$, há que se garantir que $\mathrm{I}_{\mathrm{o}}$ é sempre igual nas diferentes medições - ilustração do fenômeno na Figura 17. Para escapar desse problema, mede-se a razão $\mathrm{I} / \mathrm{I}_{\mathrm{o}}$, sendo esta chamada de transmitância ( $\mathrm{T}$ ), definida na equação (9). Utiliza-se também porcentagem de transmitância (\%T).

$$
\mathrm{T}=\frac{\mathrm{I}}{\mathrm{I}_{\mathrm{o}}}
$$

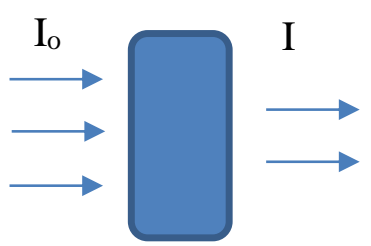

Figura 17 - Feixe de luz com intensidade $I_{o}$ incidindo sobre a região que contém os átomos capazes de absorver. Após passar pela região, o feixe terá uma nova intensidade I.

$\mathrm{Na}$ atmosfera terrestre, a absorção ocorre devido à presença de moléculas ou átomos com bandas ou linhas em uma dada faixa de comprimentos de onda. Por exemplo, o $\mathrm{O}_{2}$ (oxigênio molecular) e o $\mathrm{O}_{3}$ (ozônio) apresentam bandas de absorção na região ultravioleta $(0,001-0,39 \mathrm{~mm})$ do espectro eletromagnético, e outras espécies como $\mathrm{H}_{2} \mathrm{O}$ (vapor de água) e $\mathrm{CO}_{2}$ (dióxido de carbono) absorvem fortemente na região do infravermelho [31].

O espectro de absorção dos gases é essencialmente descontínuo. No caso de um gás atômico, o espectro consiste de um número de linhas espaçadas nas regiões espectrais do ultravioleta e do visível, que correspondem a diferentes transições eletrônicas características de espécies atômicas particulares. As linhas de absorção surgem de transições de estados padrão para estados superiores excitados. 
No caso de um gás molecular, como por exemplo os utilizados neste cálculo, a absorção ocorre em bandas, constituídas de um grande número de linhas espectrais pouco espaçadas. A razão para o surgimento de bandas é que toda transição eletrônica é tipicamente acompanhada por mudanças rotacionais-vibracionais, e então cada linha eletrônica é subdividida em muitas linhas.

As linhas de absorção são específicas para cada tipo de gás, o que constitui a sua base para a detecção e medição. Portanto, os espectros de absorção das diferentes regiões espectrais têm características distintas [32], conforme pode ser observado na Figura 18.

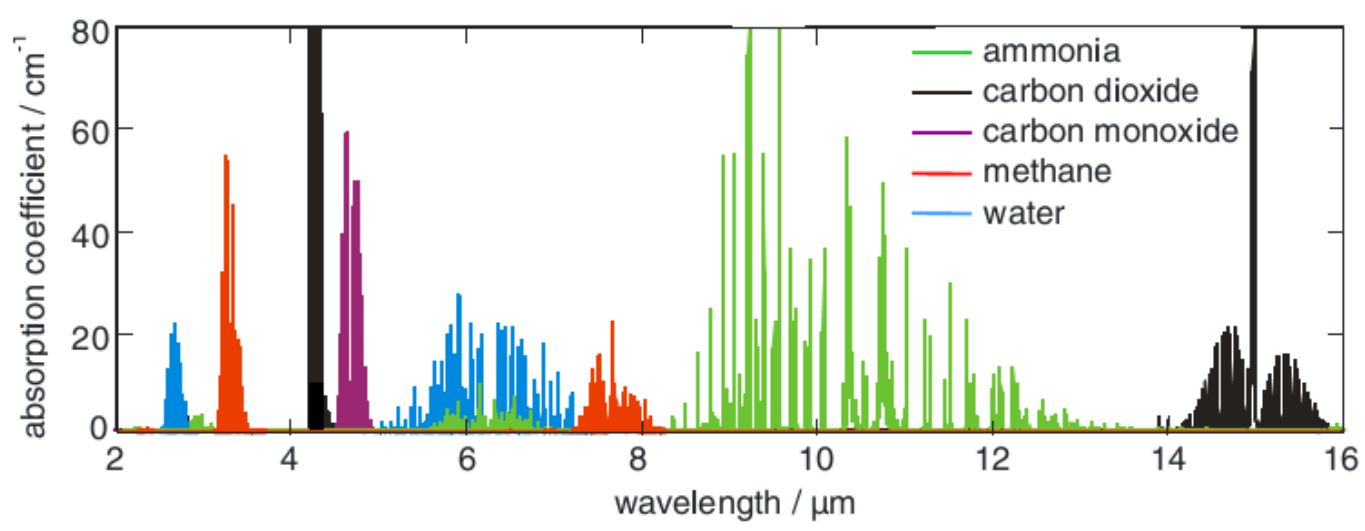

Figura 18 - Espectros de absorção para cinco gases: amônia, dióxido de carbono, monóxido de carbono, metano e vapor d'água [24].

A detecção óptica de gás utilizando a espectroscopia de absorção é baseada na aplicação da Lei de Beer-Lambert [32], conforme apresentada na equação (10):

$$
\mathrm{I}=\mathrm{I}_{0} e^{-\alpha l}
$$

Onde I é a luz transmitida através da célula de gás, I0 é a luz incidente na célula de gás, $\alpha$ é o coeficiente de absorção da amostra (tipicamente com unidades de $\mathrm{cm}^{-1}$ ) e em função do comprimento de onda, e $l$ é o comprimento do caminho óptico da célula de absorção de gás (geralmente com unidades de cm). O coeficiente de absorção $\alpha$ é o produto da concentração do gás pela absortividade específica do gás $\varepsilon$ (por exemplo, em cm $\mathrm{cm}^{-1} \mathrm{~atm}^{-1}$ [20]. 
Para o termo $\alpha$ l pequeno, a equação é convenientemente linear com $\alpha$, e tem-se que: $\frac{\Delta \mathrm{I}}{\mathrm{I}_{0}} \approx \alpha l$

Onde: $\Delta \mathrm{I}=\mathrm{I}_{0}-\mathrm{I}$, sendo $\Delta \mathrm{I} / \mathrm{I}_{0}$ a absorbância (sem unidade - descrita em "unidades de absorbância" - ua). Os limites de detecção podem ser quantificados como NEA (noise equivalente absorbance, expresso em u.a.) ou o coeficiente de absorção mínima detectável, $\alpha_{\min } \mathrm{em} \mathrm{cm}^{-1}$ [20].

A medição do nível de luz absorvida na amostra é efetivamente proporcional à densidade do número $\mathrm{N}$ de moléculas presentes nesta amostra. Para converter a unidade de $\mathrm{ppm}$ em percentual de volume $\mathrm{V}$ a diferentes temperaturas T e pressão $P$, ajustes devem ser feitos usando a equação do gás ideal expressa em (11):

$$
\mathrm{PV}=\mathrm{N} k_{B} \mathrm{~T}
$$

Sendo na equação: $\mathrm{V}$ o volume de uma célula fechada, $\mathrm{N}$ o número de moléculas na célula e $k_{B}$ a constante de Boltzman $\left(1,3806488 \times 10^{-23} \mathrm{~m}^{2} \cdot \mathrm{kg} \cdot \mathrm{s}^{-2} \cdot \mathrm{K}^{-1}\right)$.

\subsubsection{Analisador de concentração de $\mathrm{CO}_{2}$}

O nível de concentração de $\mathrm{CO}_{2}$ ambiente é verificado com o filtro óptico analisador modelo 410i Thermo Scientific 20\%, mostrado na Figura 19 que realiza medidas utilizando a tecnologia não dispersiva NDIR (non-dispersive infrared). $\mathrm{O}$ equipamento oferece flexibilidade e confiabilidade na avaliação dos sistemas em teste [33]. 


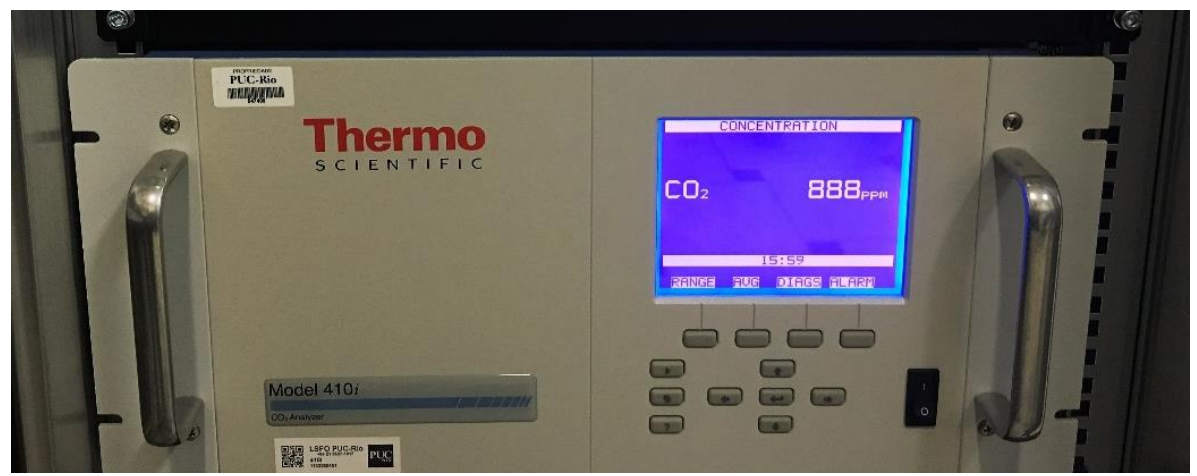

Figura 19 - Filtro óptico analisador de $\mathrm{CO}_{2}$ modelo 410i (Thermo Scientific) [23].

\subsection{Comentários e conclusões do Capítulo}

O presente Capítulo introduz a teoria eletromagnética da luz associada às fibras ópticas e a espectroscopia destes elementos quando utilizadas no guiamento de sinais ópticos. São apresentadas ainda as fibras ópticas do tipo micro estruturadas e a forma como o sinal óptico pode propagar-se nestas. Em seguida, são apresentadas algumas técnicas ópticas que permitem trabalhar com interações nas regiões dos campos evanescentes das fibras. Conceitos básicos de absorção, detecção e medidas de concentração de gases são introduzidos juntamente com as técnicas de Espectroscopia de Correlação, Espectrofotometria, Cavity ringdown spectroscopy (CRDS), Detecção Fotoacústica. Desta forma, estão destacados e descritos os conceitos e técnicas básicas utilizadas nos próximos Capítulos. 


\section{Novos métodos para detecção de gases}

Este Capítulo apresenta a aplicação de ferramentas computacionais com finalidade de avaliar o comportamento de fibras ópticas em função dos índices de refração de suas camadas e os fatores de atenuação associados, podendo estes apresentar valores variados. São avaliadas fibras monomodo e multimodo com núcleos de várias dimensões tendo como objetivo aplicações destas fibras como sensores. São estudados fenômenos físicos que descrevem o comportamento das fibras ópticas sem casca para melhor caracteriza-las visando futuras aplicações no sensoriamento de gases em várias faixas de absorção por comprimento de onda. Ainda neste Capítulo, um sistema de interrogação baseado em laser em anel é apresentado. Nesta etapa, são introduzidas as FBG (Fiber Bragg Gratting) como elemento principal e uma breve descrição teórica destas.

\subsection{Caracterização de fibras ópticas por simulações eletromagnéticas}

O software utilizado para simulação das fibras ópticas a serem aplicadas como sensores de gás por campo evanescente é o Optiwave, com os pacotes OptiBPM (beam propagation mode) e Optisystem. O OptiBPM é um ambiente de CAD global utilizado para a concepção de guias de onda ópticos complexos. Este software permite simular a passagem da luz através de qualquer meio de guiamento de onda, possibilitando aos designers observar a distribuição, propagação e radiação do campo eletromagnético, simultaneamente. O Optisystem é um conjunto abrangente de design de software que proporciona aos usuários planejar, testar e simular enlaces ópticos na camada de transmissão de redes ópticas modernas [34].

O OptiBPM permite criar o perfil da fibra a ser caracterizada por inserção dos parâmetros: índices de refração das camadas constituintes e fator de atenuação associado; raio e comprimento do cilindro guia de onda; comprimento 
de onda de operação e característica do sinal de entrada. Ao concluir a simulação, o software apresenta dados completos como análise do modo de propagação fundamental, diagrama $2 \mathrm{D}$ e $3 \mathrm{D}$ do sinal luminoso ao longo do guia, com informações de amplitude e fase, e gráfico indicando os níveis de potência na direção de propagação. Estas informações finais podem ser exportadas e comparadas com o objetivo de caracterizar as fibras ópticas com diferentes perfis.

\subsubsection{Validação das simulações para fibras ópticas padrão SMF-28}

O objetivo desta atividade de simulação é avaliar o perfil da propagação do campo evanescente numa fibra óptica quando esta for aplicada como um sensor de monitoramento de gás por absorção em um determinado comprimento de onda. Para tal análise, é necessário inserir no índice de refração da casca da fibra um termo imaginário que representa o coeficiente de absorção do material utilizado, sendo este parâmetro responsável pela atenuação do sinal óptico. Cada material apresenta um valor de coeficiente de atenuação característico em função do comprimento de onda e de outros parâmetros como temperatura e pressão.

A Figura 20 a seguir mostra uma tela extraída do software OptiBPM na etapa de introdução das propriedades dos materiais que constituem o guia óptico. No quadro em vermelho está indicando o campo de inserção do índice imaginário. As simulações eletromagnéticas foram realizadas considerando este coeficiente na casca da fibra óptica com os respectivos valores: $10^{-6}, 10^{-5}, 2,5 \times 10^{-5}, 5 \times 10^{-5}, 10^{-4}$, $2 \times 10^{-4}$ e $10^{-3}$. [35] 


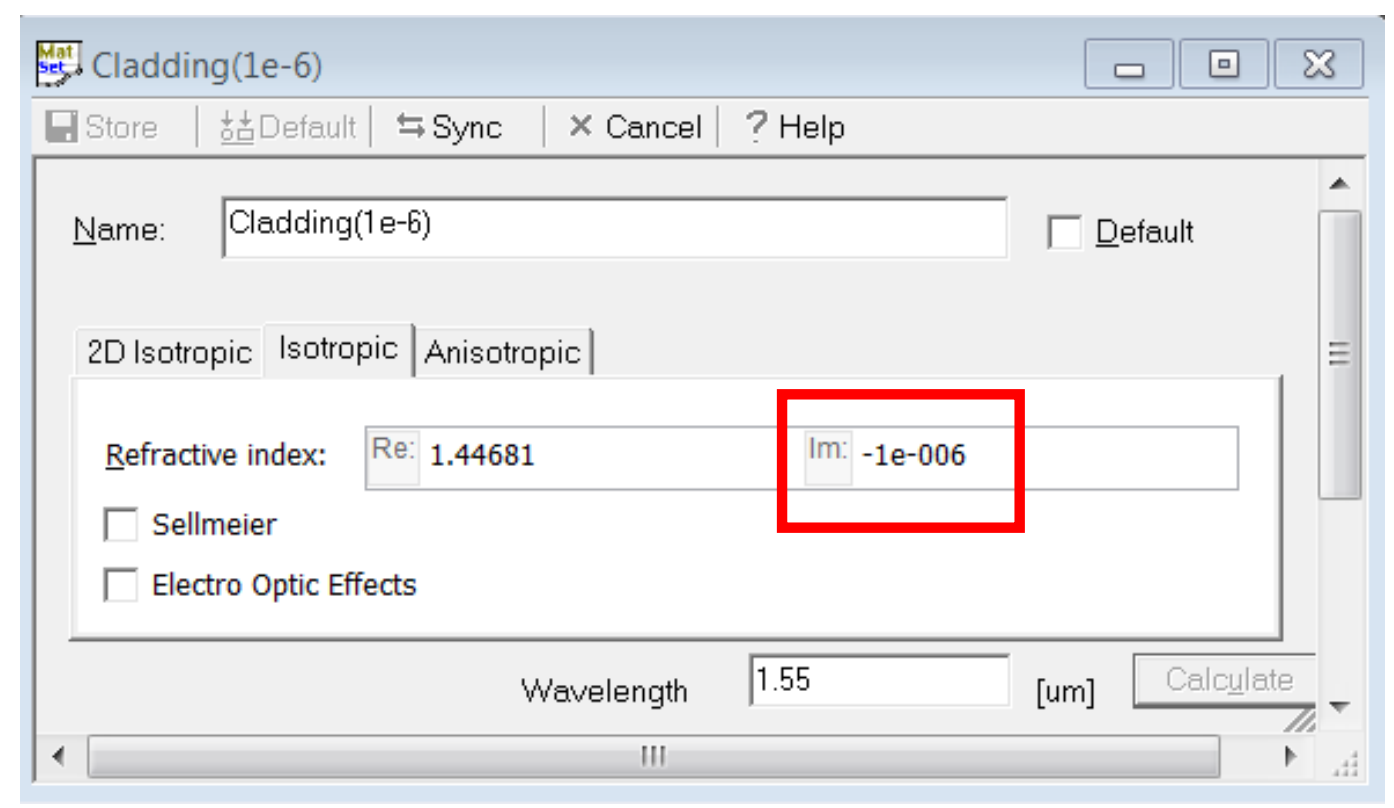

Figura 20 - Tela Profile Design OptiBPM indicando a inserção de absorção na ordem de $10^{-6}$ no índice de refração da casca da fibra óptica simulada.

No caso específico de uma fibra óptica índice degrau, monomodo padrão SMF-28, suas características são apresentadas na Tabela 1, e os gráficos obtidos da primeira etapa de simulações podem ser observados na Figura 21. Um diagrama 3D mostra a região cilíndrica da fibra ao longo da direção de propagação z e o perfil degrau do índice de refração selecionado, onde a região em vermelho corresponde ao índice de refração do núcleo.

\begin{tabular}{|l|c|c|}
\hline Fibra óptica SMF-28, $\Lambda$ = $1550 \mathrm{~nm}$ & Núcleo & Casca \\
\hline Diâmetro $(\boldsymbol{\mu m})$ & 8 & 125 \\
\hline Índice de Refração & 1,45205 & 1,44681 \\
\hline
\end{tabular}

Tabela 1 - Características de uma fibra óptica SMF-28. 

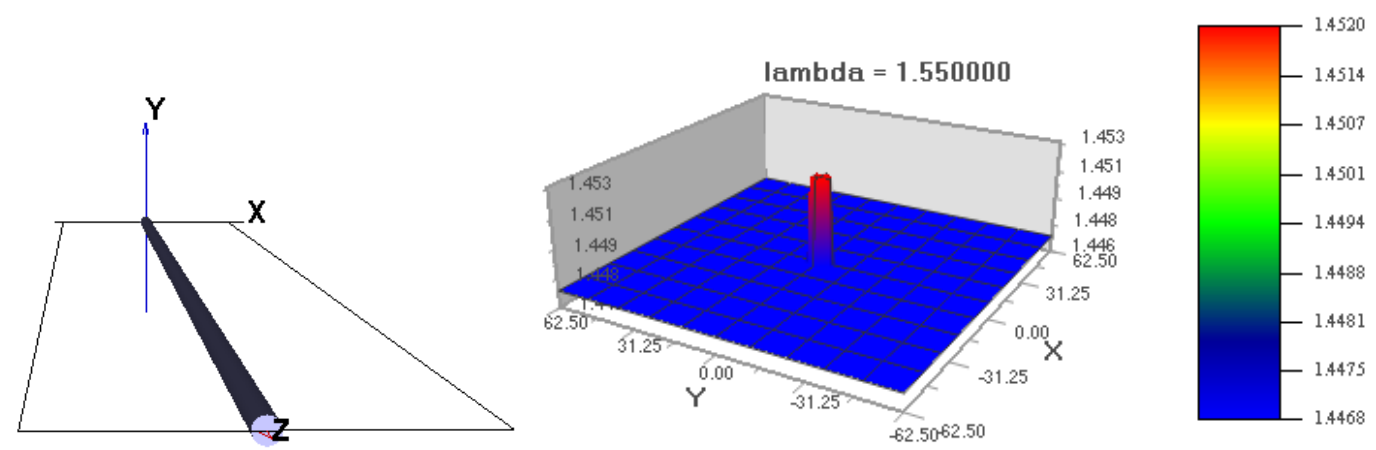

Figura 21 - Perfil da fibra óptica monomodo SMF-28 padrão aplicada em telecomunicações, com comprimento $1 \mathrm{~cm}$, diâmetro e índices de refração do núcleo e revestimento respectivamente $8 \mu \mathrm{m}$ e $125 \mu \mathrm{m}, 1,45205$ e 1,46681.

As simulações são realizadas considerando a fibra óptica padrão SMF-28 (Tabela 1). A propagação do sinal óptico nesta fibra pode ser analisada em diferentes comprimentos de guia. Entretanto, para aquisição mais rápida dos resultados foram simuladas para os comprimentos de $1 \mathrm{~cm}, 5 \mathrm{~cm}, 10 \mathrm{~cm}$ e $1 \mathrm{~m}$.

Na etapa inicial de processamento, há uma função no software que permite o cálculo do modo de propagação na fibra óptica, de acordo com as informações inseridas no perfil, indicando as características da fibra a ser analisada. O número de modos propagantes no guia é considerado como sendo igual ao modo fundamental. Por análise da Figura 22, é possível observar que em ambas situações ((a) sem absorção e (b) com absorção na casca), o sinal gaussiano está concentrado no núcleo da fibra óptica. Comparando o eixo y dos gráficos apresentados em função do diâmetro da fibra, observa-se na saída que há alteração na intensidade do sinal de entrada (na ordem de 25 vezes menor para a situação com absorção). Essa diferença na amplitude é resultante da perda de inserção e do fator de absorção acrescentado no índice de refração casca, que neste exemplo é na ordem de $10^{-3}$. 

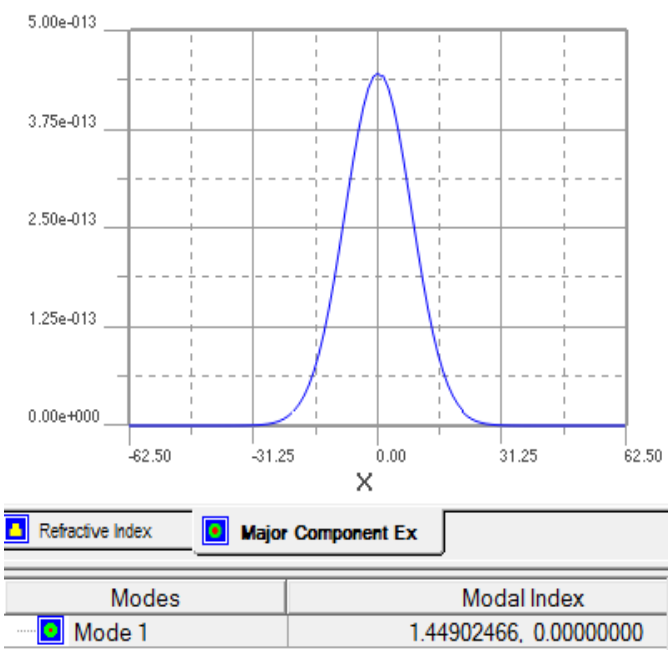

(a) Sem absorção $(n=1,46681)$

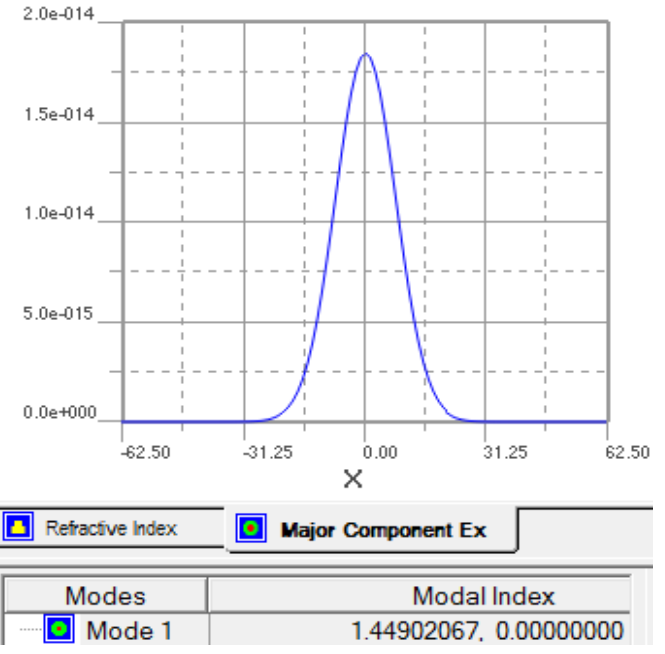

(b) Com absorção na ordem $10^{-3}\left(n=1,46681-10^{-3}\right)$

Figura 22 - Perfil do sinal gaussiano para o modo de propagação calculado em ambas situações com e sem fator de absorção na casca da fibra óptica caracterizada.

A realização da simulação eletromagnética inicial considera uma fibra óptica SMF-28 cujas características estão descritas na Tabela 1, sem absorção na casca e com comprimento de guia igual a $1 \mathrm{~cm}$. Na etapa de pós-processamento, são extraídas dos resultados de simulação e apresentadas graficamente na Figura 23 as características de um sinal gaussiano a $1550 \mathrm{~nm}$. É ilustrado a propagação do campo óptico no núcleo da fibra, cuja intensidade máxima da potência em vermelho é igual a 1. Vez que não há absorção e trata-se de uma fibra padrão de transmissão aplicada em sistemas de telecomunicações, os resultados obtidos estão de acordo com a literatura [16]. São mostrados a propagação em 3D do sinal gaussiano ao longo do núcleo da fibra óptica.
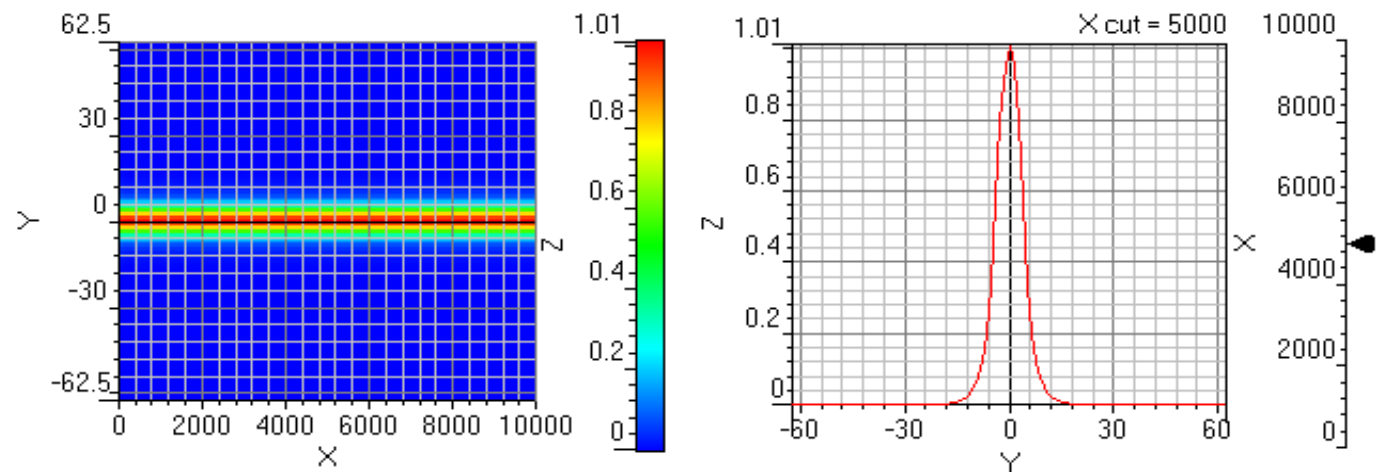

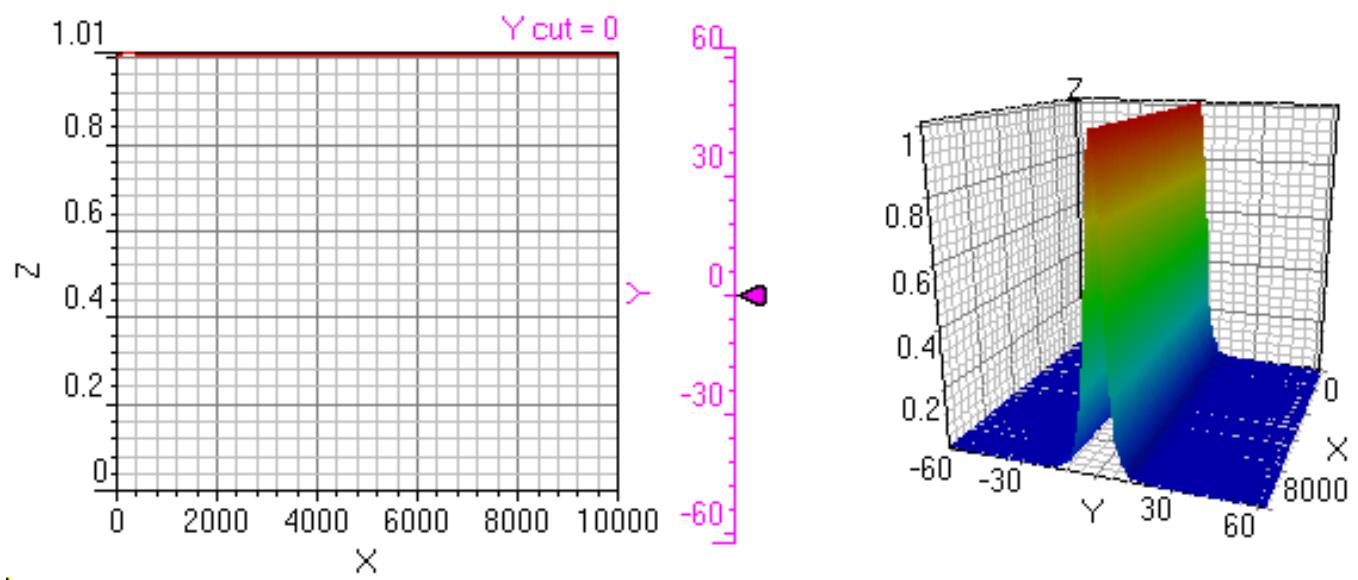

Figura 23 - Fibra óptica ideal monomodo padrão de telecomunicações em 1550 nm, com diâmetros e índices de refração do núcleo e da casca de 8 e 125 um, 1,45205 e 1,44681, respectivamente. Análise em $1 \mathrm{~cm}$ de comprimento de guia.

Como exemplo da propagação de um sinal óptico com atenuação, considere a mesma fibra SMF-28 (Tabela 1), porém nesta etapa com um coeficiente de absorção na casca, na ordem de $10^{-5}$. A Figura 24 mostra esta configuração em um dos gráficos de simulação gerados pelo software. É plotada a relação da intensidade de potência óptica atenuada (eixo y) em função da propagação do sinal ao longo do guia (eixo x). Para um comprimento de guia igual a $1 \mathrm{~cm}$, a potência de saída é equivalente a 0,82 . O cálculo da atenuação realizado para esta situação mostra uma perda de $0,88 \mathrm{~dB} / \mathrm{cm}$.

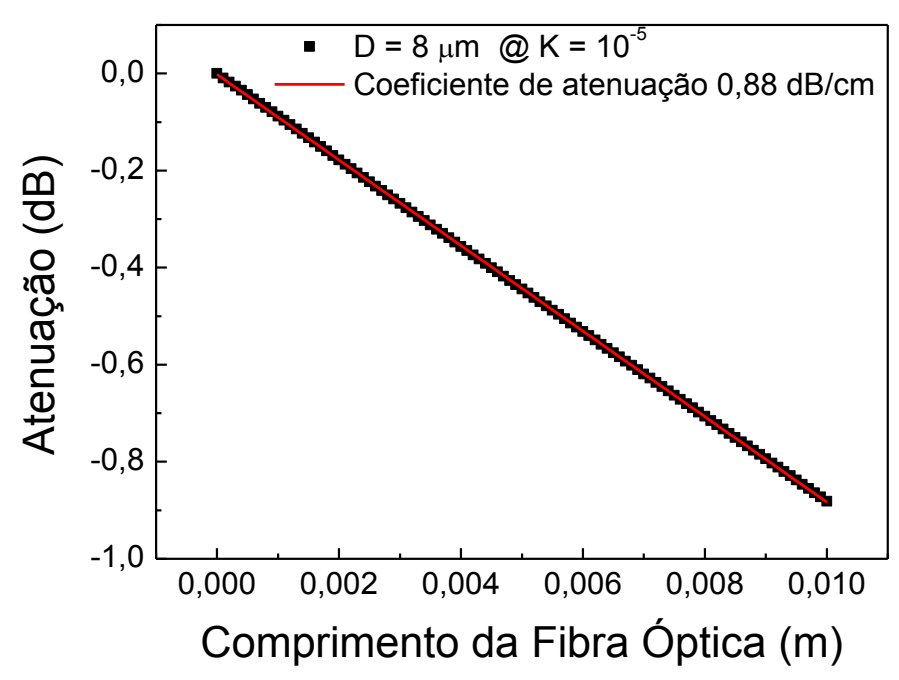

Figura 24 - Atenuação da potência por comprimento de fibra óptica quando o fator de absorção na casa é na ordem de $10^{-5}$. 
Conforme mencionado na introdução deste Capítulo, o software OptiBPM permite que a fibra óptica caracterizada seja exportada para análise no Optisystem. Assim, o sistema de detecção a ser montado em laboratório pode ser primeiramente simulado. O conjunto montado para análise: laser em $1550 \mathrm{~nm}$, fibra óptica como sensor e equipamento analisador de espectro óptico, está representado na Figura 25 a seguir.
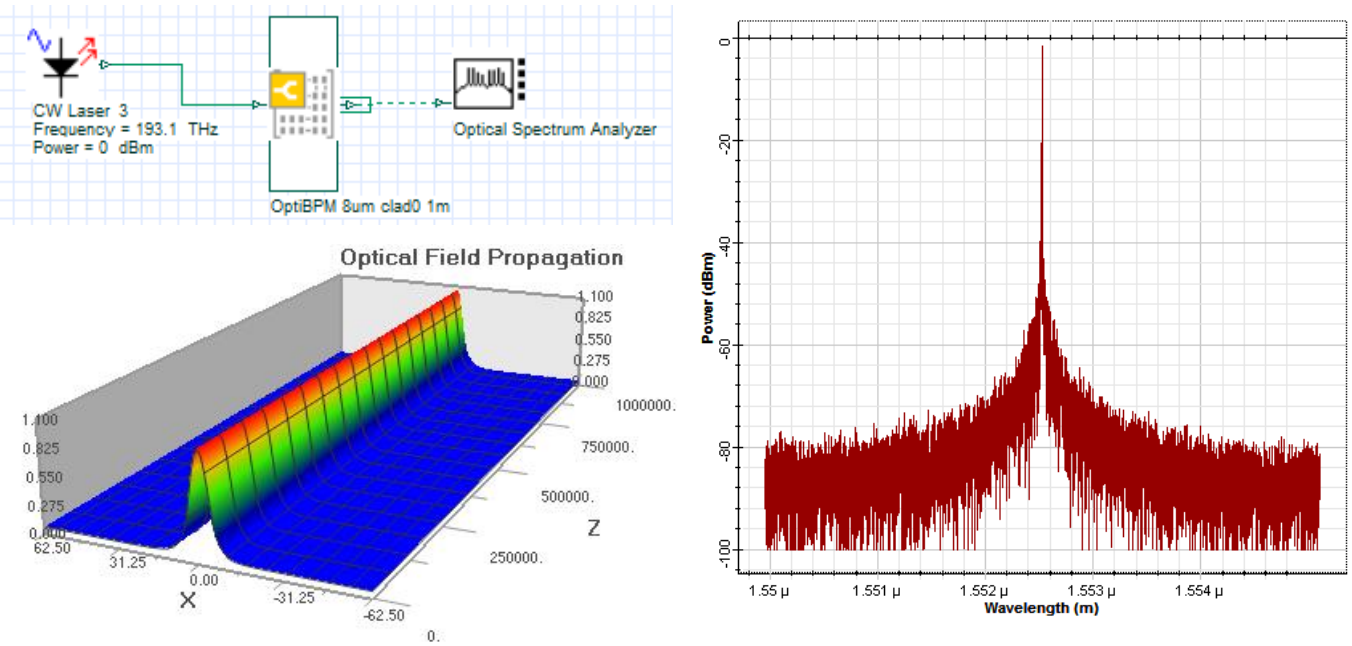

Figura 25 - Simulação no software Optisystem de um sistema de fibra monomodo, 8 um e $1550 \mathrm{~nm}$, com comprimento de $1 \mathrm{~m}$, caracterizada no software BPM. Em (a) tem-se a relação da potência com o comprimento do guia e em (b) pode-se verificar análise do espectro do sinal do laser em $1550 \mathrm{~nm}$. Ambas análises sem grandes perdas, conforme esperado, vez que o comprimento de transmissão é curto.

\subsubsection{Simulações para validação da fase sensora de fibras ópticas de diferentes diâmetros de núcleos e fatores de absorção na casca de vidro}

Quando a fibra óptica é utilizada como sensor, uma região sem casca proporciona a interação do gás com a luz a ser absorvida em determinado comprimento de onda (no caso das simulações, $1550 \mathrm{~nm}$ ). Logo, se estas fibras tiverem um núcleo de maior diâmetro facilitaria o manuseio mecânico e o acoplamento ao sistema. Sendo assim, introduz-se nesta etapa de atividades simulações de fibras ópticas tipo multimodo, que possuem diâmetro do núcleo na ordem de 50 a $62,5 \mu \mathrm{m}$. 
Inicialmente os guias ópticos são analisados considerando a casca de vidro cujo índice de refração é igual a 1,44681 ao longo da fibra.

Todo procedimento inicial de preparo da simulação descrita anteriormente para SMF-28, é realizada nesta etapa para fibras multimodo cujo diâmetro está compreendido em 20, 40 e 60 m. Em relação ao índice de refração, são consideradas novamente absorções na casca na ordem de $10^{-6}$ a $10^{-3}$. No caso de fibras multimodo, o índice de refração efetivo não depende apenas do comprimento de onda de operação, mas também do modo de propagação do sinal óptico. Por esta razão, é chamado índice modal.

Analisando os resultados obtidos das simulações processadas para os diâmetros de núcleo propostos $(8,20,40$ e $60 \mu \mathrm{m})$, mantendo-se o diâmetro da casca e índice de refração igual ao da fibra SMF-28, sem absorção, observa-se que para todas as situações os dados apresentaram valores de atenuação próximo de zero em centenas de metros de fibra óptica.

Em seguida, são iniciadas as simulações inserindo-se o índice de refração imaginário na casca da fibra. A Tabela 2 apresenta os dados obtidos ao fim da simulação, onde observa-se que com o aumento da absorção de $10^{-6}$ para $10^{-3}$, há consequentemente aumento da atenuação $(\mathrm{dB} / \mathrm{cm})$ do sinal óptico propagado para todos os diâmetros de núcleos propostos. Este resultado pode ser observado através da Figura 26, onde estão agrupados os dados extraídos das simulações para os núcleos de diferentes diâmetros. O eixo y indica a atenuação (calculada pela relação entre a potência de entrada e saída $(\mathrm{dB})$ ) por determinado comprimento de fibra óptica (no caso, em $(\mathrm{cm}))$. O eixo x indica os termos imaginários $\left(10^{-6}\right.$ a $\left.10^{-3}\right)$ associados ao índice de refração da casca. A seta em vermelho indica o ponto cujo gráfico está apresentado na Figura 26. 


\begin{tabular}{|c|l|l|l|l|l|l|l|l|}
\hline \multirow{2}{*}{$\begin{array}{c}\text { Índice de refração } \\
\text { imaginário } i(\mathrm{k})\end{array}$} & \multicolumn{5}{|c|}{ Potência de saída / Atenuação (dB/cm) } \\
\cline { 2 - 9 } & \multicolumn{2}{|c|}{$8 \mu \mathrm{m}$} & \multicolumn{2}{|c|}{$20 \mu \mathrm{m}$} & \multicolumn{2}{|c|}{$40 \mu \mathrm{m}$} & \multicolumn{2}{c|}{$60 \mu \mathrm{m}$} \\
\hline 0 & 0,9995 & 0,0021 & 0,99998 & $8,6 \times 10^{-5}$ & 0,9999995 & $2,17 \times 10^{-6}$ & 0,9999994 & $2,60 \times 10^{-6}$ \\
\hline $10^{-06}$ & 0,9780 & 0,0960 & 0,99780 & 0,0095 & 0,999640 & 0,0015 & 0,99986 & $6,08 \times 10^{-4}$ \\
\hline $10^{-05}$ & 0,8200 & 0,8610 & 0,97800 & 0,0960 & 0,996400 & 0,0156 & 0,99860 & 0,0061 \\
\hline $2,5 \times 10^{-05}$ & 0,6000 & 2,2184 & 0,93400 & 0,2965 & 0,991000 & 0,0392 & 0,98200 & 0,0780 \\
\hline $5 \times 10^{-05}$ & 0,3600 & 4,4369 & 0,89000 & 0,5060 & 0,982000 & 0,0788 & 0,99300 & 0,0305 \\
\hline $10^{-04}$ & 0,1400 & 8,5380 & 0,80000 & 0,9600 & 0,964000 & 0,1500 & 0,98600 & 0,0610 \\
\hline $2 \times 10^{-04}$ & 0,0200 & 16,989 & 0,64000 & 1,9382 & 0,930000 & 0,3151 & 0,97400 & 0,1144 \\
\hline $10^{-03}$ & 0 & $\infty$ & 0,10000 & 10 & 0,700000 & 1,5000 & 0,87600 & 0,5000 \\
\hline
\end{tabular}

Tabela 2 - A tabela mostra a atenuação referente às situações em que o índice de refração do núcleo e da casca são 1,45205 e 1,44861, respectivamente, com inserção do termo imaginário $\left(10^{-6}\right.$ a $\left.10^{-3}\right)$ como fator de absorção na casca, para diferentes núcleos.

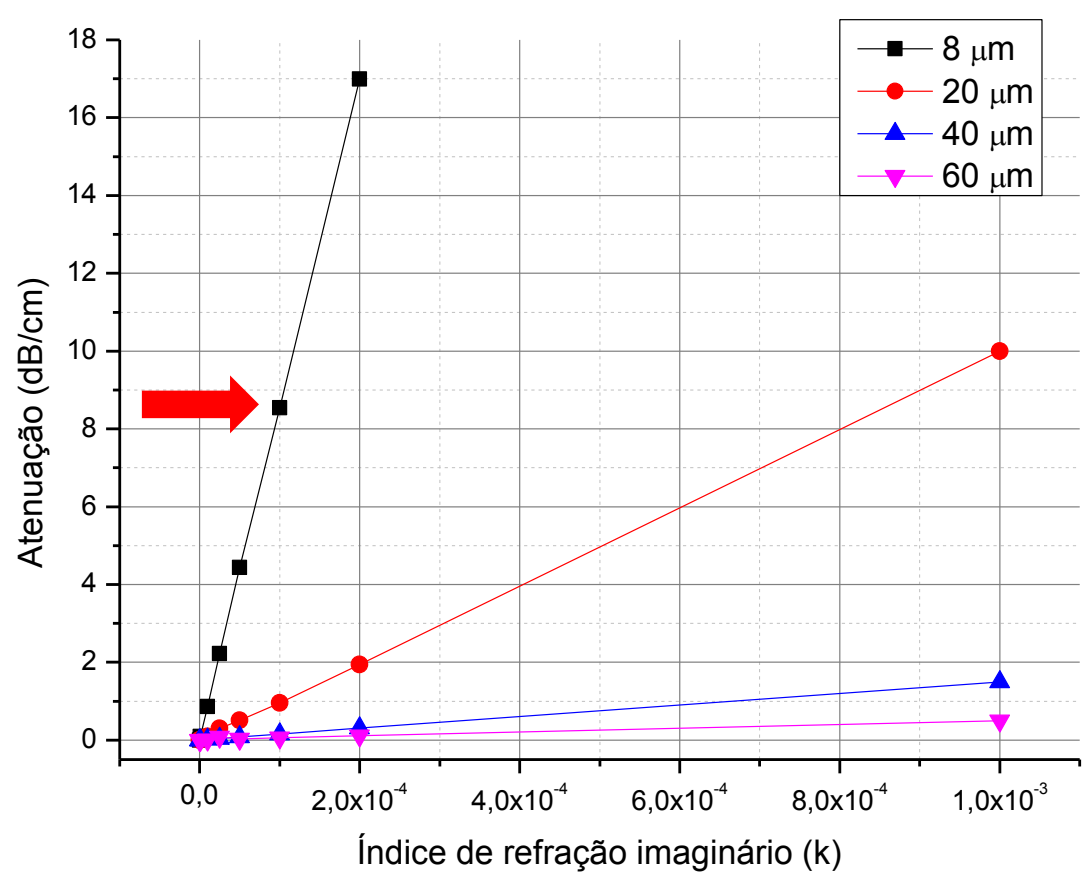

Figura 26 - Gráfico plotado a partir da Tabela 1 para fibras ópticas cujos núcleos são de diferentes diâmetros $(8,20,40$ e $60 \mu \mathrm{m})$ e mesmo índice de refração igual a 1,45205. 0 índice de refração da casca em sílica é igual a 1,44681, com inserção dos índices imaginários (na ordem de $10^{-6}$ a $10^{-3}$ ) que representam o fator de atenuação entre esta região e o ambiente externo. 
Comparadas às fibras monomodo, as fibras multimodo possuem núcleo de diâmetro maior, sendo capazes de lançar mais potência óptica ao sistema. Quando o diâmetro do núcleo das configurações propostas (de 20 a $60 \mu \mathrm{m}$ ) é aumentado, observa-se que a atenuação destas fibras é reduzida. Isso ocorre porque nas fibras monomodo (diâmetro de aproximadamente $8 \mu \mathrm{m}$ ), a região da casca torna-se suficientemente espessa para acomodar completamente o campo evanescente do modo propagado, tornando-o desprezível no exterior a esta região. Sendo o objetivo deste projeto a construção de sensores a fibra óptica baseados na absorção do campo evanescente, é necessário que a luz interaja com o ambiente externo onde está presente o gás. Conforme descrito anteriormente, as fibras monomodo padrão com núcleo de $8 \mu \mathrm{m}$ sem casca, seriam mecanicamente de difícil manuseio. Este argumento justifica a ampliação dos diâmetros dos núcleos destas fibras simuladas a serem aplicadas como sensores. No entanto, os resultados mostram a possibilidade de trabalhar em distâncias equivalentes a dezenas de metros com fibras multimodo, cujos diâmetros sejam próximos ou superiores a 20 $\mu \mathrm{m}$.

\subsubsection{Simulação de fibra óptica cujas cascas possuem índices de refração igual ao da água $(n=1,33)$ e do ar $(n=1)$}

As simulações eletromagnéticas realizadas nesta etapa consideram os índices de refração na casca como sendo iguais ao da água $(\mathrm{n}=1,33)$ e o do ar $(n=1)$. Nesta fase de estudo o objetivo é proporcionar uma análise mais segura da propagação do sinal óptico em meios com diferentes índices de refração. $\mathrm{O}$ gás $\mathrm{CO}_{2}$ a ser monitorado possui índice de aproximadamente 1,00045 , a temperatura de $0^{\circ} \mathrm{C}$ e pressão de 1 atm.

O objetivo nesta próxima etapa de pesquisa é a avaliação de uma fibra óptica $\mathrm{SiO}_{2}$ cujo diâmetro do núcleo é de $40 \mu \mathrm{m}$ e comprimento de guia $2 \mathrm{~m}$, sem casca, com finalidade de realizar teste de absorção do gás $\mathrm{CO}_{2}$ por campo evanescente. Sendo assim, é realizada uma série de simulações voltadas para este tipo de fibra com distintos índices de refração. 
A análise e caracterização dos resultados exibidos conforme Figura 27, mostram nos gráficos (a) e (b) que nas curvas de intensidade de potência do sinal tanto para o índice de refração da água quanto para o do ar, há uma queda em aproximadamente $-0,15 \mathrm{~dB}$ para $5 \mathrm{~cm}$ de comprimento da fibra óptica de núcleo 40 $\mu \mathrm{m}$ sem casca. Entretanto, ao aumentar o fator de absorção de $10^{-6}$ para $10^{-3}$, verifica-se que há aumento na atenuação, sendo que na ordem de $10^{-3}$ a curva de intensidade para a água (b) é notavelmente mais inclinada. Tais interpretações estão de acordo com o previsto teoricamente no estudo da revisão bibliográfica [36]. Pela lei de Lambert-Beer, o coeficiente de extinção $(\mathrm{K})$ é dado pelo produto da absorbância ( $\mathrm{S}$ - quantidade de energia radiante absorvida pela substância) versus a concentração da substância (C), isto é: $\mathrm{K}=\mathrm{SC}$ - deve ser observado que $\mathrm{S}$ é diretamente proporcional a concentração da substância.

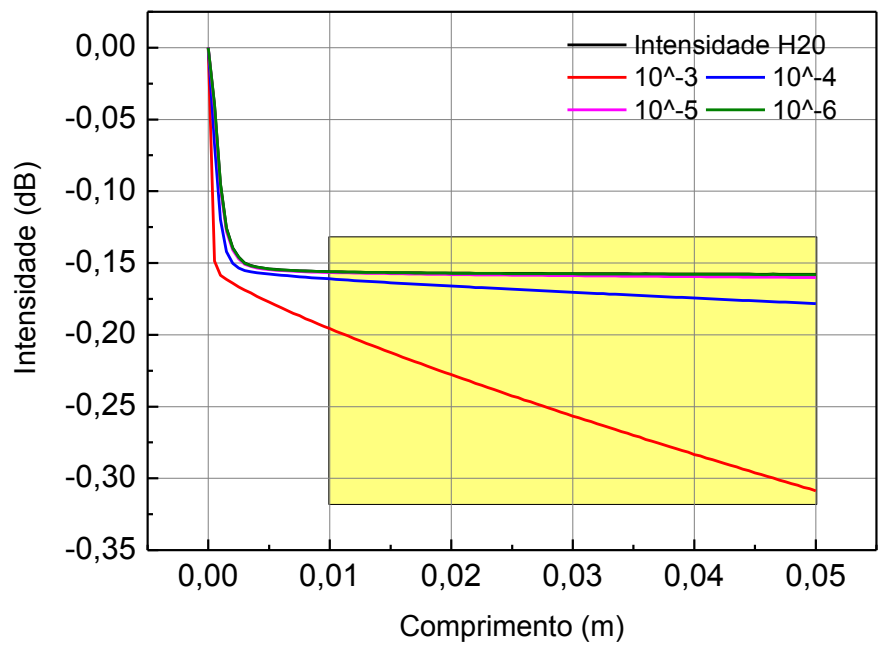

(a)

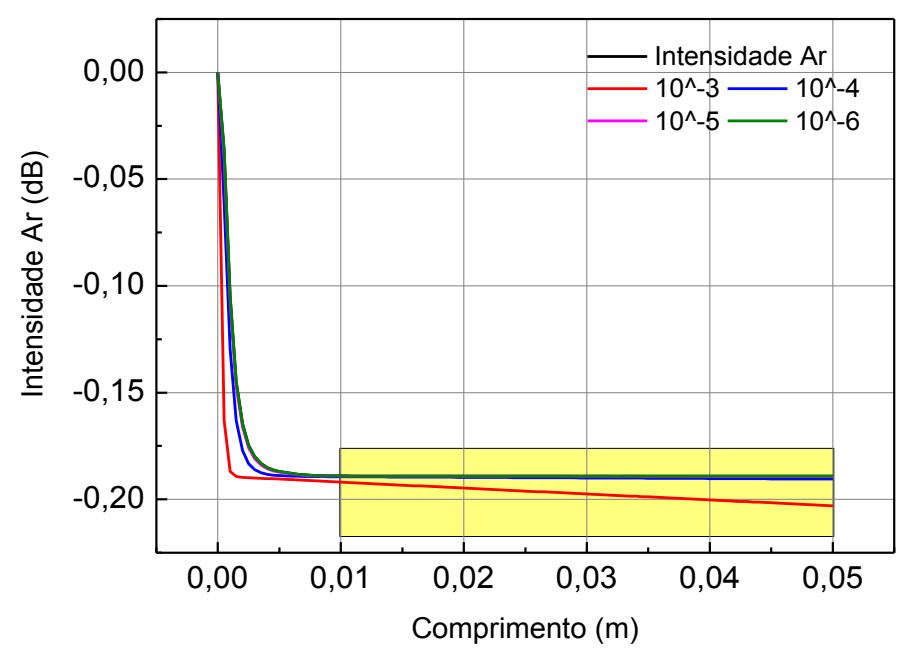

(b) 


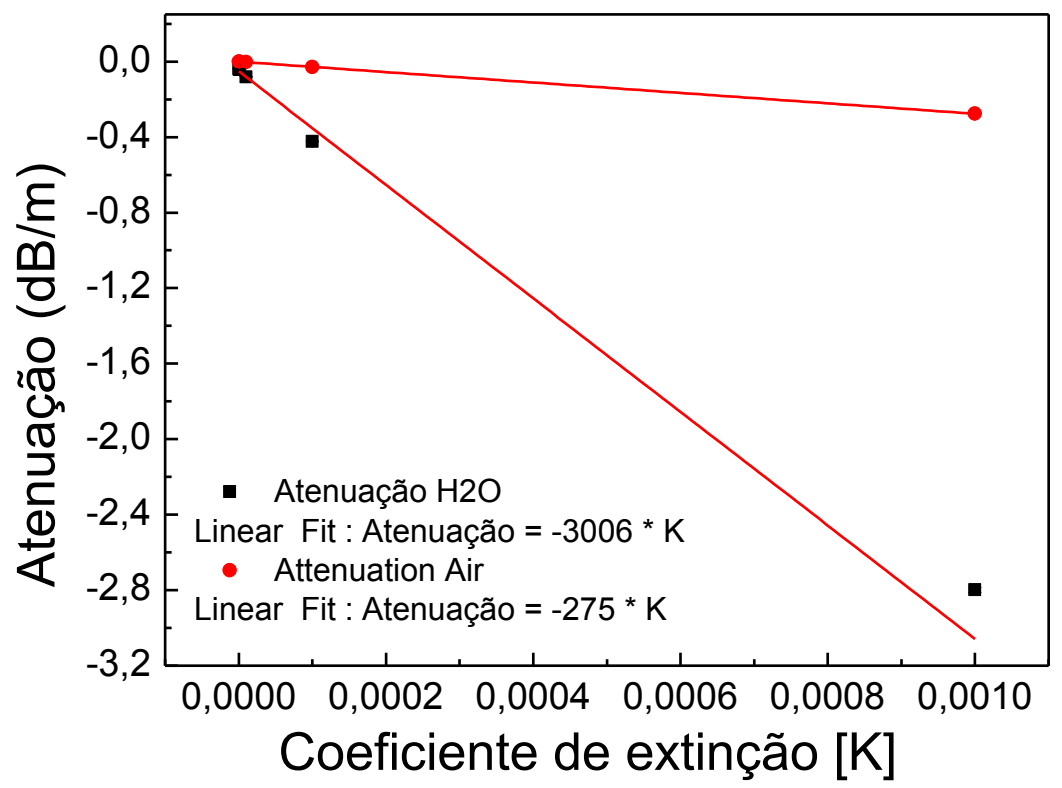

(c)

Figura 27 - Resultados de simulação para uma fibra óptica com núcleo de diâmetro igual a $40 \mu \mathrm{m}$, sendo os índices de refração na casca: (a) água $(n=1,33)$ e $(b) \operatorname{ar}(n=1)$. Os gráficos $(a)$ e (b) indicam a relação da atenuação $(\mathrm{dB} / \mathrm{m})$ com o comprimento de fibra, considerando diferentes fatores de absorção na ordem de $10^{-6}$ a $10^{-3}$. Em (c) é plotada a relação da atenuação ao longo do comprimento da fibra em função do coeficiente de extinção (fator de absorção).

O contraste de índice de refração sendo menor, há mais campo evanescente na casca, explicando a maior sensibilidade.

Na Figura 27 (c), é feito o ajuste linear para os índices de refração do ar e da água. O gráfico relaciona a atenuação do sinal óptico propagante no guia (eixo y em $(\mathrm{dB} / \mathrm{m}))$ e os coeficientes de absorção na casca (eixo x). Por comparação dos dados, verifica-se que para o índice de refração da água a atenuação é maior em relação ao índice do ar.

Com esta análise para a fibra óptica de $40 \mu \mathrm{m}$ quando é considerado o índice de refração na casca é igual a 1 (ar), torna-se possível compreender o comportamento do sinal óptico propagante numa fibra sem casca. Logo, os resultados obtidos indicam que a fibra caracterizada pode ser aplicada como um sensor de monitoramento de $\mathrm{CO}_{2}$, possibilitando assim iniciar as atividades de testes e medidas do sistema em laboratório com a fibra óptica sem casca de $40 \mu \mathrm{m}$. 
Nesta fase inicial, para a geração e detecção do sinal na faixa de 2 $\mu \mathrm{m}$, referente a absorção do $\mathrm{CO}_{2}$, foi realizada a aquisição dos seguintes equipamentos descritos a seguir:

- Laser sintonizável modo de operação $\mathrm{CW}$, potência $\geq 50 \mathrm{~mW}$, comprimento de onda centrado em $2 \mu \mathrm{m}$ e largura de linha espectral $\leq 100 \mathrm{MHz}$ (IPG Photonics).

- Analisador de espectro óptico OSA203 a ser utilizado na avaliação das respostas dos sensores por medida da potência óptica em função do comprimento de onda do laser aplicado, cuja faixa de leitura está compreendida de 1000 a $2500 \mathrm{~nm}$ (Thorlabs).

- Aluguel de cilindros contendo $\mathrm{CO}_{2}$ com percentual de $20 \%$, devido a especificação do analisador de concentração $\mathbf{4 1 0 i}$.

Pelos resultados obtidos do processamento das simulações realizadas, verifica-se a possibilidade da fabricação, teste e validação de fibra óptica multimodo sem casca, com núcleos variando de 20 a $60 \mu \mathrm{m}$, para aplicação em sensores ópticos de gás por absorção de campo evanescente.

$\mathrm{O}$ foco de aplicação desta pesquisa se destina a detecção de $\mathrm{CO}_{2}$, cuja absorção encontra-se em um comprimento de onda na faixa de $2 \mu \mathrm{m}$, a ser considerada nas etapas de simulações posteriores.

Os testes da fibra óptica serão realizados conforme ilustrado na Figura 28 a seguir. 


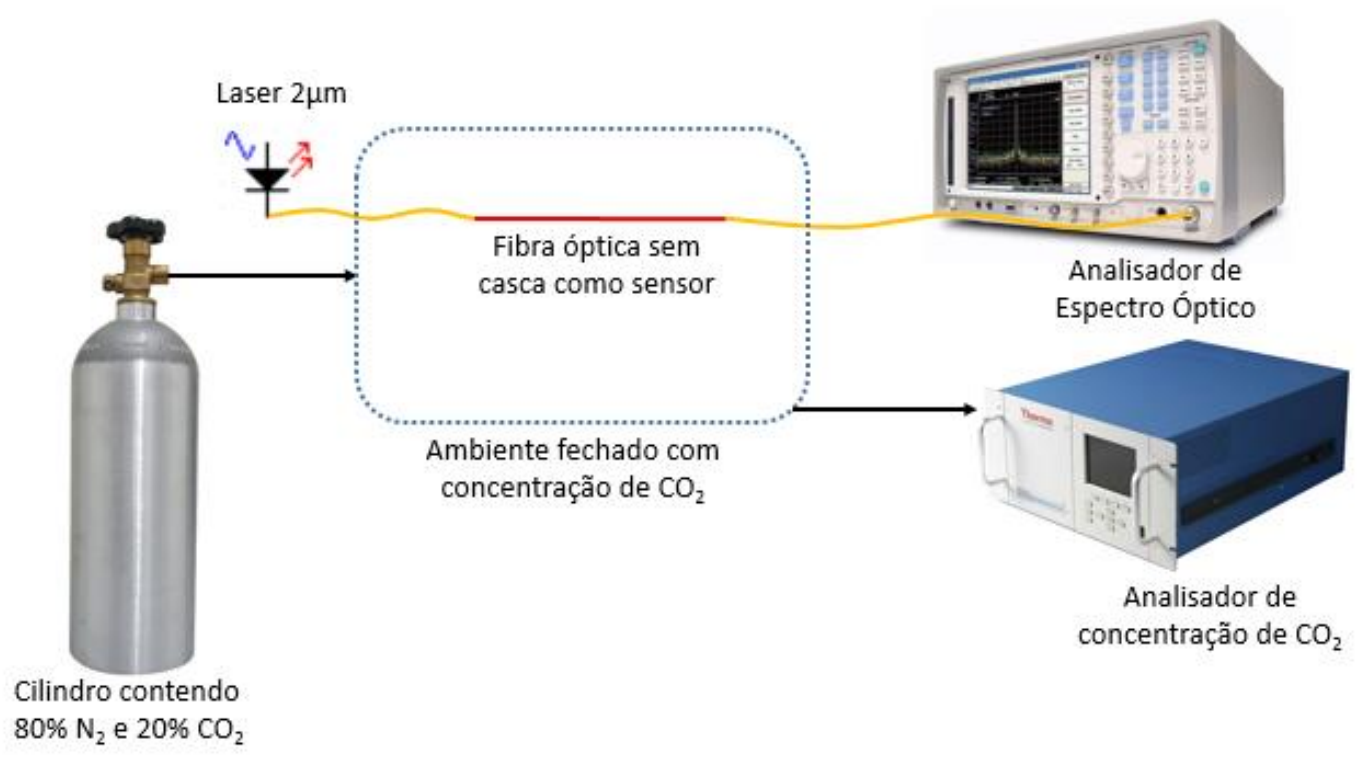

Figura 28 - llustração do sistema a ser montado para teste de fibras ópticas como sensores de $\mathrm{CO}_{2}$ por absorção do campo evanescente.

$\mathrm{O}$ cilindro contendo determinada concentração de $\mathrm{CO}_{2}$, a câmara de ambiente fechado e o filtro analisador de concentração se encontram instalados no Laboratório de Sensores a Fibra Óptica do Departamento de Engenharia Mecânica da PUC-Rio (LSFO/DEM/PUC-Rio).

Apesar das tentativas exaustivas na etapa de medição das fibras sem casca, não foi possível observar a interação esperada entre luz e gás em fluxo. Devido à proximidade do índice de refração do $\mathrm{CO}_{2}$ do ar, o sistema não teve sensibilidade suficiente para distinguir o gás, mesmo em altas concentrações. É possível que a detecção só seja observada a uma camada micrométrica da região cilíndrica da fibra em análise.

Como segunda alternativa de aplicação de fibras ópticas como elemento sensor de $\mathrm{CO}_{2}$, introduz-se uma segunda etapa de estudo e avaliação das fibras microestruturadas.

\subsection{Caracterização de fibras ópticas microestruradas}

Externamente, uma fibra óptica microestruturada é muito parecida com uma fibra óptica convencional. A diferença é encontrada na seção transversal 
da fibra microestruturada, que possui furos microscópicos no plano perpendicular ao eixo deste, estendendo-se ao longo de todo o comprimento da fibra. Estes buracos de ar formam uma microestrutura periódica, de baixo índice de refração em torno de um núcleo que pode ser sólido ou oco. Devido às suas singulares microestruturas, estas fibras podem apresentar um grande número de propriedades ópticas não comuns em fibras ópticas convencionais. A presença dos buracos cria novos graus de liberdade que permitem controlar a propriedade e a sensibilidade da fibra sob diferentes parâmetros físicos de interesse, uma flexibilidade que fibras ópticas convencionais não podem proporcionar [37].

A presença, a distribuição e o tamanho destes buracos são responsáveis pelo confinamento e pela condução da luz. Através de diferentes arquiteturas é possível definir e controlar propriedades ópticas especiais como: a dispersão, birrefringência, e não linearidade [38]. Estas propriedades especiais levaram ao desenvolvimento de diversas aplicações nas áreas de comunicações ópticas, óptica não-linear, e sensoriamento [39].

\subsubsection{Cooperação PUC-Rio ACREO}

No decorrer do desenvolvimento do trabalho, foi estabelecida uma colaboração com o grupo de pesquisa da ACREO - Suécia [40]. No âmbito desta colaboração foram fornecidas para o desenvolvimento do sensor duas fibras ópticas microestruturadas denominadas FOM1 e FOM2. As fibras são fabricadas com sílica pura e os mecanismos de condução da luz nestas não são conhecidos para o comprimento de onda de $2 \mu \mathrm{m}$.

A caracterização das fibras ópticas microestruturadas segue as etapas:

1. Dimensionamento da microestrutura através de microscopia

2. Medição de campo próximo

3. Teste de acoplamento de luz @ $2 \mu$ m e de injeção de gás 


\subsubsection{Dimensionamento da microestrutura por microscopia}

A Figura 29 mostra as seções transversais das fibras mencionadas, que são constituídas basicamente por um cilindro e um anel concêntrico de uma estrutura adicional. No caso da FOM2 a estrutura é constituída de 8 cilindros menores que resultam num buraco octogonal central. Já no caso da FOM1 a estrutura é constituída de 7 triângulos equiláteros com um meio círculo, o que também resulta num buraco central octogonal (respectivamente apresentadas na Figura 29). O lado do octógono é de $39 \mu \mathrm{m}$ e $40 \mu \mathrm{m}$ respectivamente para cada fibra óptica.

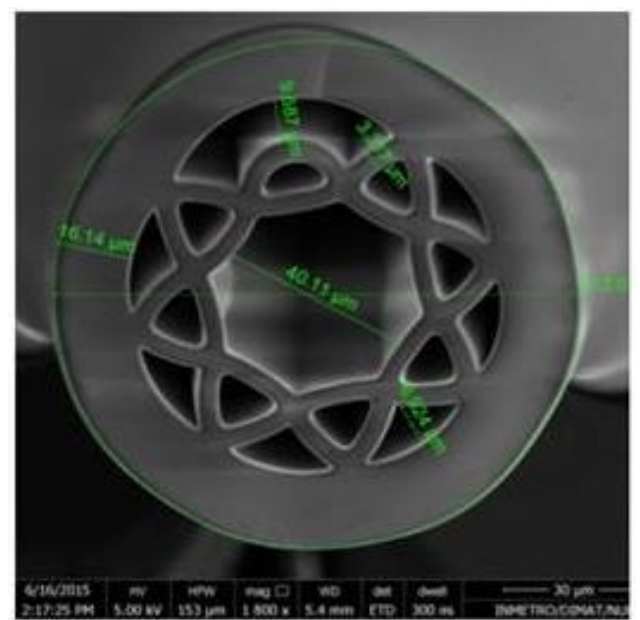

ACREO FOM1

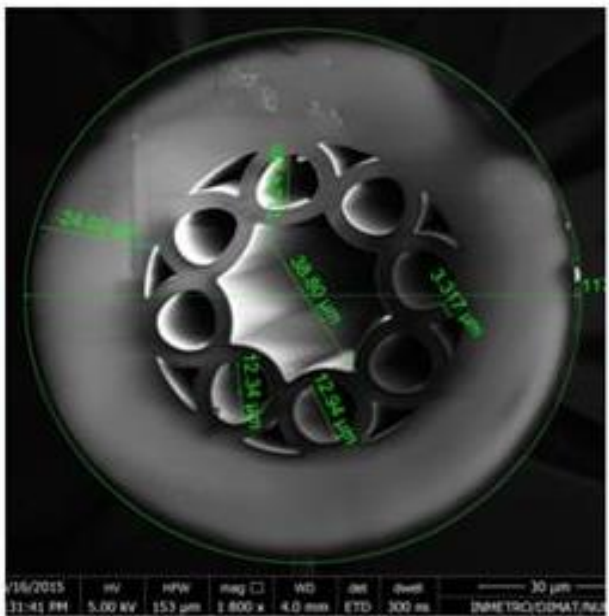

ACREO FOM2

Figura 29 - Fotografia em microscópio eletrônico da seção transversal das fibras microesturadas.

\subsubsection{Medição de campo próximo}

A medição de campo próximo nas fibras microestruturadas aqui utilizadas pode auxiliar na caracterização destas e na interpretação dos resultados a serem adquiridos quando forem aplicadas no sensor desenvolvido. O recurso utilizado para aquisição das informações provenientes dessa medição é a aplicação de uma câmera CCD (charge-coupled device) para aquisição de imagens referentes 
à propagação do sinal luminoso no guia. Com essas imagens é possível verificar e compreender se estaria ocorrendo a interação entre o sinal óptico transmitido no núcleo oco e o gás inserido nesta região da fibra, que é analisada na etapa posterior das atividades. Infelizmente, para esta análise não havia disponibilidade de uma câmera CCD com leitura em $2 \mu \mathrm{m}$, mas uma outra câmera modelo Thorlabs em 600 nm, que foi então empregada. Logo, nesta caracterização foi utilizado em vez da fonte de luz em $2 \mu \mathrm{m}$, um laser $\mathrm{HeNe}$ em $633 \mathrm{~nm}$ e $1 \mathrm{~mW}$. Todo o sistema foi cuidadosamente microposicionado para evitar atenuações indesejadas nas medidas. Para focalizar a luz na câmera, utiliza-se uma lente objetiva de 45x. Este arranjo experimental está representado na Figura 30 a seguir.

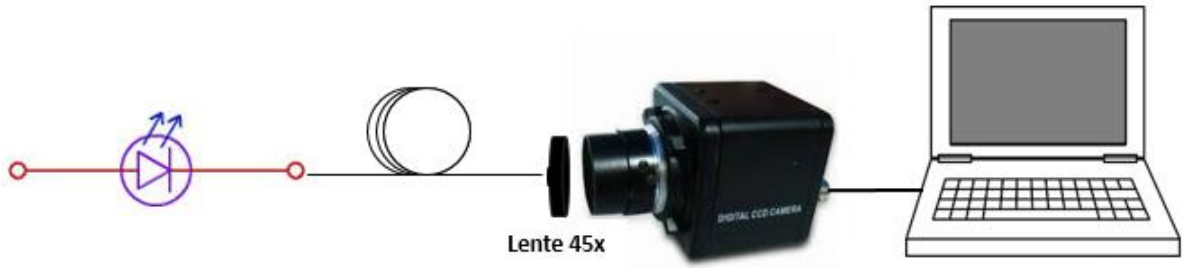

Figura 30 - Sistema microposicionado para medida do campo próximo com uma câmera CCD.

A intensidade luminosa capturada desta análise com a câmera CCD pode ser observada na Figura 31 abaixo:

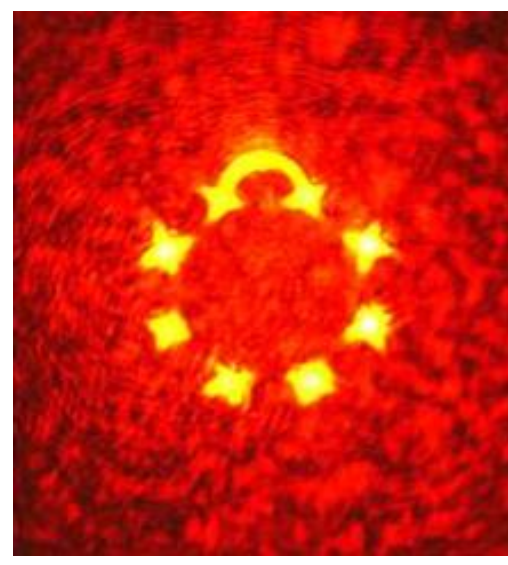

ACREO FOM1

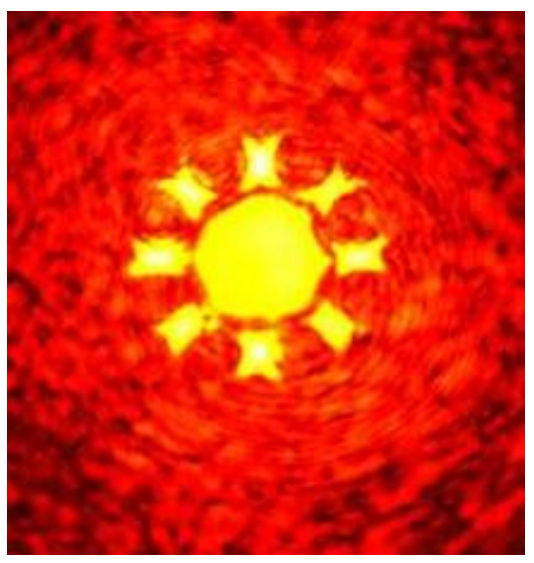

ACREO FOM2

Figura 31 - Fotografia da intensidade luminosa do campo próximo das fibras óptica microestruturadas FOM1 e FOM2, respectivamente. 
Pelas imagens adquiridas e apresentadas na Figura 31 acima, foi possível verificar que em FOM1 não há propagação de sinal óptico no núcleo da fibra, e apenas na região microestruturada constituída pelos 8 cilindros de diâmetros menores. Além de a propagação da luz dar-se notoriamente na estrutura de vidro, nesta região não há concentração de gás. Consequentemente, quando utilizada com a fonte ASE em $2 \mu \mathrm{m}$, não haverá interação entre a luz e o gás assim como não será observada com o OSA as linhas de absorção referentes a este gás. Já na imagem da FOM2, é possível observar que há luz propagando no núcleo da fibra, justamente onde há maior concentração do gás a ser inserido. Sendo assim, um segundo protótipo sensor quando desenvolvido com esta fibra deve atender o objetivo da atividade experimental proposta e aqui desenvolvida.

\subsubsection{Testes de acoplamento de luz @ $2 \mu \mathrm{m}$ com injeção de gás}

Todos os testes do sistema sensor em análise com luz e gás utiliza como fonte de sinal óptico uma ASE em torno de $2 \mu \mathrm{m}$ e $10 \mathrm{~mW}$, e um OSA (Optical Spectrum Analyzer - Thorlabs 1000 a 2600 nm) para aquisição de dados, análise e comparação dos resultados. A montagem experimental está composta de acordo com a ilustração apresentada na Figura 32 abaixo.

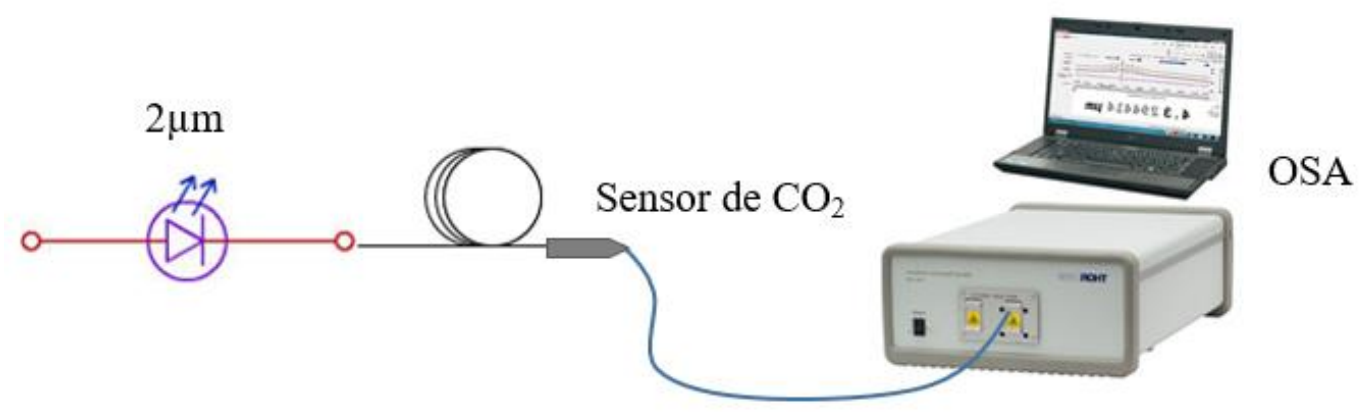

Figura 32 - Esquema de teste de transmissão do sinal óptico nas fibras fabricadas pela ACREO.

As medições realizadas com as fibras FOM1 e FOM2, respectivamente, ocorre conforme as etapas que se seguem: 
1. Primeiramente, a FOM com fonte de luz em $2 \mu \mathrm{m}$ (sem inserção de gás) para medir o nível de potência óptica para este comprimento de onda selecionado;

2. Em seguida, inserção de gás $\mathrm{CO}_{2}$ puro na mesma FOM e análise da saída de gás, a fim de verificar se este está passando através do núcleo oco da fibra aplicada;

3. Por último, medida do conjunto FOM com fonte de luz $2 \mu \mathrm{m}$ e gás inserido para obtenção das linhas de absorção referentes à interação e discussão dos resultados.

Os primeiros protótipos desenvolvidos utilizaram a fibra FOM1 como parte do sensor. Durante os testes realizados em laboratório, sendo conhecida a potência incidente da fonte ASE (aproximadamente $-20 \mathrm{dBm}$ ), verificou-se que a intensidade da potência óptica transmitida na FOM analisada é muito baixa (cerca de -60 dBm - vide Figura 33 (a)). Apesar da atenuação notória, este resultado foi armazenado para ser posteriormente comparado à última etapa de medição (3).

$\mathrm{Na}$ etapa (2), é injetado gás $\mathrm{CO}_{2}$ no sensor com FOM1 por um período de aproximadamente cinco minutos. Este procedimento é importante para conferir se o gás está passando através dos núcleos ocos da fibra em estudo, uma vez que estes apresentam diâmetros muito pequenos. Ao fim deste teste, verificouse que há passagem do gás conforme interesse da pesquisa, permitindo assim iniciar a próxima etapa de medição do sistema como sensor.

Com o gás dentro da FOM1, é concretizada a terceira etapa de atividades, que tem por objetivo observar o espectro do sensor desenvolvido e identificar as linhas de absorção referentes à interação do conjunto gás e sinal óptico em $2 \mu \mathrm{m}$. Ao fim desta montagem, os dados capturados da medida mostraram que não haviam variações no sinal óptico quando comparado ao sinal obtido antes da injeção de gás no núcleo oco da fibra analisada. Tais variações esperadas corresponderiam às linhas de absorção da luz pelo $\mathrm{CO}_{2}$ no sensor FOM1. O sinal medido antes e após o dispositivo ser preenchido com o gás apresentava a mesma curva característica com grande atenuação. A avaliação deste resultado leva à conclusão de que assim como observado e relatado em (3.2.2) com a câmera CCD em $600 \mathrm{~nm}$, em $2 \mu \mathrm{m}$ a luz também se propaga na estrutura de vidro da fibra, e não no núcleo oco. Por este motivo, não houve interação do sinal óptico com o gás e, consequentemente, que não houve absorção da luz no comprimento de onda selecionado nesta fibra aplicada. Sendo assim, FOM1 não é útil para o objetivo proposto. 
Em continuação às atividades, as etapas descritas e realizadas acima para FOM1 foram posteriormente repetidas para o sensor desenvolvido com FOM2, a fim de caracterizar este segundo protótipo. $\mathrm{Na}$ análise dos resultados após todo o procedimento de montagem e medidas, verificou-se que o dispositivo sensor com esta fibra apresentou dados similares aos adquiridos com a FOM1: baixa intensidade de potência óptica (aproximadamente $-55 \mathrm{dBm}$ - vide Figura 33 (b)) e nenhuma variação no sinal ao ser inserido o $\mathrm{CO}_{2}$. Aumentamos o período de preenchimento de gás nas fibras, e ainda assim não foi possível observar o espectro referente às linhas de absorção. Outros protótipos com FOM1 e FOM2 foram construídos. Inúmeros testes com ambas fibras atuando como sensores foram realizados, porém em nenhuma das medidas foi detectada a interação entre sinal óptico e gás $\mathrm{CO}_{2}$. Estes resultados comentados estão mostrados na Figura 33 a seguir.

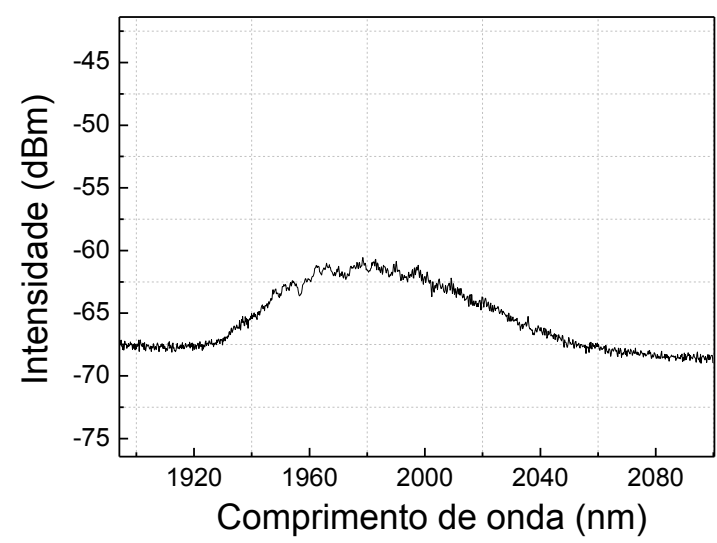

(a)

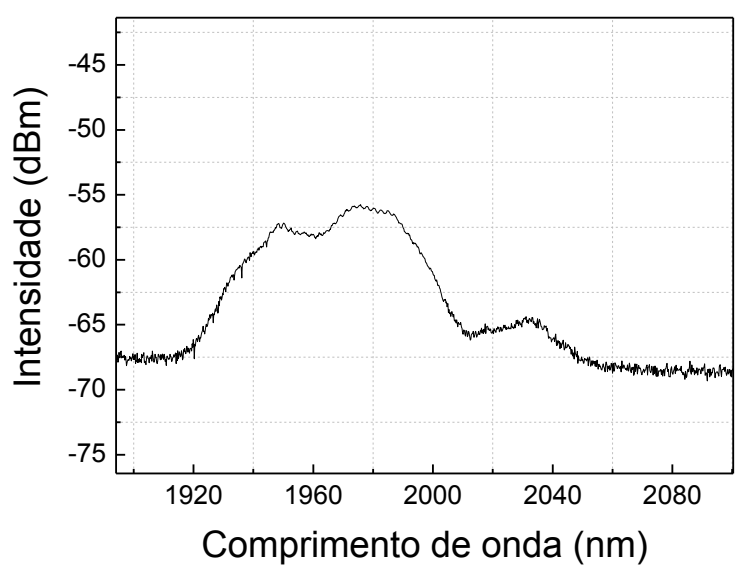

(b)

Figura 33 - Resultados experimentais obtidos com o OSA, referentes às medidas dos sensores com FOM1 e FOM2, respectivamente. 
Apesar de as imagens obtidas com a câmera CCD mostrarem que na fibra FOM2 há propagação de sinal óptico no núcleo oco, deve-se destacar que este resultado é baseado em medidas como comprimento de onda na ordem de $600 \mathrm{~nm}$. Para os resultados adquiridos dos testes realizados na região do infravermelho correspondente a $2 \mu \mathrm{m}$, conclui-se, portanto, que para este comprimento de onda do espectro o guiamento do sinal óptico nesta fibra parece ocorrer na estrutura de vidro e não nos núcleos de ambas testadas, conforme esperava-se. Consequentemente, esta fibra também não seria apropriada para a aplicação e desenvolvimento do sensor de $\mathrm{CO}_{2}$ proposto, vez que é nesta região do espectro que ocorre a absorção da luz por este gás.

Os resultados apresentados foram relatados aos pesquisadores da ACREO, que analisaram, realizaram medidas e cálculos com estas fibras FOM1 e FOM2 que haviam sido fornecidas para o trabalho. Retornaram com as seguintes descrições:

Por limitações dos equipamentos de medidas da instituição, não é possível medir comprimentos de onda acima de $1600 \mathrm{~nm}$. No entanto, é possível calcular o período médio das frequências dos vários picos transmitidos no espectro. A medida para FOM1 mostra que o deslocamento de frequência entre os picos é, em média, de 37,43 THz $(\Delta v)$. Estes dados obtidos para o cálculo da média estão expressos na Tabela 1 abaixo:

\begin{tabular}{|c|c|c|c|c|c|c|c|c|c|}
\hline$\lambda_{\text {central }}(\mathrm{nm})$ & 638 & 690 & 752 & 830 & 930 & 1055 & 1215 & 1440 & $?$ \\
\hline$v_{\text {central }}(\mathrm{nm})$ & 470,2 & 434,8 & 398,9 & 361,4 & 322,6 & 284,4 & 246,9 & 208,3 & \\
\hline$\Delta v(\mathrm{THz})$ & --- & 35,4 & 35,9 & 37,5 & 38,8 & 38,2 & 37,5 & 38,6 & $-37,4$ \\
\hline
\end{tabular}

Tabela 3 - Dados obtidos por análise espectral para o cálculo da média de $\Delta \mathrm{u}$, considerando FOM1.

Se utilizado por exemplo o comprimento de onda mais distante medido em $1440 \mathrm{~nm}$ e subtrai-lo 37,43 THz, obtém-se $1756 \mathrm{~nm}$, que é o próximo pico onde haverá transmissão. O pico seguinte ocorreria em $2248 \mathrm{~nm}$ e assim sucessivamente. Na Tabela 2 a seguir, estão indicados os dados referentes ao cálculo comentado: 


\begin{tabular}{|l|r|r|r|}
\hline & \multicolumn{1}{|c|}{ Medido } & \multicolumn{1}{|c|}{ Estimado } & \multicolumn{1}{c|}{ Estimado } \\
\hline$\Delta v(\mathrm{THz})$ & --- & 37,43 & 37,43 \\
\hline$v_{\text {central }}(\mathrm{THz})$ & 208,3 & 170,87 & 133,44 \\
\hline$\lambda_{\text {central }}(\mathrm{nm})$ & 1440 & 1756 & 2248 \\
\hline
\end{tabular}

Tabela 4 - Cálculo do deslocamento de frequência considerando o espectro de FOM1.

Pelos dados apresentados, é notável que o comprimento de onda 2 $\mu \mathrm{m}$ cai exatamente no meio de dois picos transmitidos (1756 e $2248 \mathrm{~nm}$ ). Isto significa que é improvável que toda a luz seja guiada pelo núcleo oco desta fibra neste valor de interesse.

No caso das medidas realizadas para a FOM2, a análise mostra que o deslocamento de frequência $(\Delta v)$ neste caso é de 24,94 $\mathrm{THz}$ (apresentado na Tabela 3).

\begin{tabular}{|c|c|r|r|r|r|r|r|r|r|r|r|r|c|}
\hline $\begin{array}{c}\lambda_{\text {central }} \\
(\mathrm{nm})\end{array}$ & 608 & 638,5 & 675 & 714 & 760 & 811,5 & 868 & 938 & 1017 & 1110 & 1225 & 1366 & 1546 \\
\hline $\begin{array}{c}v_{\text {central }} \\
(\mathrm{nm})\end{array}$ & 493,4 & 469,9 & 444,4 & 420,2 & 394,7 & 369,7 & 345,6 & 319,8 & 295 & 270,3 & 244,9 & 219,6 & 194,1 \\
\hline $\begin{array}{c}\Delta v \\
(\mathrm{THz})\end{array}$ & --- & 23,5 & 25,5 & 24,2 & 25,5 & 25 & 24,1 & 25,8 & 24,8 & 24,7 & 25,4 & 25,3 & 25,5 \\
\hline
\end{tabular}

Tabela 5 - Dados obtidos por análise espectral para o cálculo da média de $\Delta \mathrm{u}$, considerando FOM2.

Seguindo o mesmo raciocínio aplicado para FOM1, a Tabela 4 apresenta os picos de transmissão no espectro de FOM2.

\begin{tabular}{|c|c|c|c|}
\hline & Medido & Estimado & Estimado \\
\hline$\Delta v(\mathrm{THz})$ & & 24.94 & 24.94 \\
\hline$v_{\text {central }}(\mathrm{THz})$ & 194.1 & 169.16 & 144.2 \\
\hline$\lambda_{\text {central }}(\mathrm{nm})$ & 1546 & 1773 & 2080 \\
\hline
\end{tabular}

Tabela 6 - Cálculo do deslocamento de frequência considerando o espectro de FOM2.

Neste cálculo, obteve-se o comprimento de onda em $2080 \mathrm{~nm}$, que estaria muito próximo a $2 \mu \mathrm{m}$. No entanto, é necessário analisar se este pico seria 
interessante para a transmissão da luz, supondo a periodicidade calculada igual a 24,94 THz. Se a frequência for deslocada por $12,47 \mathrm{THz}$, indica o mínimo da banda de transmissão. O cálculo da FWHM seria: $\Delta v / 2=12,47 \mathrm{THz} / 2=6,23 \mathrm{THz}$. Logo, no pico $2080 \mathrm{~nm}$, somando e subtraindo $6,23 \mathrm{THz}$, é determinada a largura do pico: $v_{+}=150,43 \mathrm{THz}$ e $v_{-}=137,97 \mathrm{THz}$, que correspondem aos comprimentos de onda de $1994 \mathrm{~nm}$ e $2174 \mathrm{~nm}$, respectivamente. Estes números mostram que o pico desejado em $2000 \mathrm{~nm}$ é muito próximo a v_, onde há grande perda de potência óptica. A análise mostra, portanto, que dificilmente será observada transmissão de sinal óptico neste pico, e, consequentemente, as fibras fornecidas pela ACREO não são úteis para o objetivo do projeto em desenvolvimento.

\section{- Análise de nova fibra micoestruturada FOM3:}

Recentemente, uma terceira fibra óptica de núcleo oco, foi fornecida pela ACREO. Por referência de experiências realizadas anteriormente com esta fibra, os resultados preliminares indicam que o guiamento se dá no núcleo oco da fibra na banda de operação de $1500 \mathrm{~nm}$. Foram então realizados testes de acoplamento de luz e injeção de gás. Na Figura 34 é possível observar os espectros de transmissão de duas fontes ASE de luz, uma centrada em $1500 \mathrm{~nm}$ e outra em $2000 \mathrm{~nm}$, linha vermelha e preta, respectivamente. Observa-se que a luz transmitida em $1500 \mathrm{~nm}$ é muito maior quando comparada com a fonte em $2000 \mathrm{~nm}$, para os valores máximos conhecidos de ambas fontes. Este resultado evidencia que a fibra óptica FOM 3 opera em comprimentos de onda em torno de $1500 \mathrm{~nm}$. 


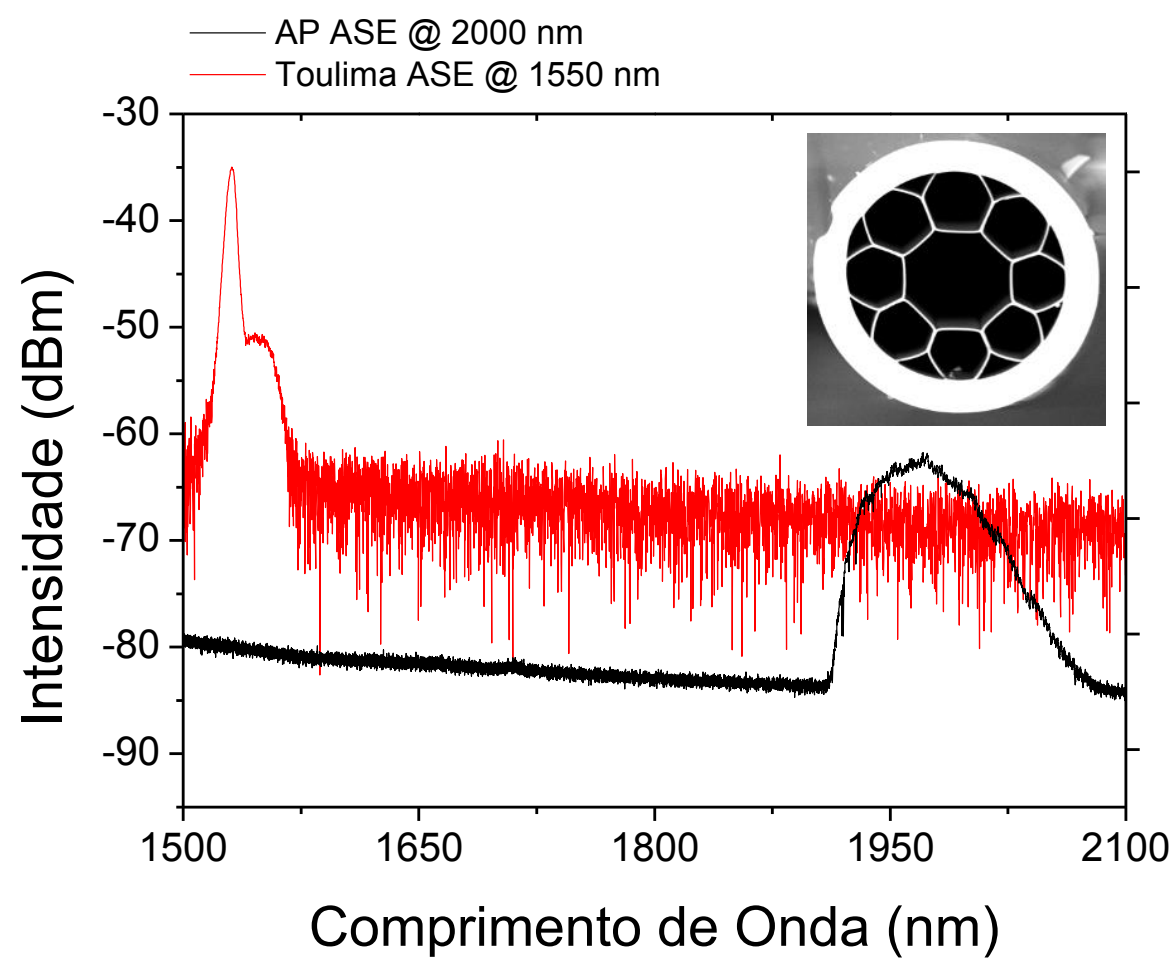

Figura 34 - Espectro de transmissão da fibra óptica FOM3 para duas fontes ASE centradas em $1500 \mathrm{~nm}$ e $2000 \mathrm{~nm}$.

Para o teste de injeção, o gás de análise foi o acetileno $\left(\mathrm{C}_{2} \mathrm{H}_{2}\right)$. A escolha do acetileno está relacionada às acentuadas bandas de atenuação que este gás apresenta nos comprimentos de onde próximos a $1500 \mathrm{~nm}$, como representado na Figura 35 (linha verde - base de dados do Hitran [35]). Já a linha vermelha reapresenta o espectro da fonte ASE, com as respectivas linhas de atenuação.

Do ponto de vista de projeto do dispositivo sensor de gás, este resultado é muito promissor, pois mostra que o conceito do sensor funciona. No entanto, esta fibra não é adequada para o desenvolvimento do sensor de $\mathrm{CO}_{2}$, uma vez que a banda de absorção do $\mathrm{CO}_{2}$ é muito fraca, assim inviabilizando sua utilização. 


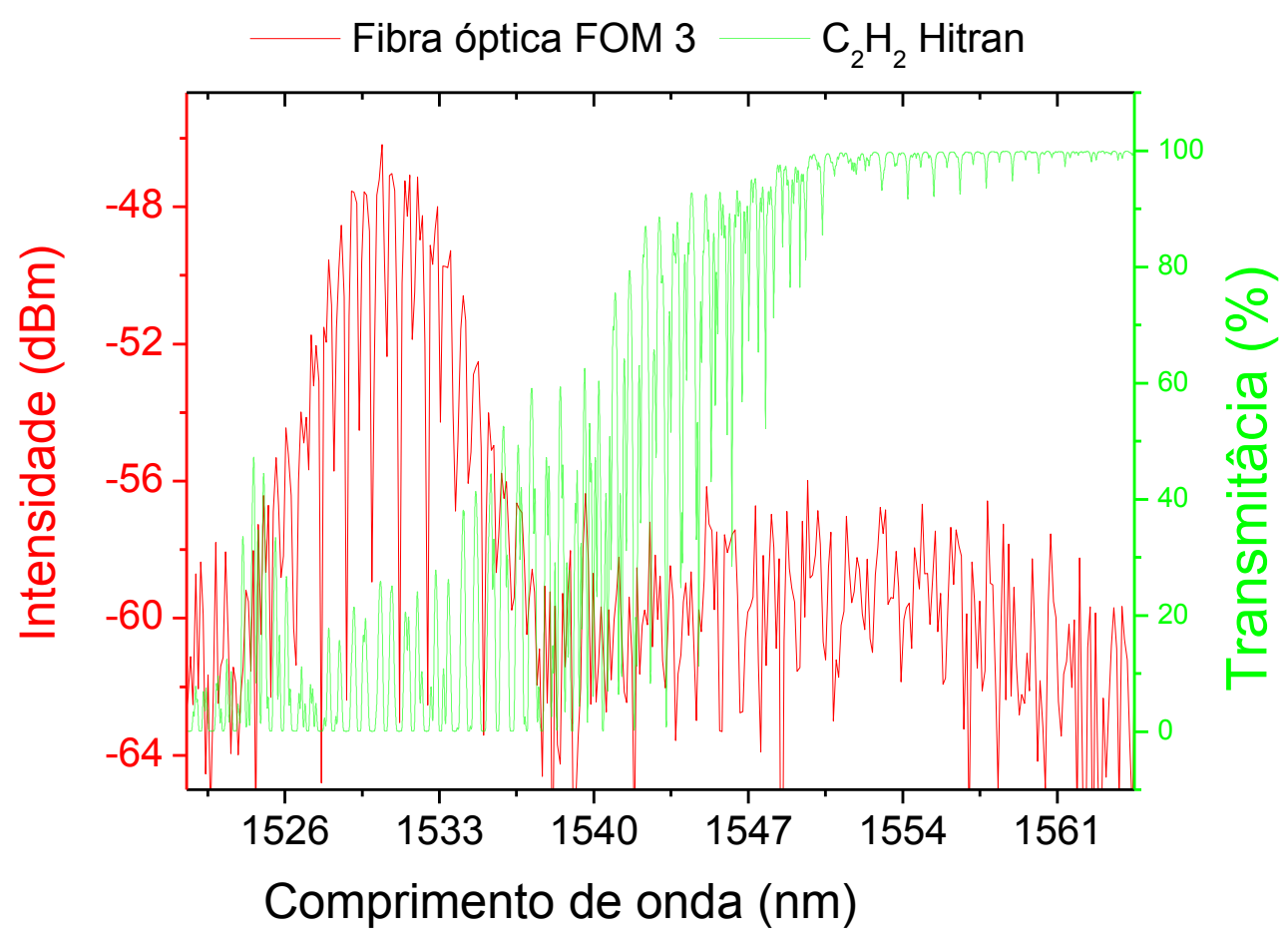

Figura 35 - Espectro referente ao gás acetileno medido na saída da FOM3.

\subsubsection{Aquisição de fibra óptica microestruturada comercial (HC-2000 Thorlabs)}

O foco desta etapa de atividades do projeto está baseado em aplicar fibras ópticas microestruturadas de núcleo oco como o guia óptico constituindo parte do protótipo do sensor de $\mathrm{CO}_{2}$ em desenvolvimento. Entretanto, como as fibras fornecidas pela ACREO e inicialmente utilizadas não apresentaram resultados satisfatórios para o sensoriamento do gás na região de $2 \mu \mathrm{m}$, o fornecedor NKT/Thorlabs dispõe de uma fibra óptica de núcleo oco (HC-2000) que atende todos os requisitos técnicos para o teste e posterior montagem do dispositivo. Tal fibra e suas características geométricas e de transmissão estão respectivamente apresentadas nas Figura 36 e Figura 37 a seguir. 

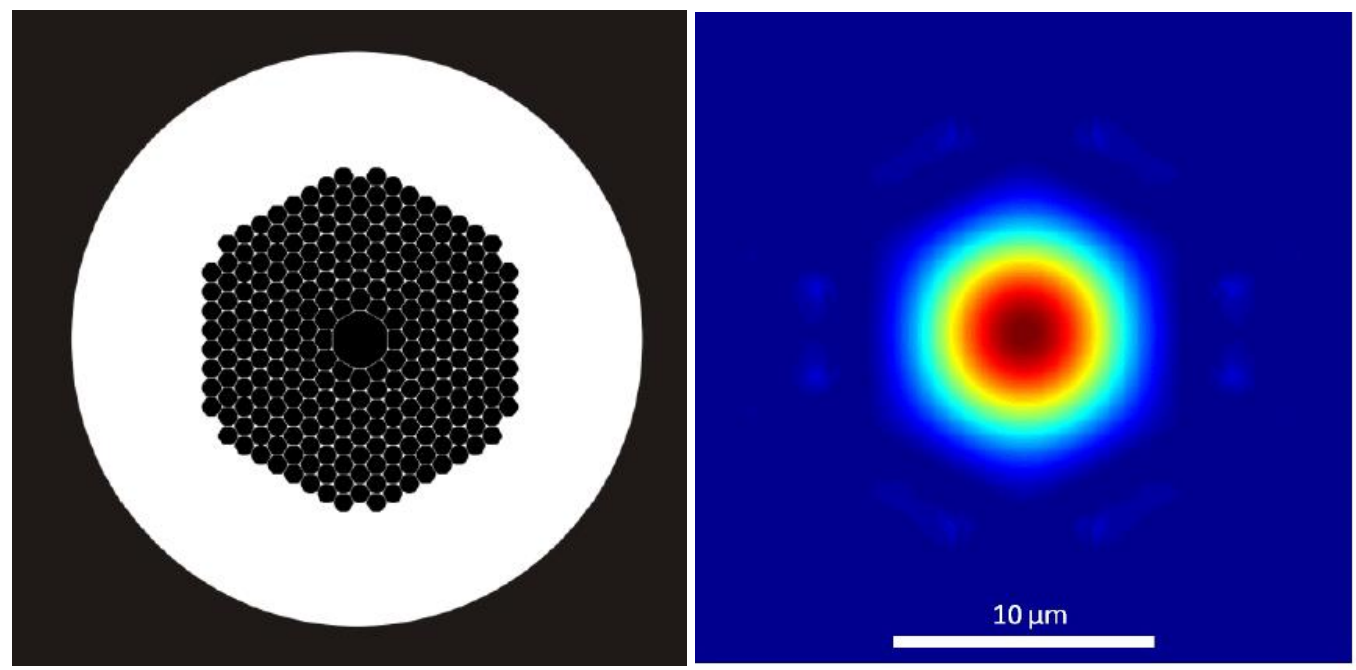

Figura 36 - Imagens adquiridas no datasheet da nova fibra óptica microestruturada modelo $\mathrm{HC}-2000 \mathrm{NKT}$, a ser aplicada no desenvolvimento de sensores de $\mathrm{CO}_{2}$.

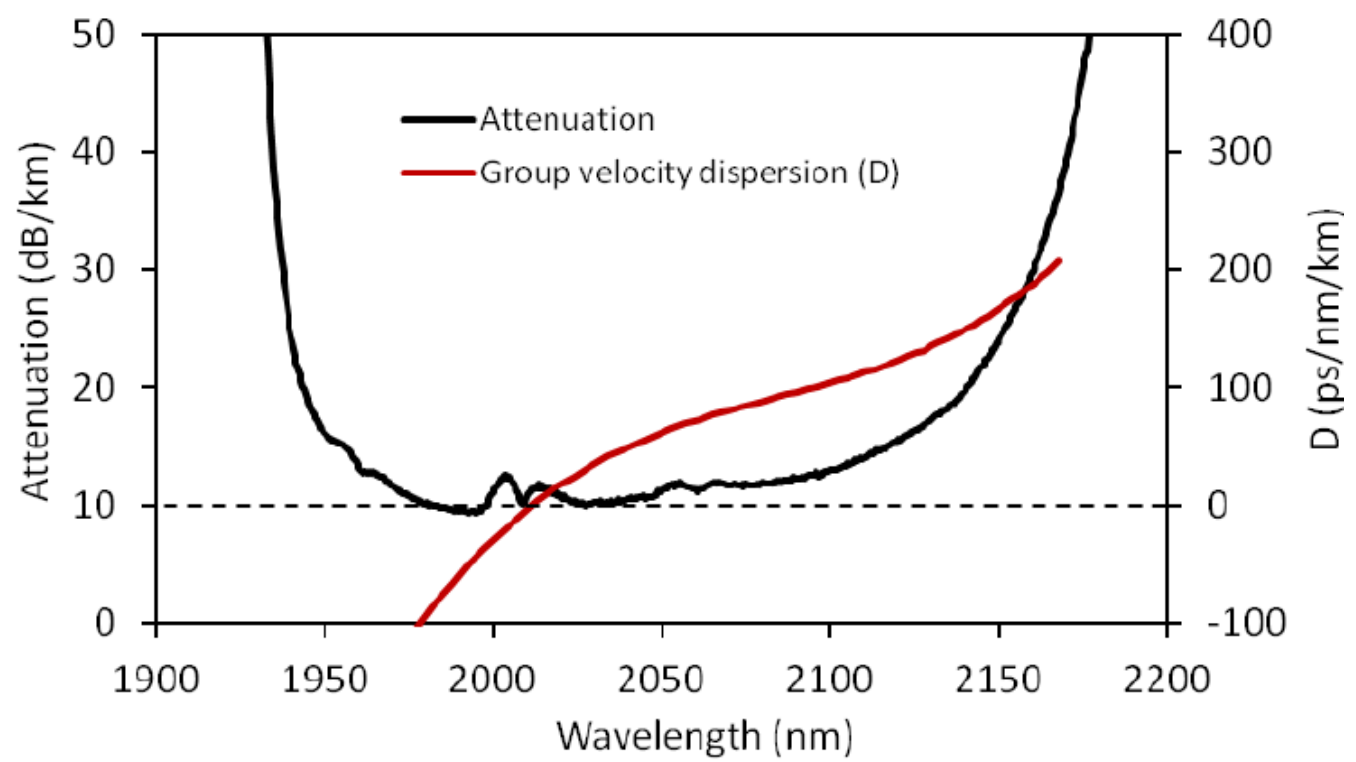

Figura 37 - Características de transmissão da fibra HC-2000 [34].

O mesmo esquema de montagem e injeção de gás realizado para as fibras microestruturadas anteriores foi aplicado a fibra HC-2000. O teste inicial foi realizado com $1 \mathrm{~m}$ da fibra. Felizmente, com esta foi possível observar as linhas de absorção de $\mathrm{CO}_{2}$, o que indica que houve acoplamento e consequente interação do gás com o sinal óptico propagante em $2 \mu \mathrm{m}$ no núcleo da fibra. Tais resultados satisfatórios estão no gráfico a seguir na Figura 38, para uma concentração de $\mathrm{CO}_{2}$ de aproximadamente1300 ppm. Deve ser destacado que, apesar da verificação da inserção de $\mathrm{CO}_{2}$ com o sinal propagante na fibra HC-2000, não foi possível alterar 
a concentração deste gás. Devido a esta limitação, a variação do sinal recebido em função do percentual de $\mathrm{CO}_{2}$, isto é, a sensibilidade desta fibra microestruturada não pôde ser relatada.

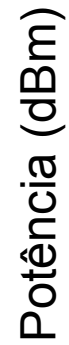

\section{Comprimento de onda $(\mathrm{nm})$}

(b)

Figura 38 - Resultados do teste realizado na fibra $\mathrm{HC}-2000$ Thorlabs com injeção de $\mathrm{CO}_{2}$ (concentração 1300 ppm): (a) comparação entre a medida da intensidade de luz antes e depois da injeção do gás; (b) Linhas de absorção do gás e luz propagando na Fibra HC2000. 
A região entre 2000 e $2003 \mathrm{~nm}$ é a que mostra as linhas de $\mathrm{CO}_{2}$ com atenuação mais acentuada. Estes resultados indicam a possibilidade de construção de dispositivos sensores a partir desta fibra HC-2000 para este comprimento de onda.

\subsection{Desenvolvimento de um sistema de interrogação baseado num laser em anel para detecção de gás carbônico}

O presente tópico apresenta a etapa de desenvolvimento e implementação de um método de controle óptico baseado no mecanismo de realimentação da potência óptica. Um laser sintonizável em anel é construído a partir de uma fonte ASE (Amplified Spontaneous Emission) em $2 \mu \mathrm{m}$ e uma FBG (Fiber Bragg Grating). Como elemento da montagem, um acoplador óptico 2 x 2 (50\%, $3 \mathrm{~dB}$ ) é utilizado para que, em uma das saídas deste dispositivo, seja possível analisar o comprimento de onda que é refletido do sistema. Conforme ilustrado na Figura 39, este mecanismo possui em um dos lados dois terminais de saída (50\% de potência óptica em cada um) e no outro lado, possui um terminal de entrada de sinal óptico mais um que possibilita medir a parcela de sinal refletido.

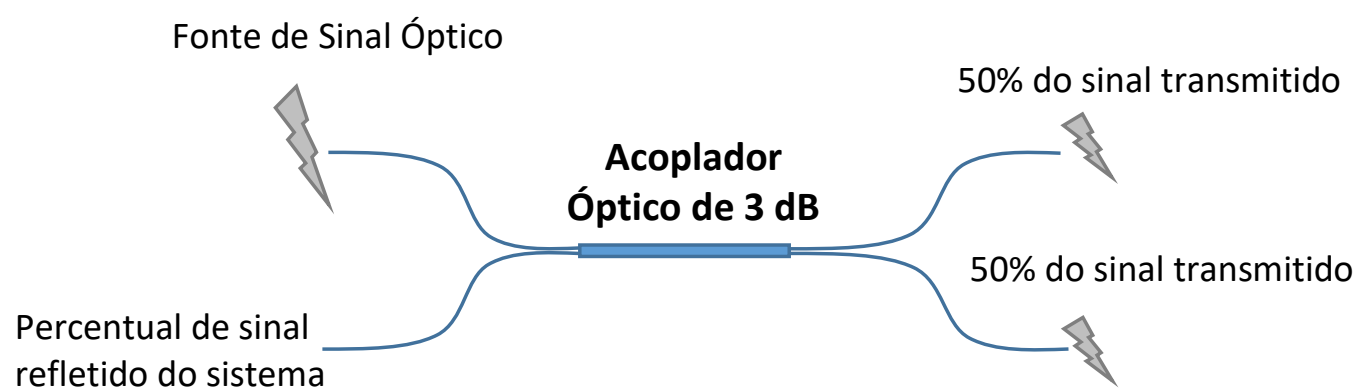

Figura 39 - Ilustração de um acoplador óptico de 3 dB quando há inserção de sinal óptico em um dos terminais. 


\subsubsection{Descrição do sistema de com aplicação da FBG}

As FBG (Fiber Bragg Grating), redes de Bragg em fibra óptica, constituem-se em modulações periódicas no índice de refração do núcleo da fibra, ao longo da direção longitudinal. A existência dessa modulação provoca a reflexão seletiva de uma banda estreita de luz, centrada no comprimento de onda de Bragg $\left(\lambda_{B}\right)$ dado pela relação (13):

$$
\lambda_{\mathrm{B}}=2 \mathrm{n}_{\mathrm{eff}} \Lambda
$$

Onde $\mathrm{n}_{\text {eff }}$ é o índice de refração efetivo do modo de propagação da luz e $\Lambda$ é o período espacial da modulação no índice de refração do núcleo da fibra. O comprimento de onda de Bragg varia em consequência de deformações longitudinais ou variações de temperatura. O deslocamento espectral $\left(\Delta \lambda_{\mathrm{B}}\right)$ associado à deformação longitudinal, $\epsilon_{\mathrm{z}}$, e à temperatura, $\mathrm{T}$, pode ser descrito pela equação (14):

$$
\frac{\Delta \lambda_{\mathrm{B}}}{\lambda_{\mathrm{B}}}=\left(1-\mathrm{p}_{\mathrm{e}}\right) \epsilon_{\mathrm{z}}+(\alpha+\eta) \Delta \mathrm{T}
$$

Onde $p_{e}$ representa o coeficiente efetivo relativo ao efeito fotoelástico, $\alpha$ o coeficiente de expansão térmica, e $\eta$ é o coeficiente termo-óptico da fibra. Para fibras de sílica com núcleo dopado com germânio $(\mathrm{Ge})$, os termos $\mathrm{p}_{\mathrm{e}} \approx 0,22$, $\alpha=0,55 \times 10^{-6}{ }^{\circ} \mathrm{C}^{-1} \mathrm{e} \eta=8,6 \times 10^{-6}{ }^{\circ} \mathrm{C}^{-1}$.

A Figura 40 mostra uma ilustração da rede descrita sendo iluminada por uma fonte de luz de banda larga. Uma faixa estreita do espectro da luz, centrada no comprimento de onda de Bragg, é refletida, sendo a restante transmitida. Qualquer deformação na rede de Bragg, ou alteração do índice de refração do modo guiado será observada através da variação da posição do comprimento de onda Bragg, dada pela equação (14). 


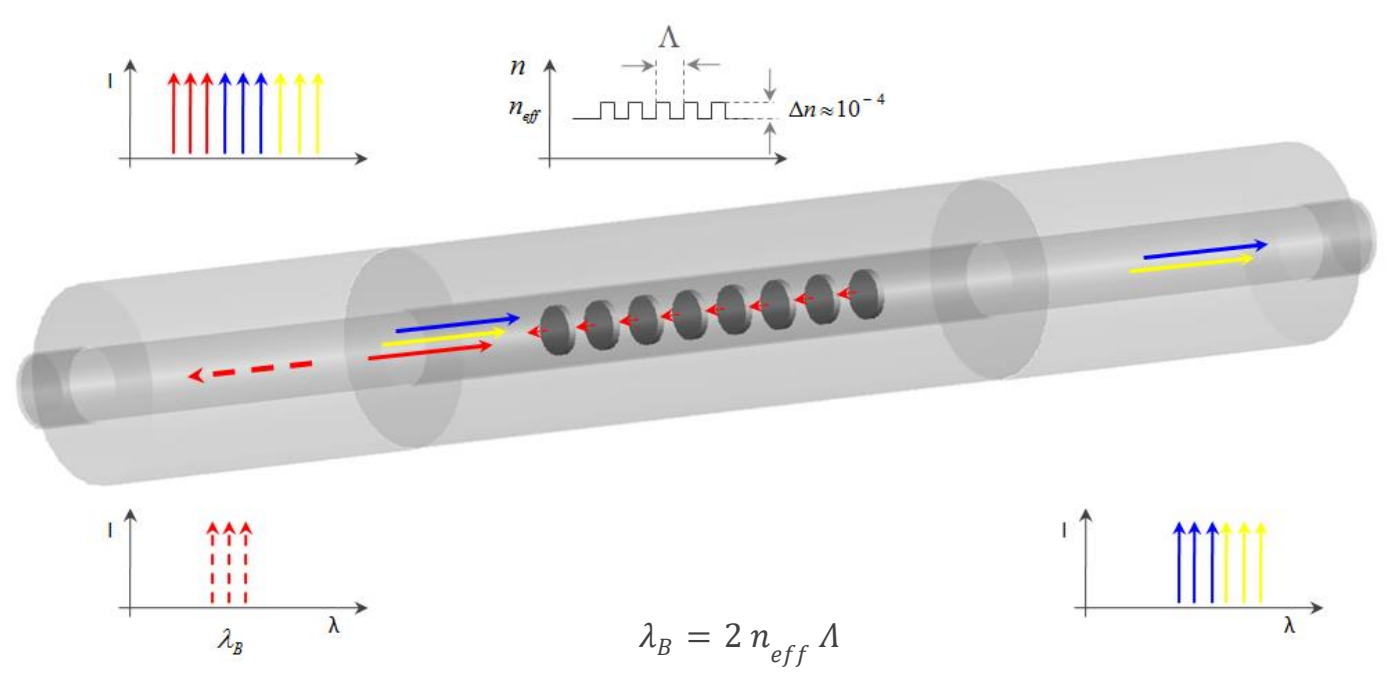

Figura 40 - llustração de uma rede de Bragg iluminada por uma fonte de banda larga.

Um avanço na tecnologia de sensores ocorreu com a descoberta das FBG. Esse tipo de tecnologia permitiu medidas de temperatura e deformação com grande precisão, e as perdas nas medidas também melhoraram [28].

Para finalidade de aplicação neste trabalho de tese, foi desenvolvida uma FBG com o objetivo de sensoriamento de $\mathrm{CO}_{2}$. Esta rede, quando inserida no sistema de detecção de concentração proposto, faz a seleção do comprimento de onda que é utilizado como laser. A realização deste protótipo é descrita no tópico a seguir.

\section{- Fabricação de redes de Bragg na Universidade Tecnológica Federal do Paraná:}

A fabricação das FBG foi possível de ser realizada em cooperação com a UTFPR (Universidade Tecnológica Federal do Paraná), Departamento Acadêmico de Eletrônica. O princípio de gravação usa a técnica de gravação interferométrica, representada na Figura 41. O sistema consiste numa fonte de luz laser ultravioleta modelo Nd:YAG $266 \mathrm{~nm}$. O feixe de luz UV, difratado nas ordens \pm 1 pela máscara de fase é recombinado na fibra através de dois espelhos. Na montagem os espelhos são montados em dois motores que possibilitam o ajuste para que os feixes interfiram no mesmo ponto da fibra e assim produzam o padrão de interferência. 


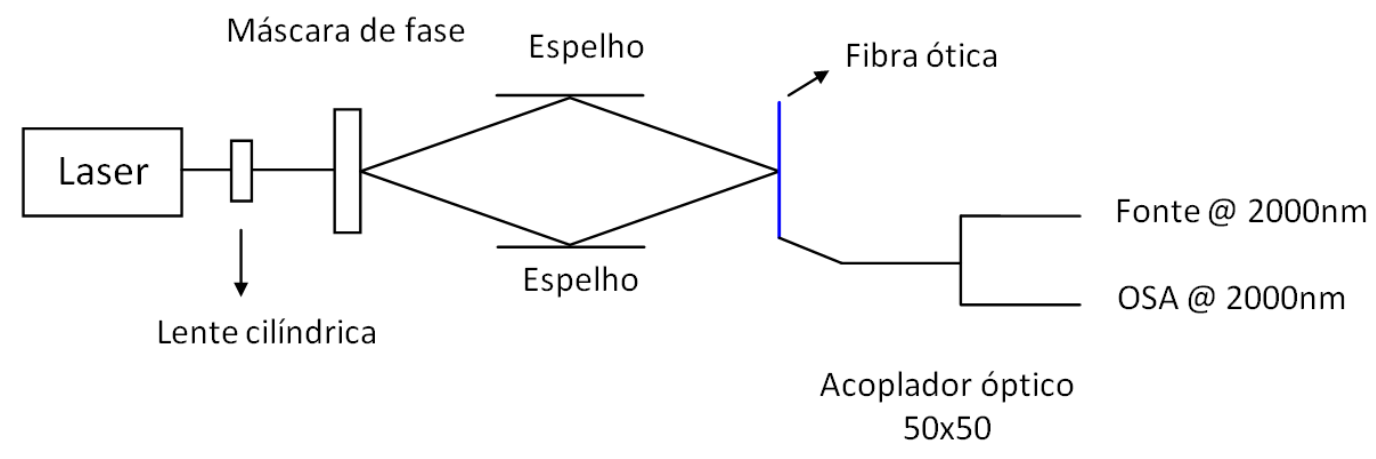

Figura 41 - Esquema da montagem utilizada para gravação de redes de Bragg pelo método interferométrico.

\section{- Sistema de sintonização do laser em anel:}

O sistema sintonização do laser em anel inicialmente utilizado é baseado numa viga em balanço, de comprimento L e espessura d, ilustrado na Figura 42.

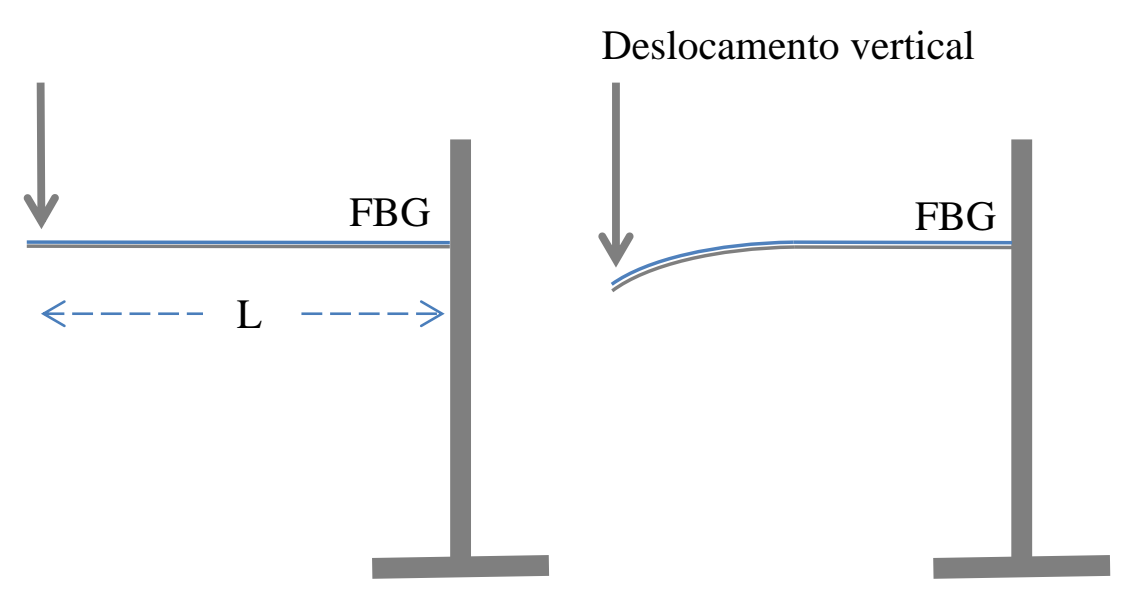

Figura 42 - Ilustração esquemática do deslocamento vertical da FBG colada na viga.

Conforme apresenta a Figura 43, a FBG é colada à direita, próximo ao engate da viga. Do lado esquerdo, há um parafuso micrométrico que é utilizado de forma a aplicar uma força lateral e assim defletir a viga, consequentemente, a 
rede de Bragg. A variação em comprimento de onda pode ser calculada através da equação (15):

$$
\frac{\Delta \lambda}{\lambda}= \pm \frac{0,78 \mathrm{PLy} / 2}{\mathrm{EI}}
$$

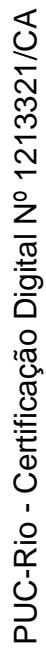
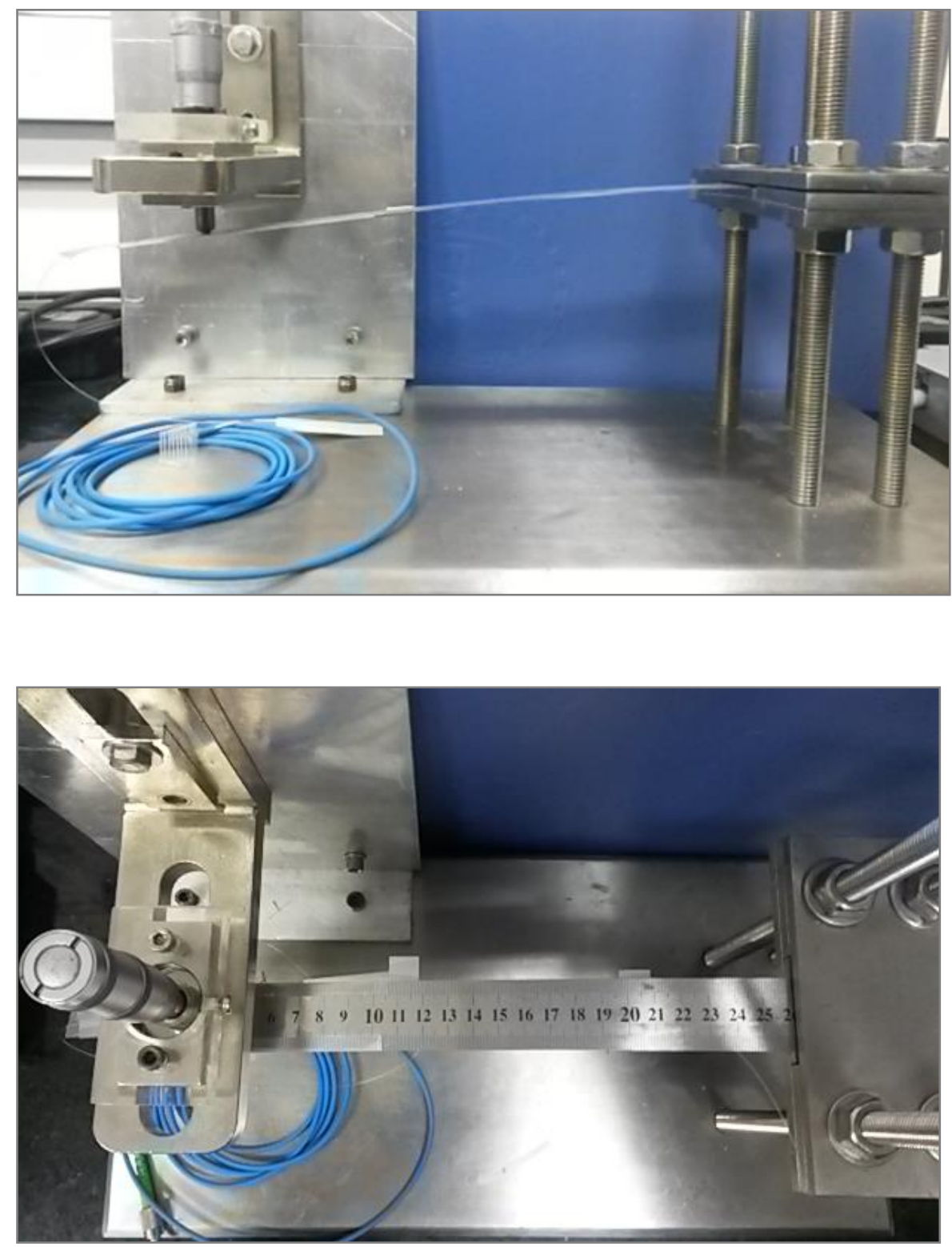

Figura 43 - Montagem experimental para a sintonização do laser em anel. 


\section{- Teste de validação do sistema de interrogação baseado num laser em anel:}

Conforme o esquema apresentado anteriormente na Figura 43, o laser em anel foi montado usando o sistema de sintonização baseado em uma viga em balanço. A fonte de sinal óptico utilizada é uma ASE em $2 \mu \mathrm{m}$ e como OSA (analisador de espectro óptico) um equipamento da fabricante Yokogawa modelo AQ6375.

Para o teste de validação da rede em sistema sensor, uma célula padrão de $\mathrm{CO}_{2}$ é conectorizada em série com o OSA. O teste consiste em causar com o parafuso micrométrico ou um atuador linear automatizado, uma força lateral na viga, de tal forma que a envergadura realize uma varredura ao longo de uma janela de comprimentos de onda onde existam pelo menos uma linha de absorção do $\mathrm{CO}_{2}$ que causa atenuação do sinal óptico. A finalidade desta etapa é a de verificar se é possível detectar o vale de atenuação referente a esta região do espectro. A Figura 44 a seguir ilustra esta descrição.

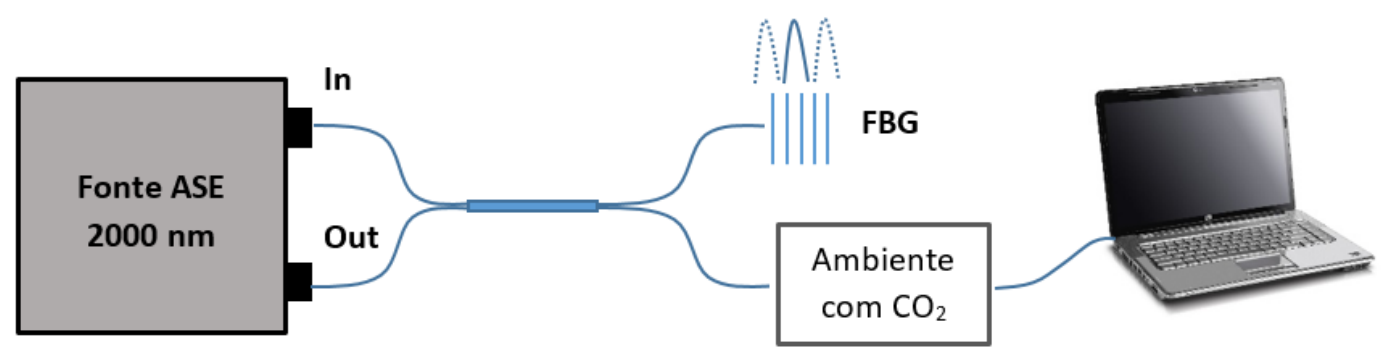

Figura 44 - Sistema de interrogação para a construção de um laser em anel - Montagem da FBG como elemento de um sistema sensor de gás $\mathrm{CO}_{2}$. Na recepção, pode ser utilizado um fotodetector com um osciloscópio ou um OSA, como indicado com o computador. 


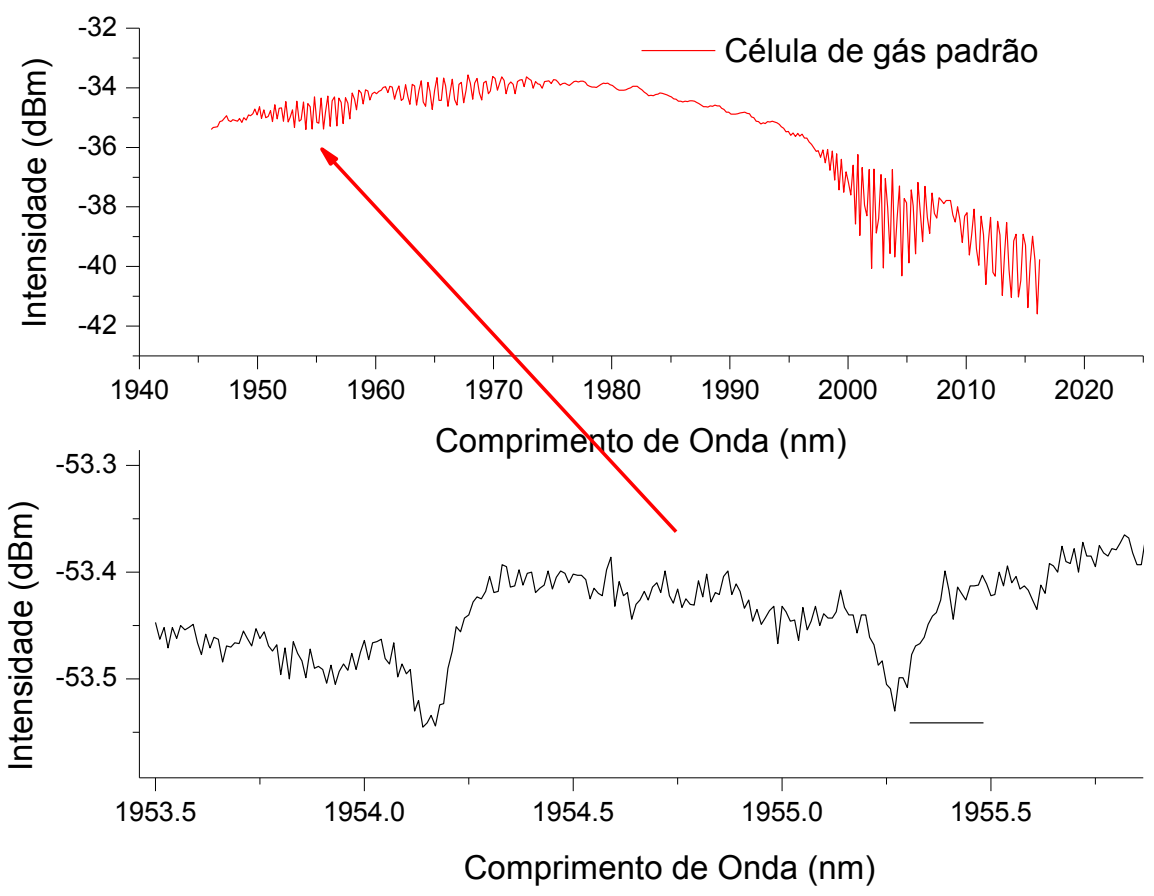

Figura 45 - Esquema montado para sistema com fonte ASE realimentada com rede Bragg - linhas de $\mathrm{CO}_{2}$ com a célula padrão.

\subsubsection{Ambiente de $\mathrm{CO}_{2}$ : Calibração do sistema - Validação da atenuação do sinal transmitido na célula de gás quando o percentual de concentração é variado}

\section{Etapa 1:}

Antes de apresentar as medidas realizadas com as células de $\mathrm{CO}_{2}$, é importante comentar como esses dados são interpretados. Por referências do HITRAN [35], é possível plotar curvas com as linhas de absorção de gases (como por exemplo, $\mathrm{C}_{2} \mathrm{H}_{2}, \mathrm{CO}_{2}$ ) considerando diferentes percentuais de concentração. $\mathrm{O}$ OSA possui um banco de referências, onde por inserção dos parâmetros de percentual de concentração, pressão atmosférica, range de comprimento de onda e comprimento do caminho óptico, é possível criar gráficos específicos às situações em análise. A Figura 46 mostra curvas referentes a base de dados do HITRAN para diferentes percentuais de baixa concentração de $\mathrm{CO}_{2}$. Conforme pode ser observado, à medida que a concentração aumenta, a transmitância diminui em (a) e a atenuação aumenta em (b). 


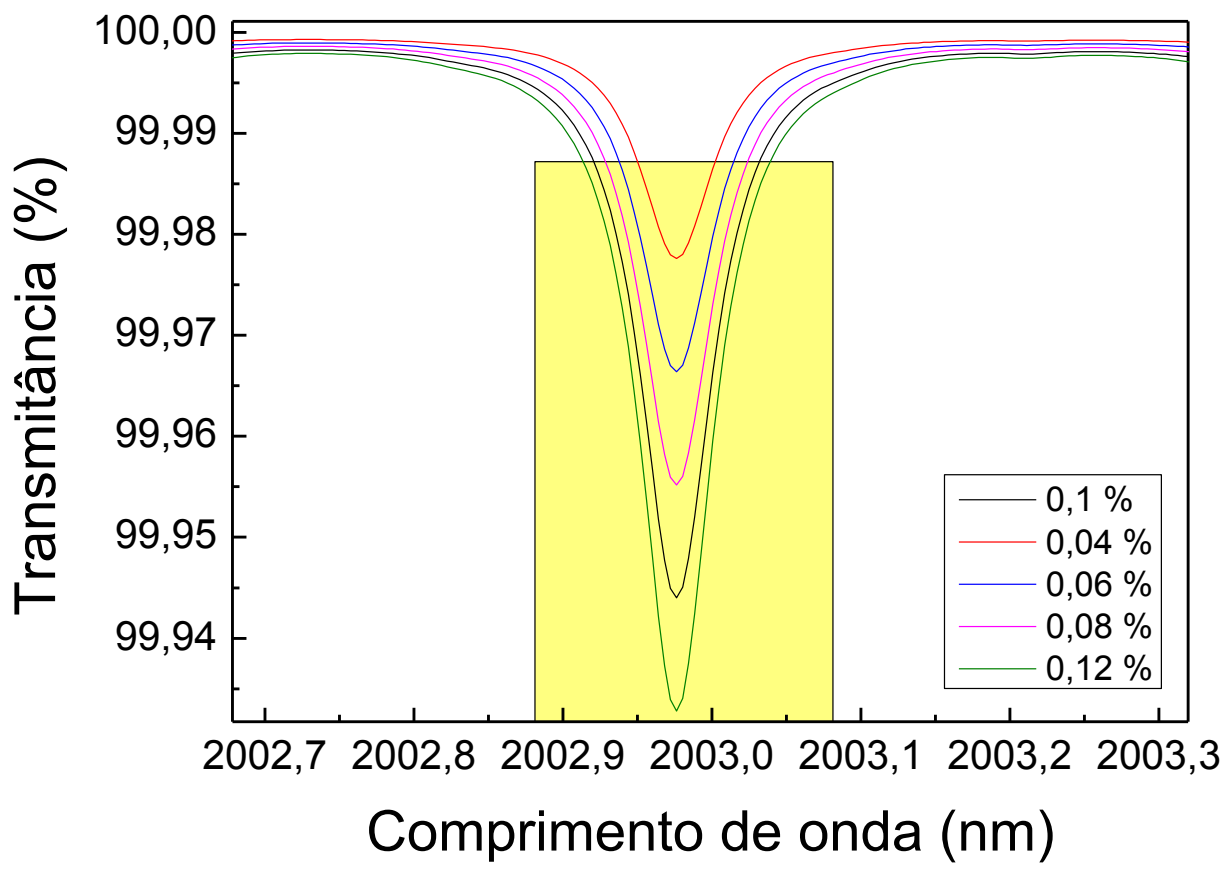

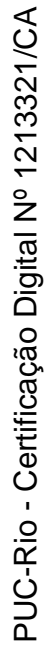

(a)

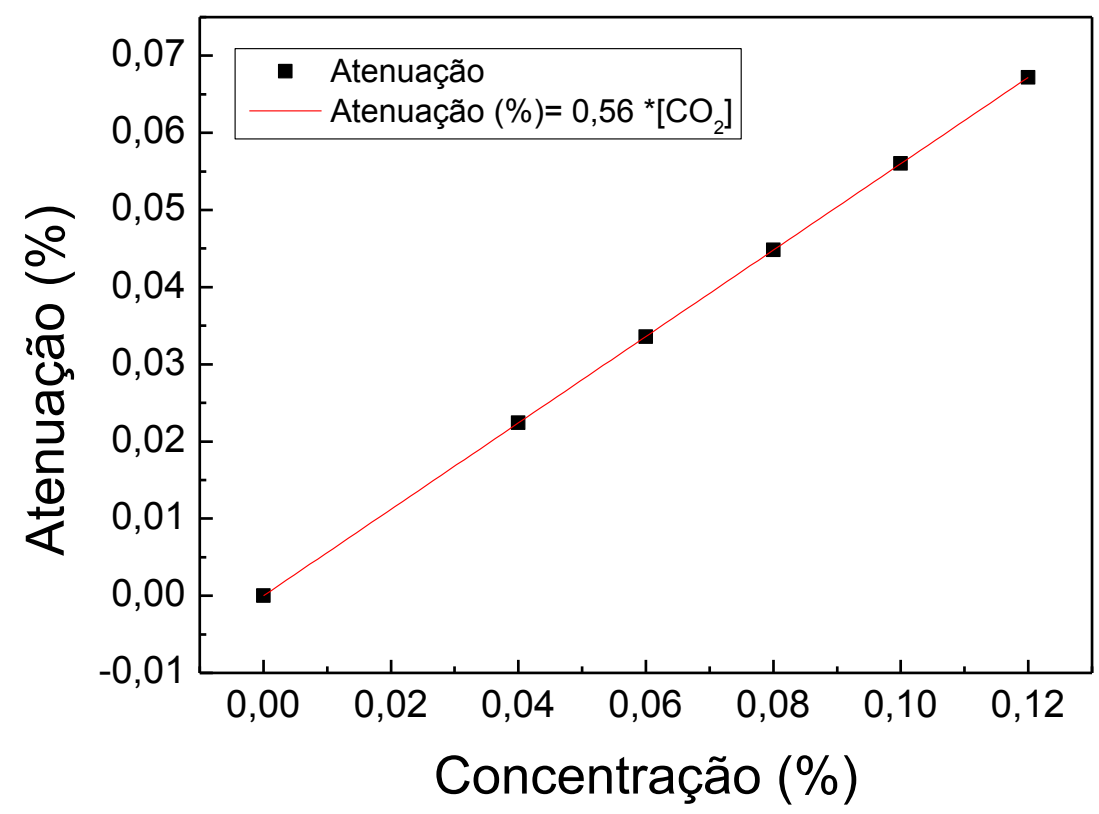

(b)

Figura 46 - Descrição: (a) Linhas de absorção de $\mathrm{CO}_{2}$ para baixas concentração do gás (b) relação do aumento da atenuação com o aumento da concentração de gás. @ 2003 nm para uma célula com caminho óptico de comprimento $78 \mathrm{~cm}$. 


\section{Etapa 2:}

Para a realização do experimento, disponibilizamos da aplicação de três elementos células ópticas do fabricante Wavelenght References que são individualmente apresentadas na Figura 47 e descritas a seguir:

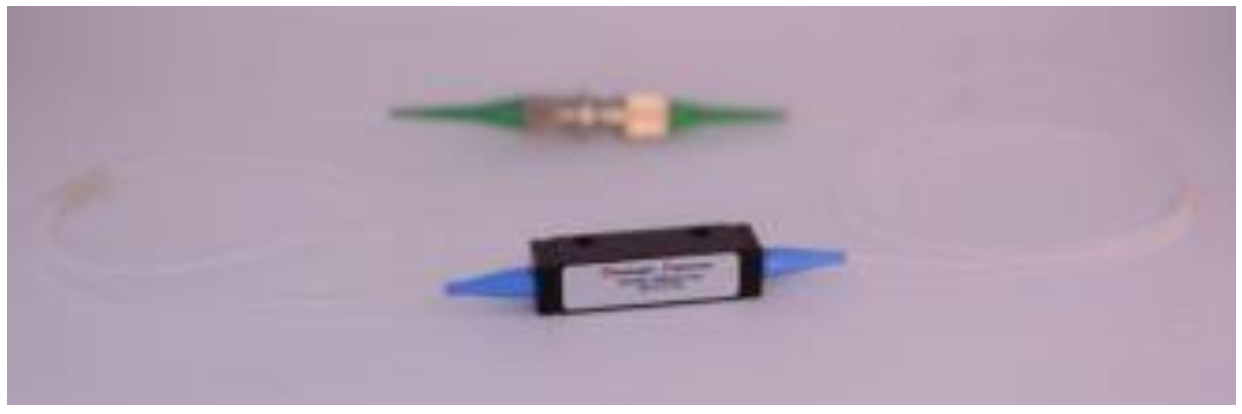

(a)

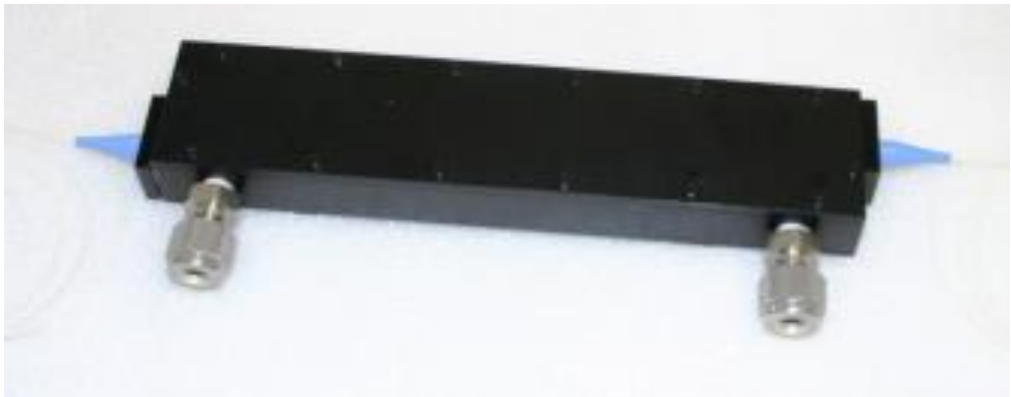

(b)

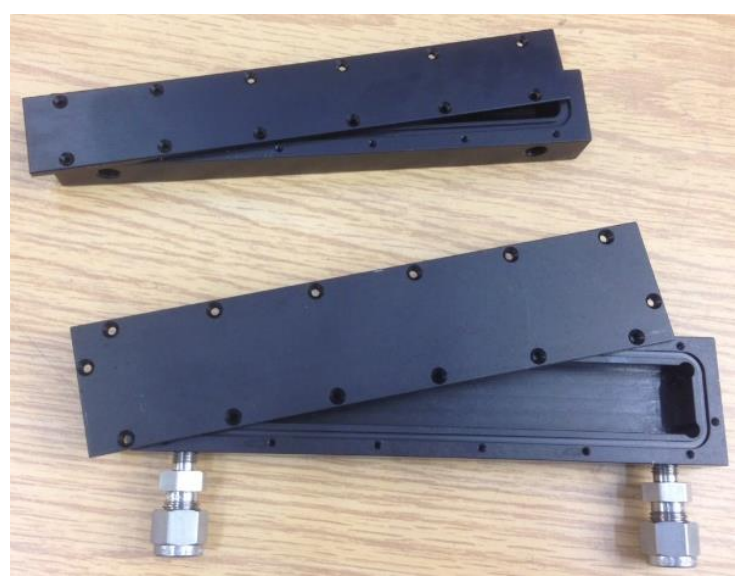

(c)

Figura 47 - Células de gás fabricante Wavelenght References com diferentes parâmetros, sendo por ordem: (a) célula de referência, (b) célula de fluxo e (c) célula aberta. 
Uma célula de referência (a) é um dispositivo totalmente vedado e conectorizado à fibra óptica nas extremidades, onde a quantidade de gás concentrado no interior é padrão do fabricante, de acordo com as características técnicas do projeto em que esta é aplicada.

Existem células abertas, conforme mostra a Figura 47 (b) e (c), que permitem controlar o gás que se deseja analisar no interior deste dispositivo de alta sensibilidade. Outra característica importante é que a entrada e saída óptica da célula é acoplada a fibras ópticas conectorizadas, o que facilita a aplicação em montagens práticas e robustas. $\mathrm{O}$ acoplamento de luz em muitas das células de gás utilizadas para detecção é facilitado pelo uso de lasers, vez que uma proporção significativamente maior de luz pode ser colimada por um feixe estreito e lançada na fibra óptica A célula de fluxo (b) possui dois terminais para entrada e saída de gás - durante a operação, é utilizada uma bomba para auxiliar no fluxo do gás interior. Por último, uma célula aberta (c) é aquela que possui uma das faces totalmente aberta para facilitar a entrada de gás no interior.

As fibras ópticas associadas às entradas e saídas das células podem ser monomodo ou multimodo. Nas multimodos, cada um dos modos pode ter um percurso diferente. Em fibras multimodo convencionais de Telecomunicações, o diâmetro do núcleo é da ordem de 50 ou $60 \mu \mathrm{m}$, e de fibras monomodo é de 3 a 10 $\mu \mathrm{m}$, ambas com revestimento de diâmetro $125 \mu \mathrm{m}$. Quando a luz coerente ou espectroscopia de resolução muito alta é empregada, a interferência entre os modos propagantes em fibra multimodo pode causar efeitos indesejáveis sobre o sinal (ruído de modo). Portanto, para comunicação, a fibra monomodo pode ser preferida. Sem amplificação, a comunicação a muitos quilômetros de fibra é possível com taxas de dados de até dezenas de $\mathrm{Gb} / \mathrm{s}$. Felizmente, aplicações em detecção de gases normalmente exigem comprimentos mais curtos de fibra e muitas vezes podem acomodar maiores perdas ópticas e menores taxas de dados. Desta forma, a fibra óptica padrão de telecomunicações podem ser usadas em uma ampla gama de comprimentos de onda para cobrir muitas linhas de absorção de gases.

Os parâmetros destas células (tais como dimensões, tipo de gás inserido, comprimento óptico, fibras monomodo ou multimodo) podem ser modificados em acordo com o fabricante em função das especificações do projeto em que são aplicadas. 
Na montagem experimental desenvolvida, estas células ópticas foram agrupadas dentro de uma caixa plástica que possui uma entrada de gás, simulando o ambiente de teste.

Para calibração dos dispositivos, as medidas iniciais foram realizadas inserindo primeiramente nitrogênio $(\mathrm{N})$ nesta caixa de teste, a fim de garantir que não haveria influência de $\mathrm{CO}_{2}$ nas medidas para as células de fluxo e aberta. A medida da célula padrão individualmente mostra que o dispositivo possui linhas de absorção mais fortes entre 2000 e 2004 nm. Sendo o vale mais acentuado em 2003 $\mathrm{nm}$, neste ponto o nível do sinal óptico inicialmente em -38 dBm tem uma atenuação devido à presença de gás de 6,4 dB.

Nos resultados a seguir apresentados na Figura 48, foram utilizadas células com comprimento de caminho óptico igual a $78 \mathrm{~cm}$ e conectorizadas com fibra óptica monomodo. A célula de referência é de $\mathrm{CO}_{2}$ e este gás é injetado posteriormente na caixa já mencionada.

Quando as três células são conectadas, o sinal em -38 dBm é atenuado $13 \mathrm{~dB}$ devido às perdas de inserção destas. $\mathrm{O}$ vale analisado novamente apresenta atenuação de $6,7 \mathrm{~dB}$. Essa pequena diferença de $0,3 \mathrm{~dB}$ pode ser devido às outras duas células (fluxo e aberta).

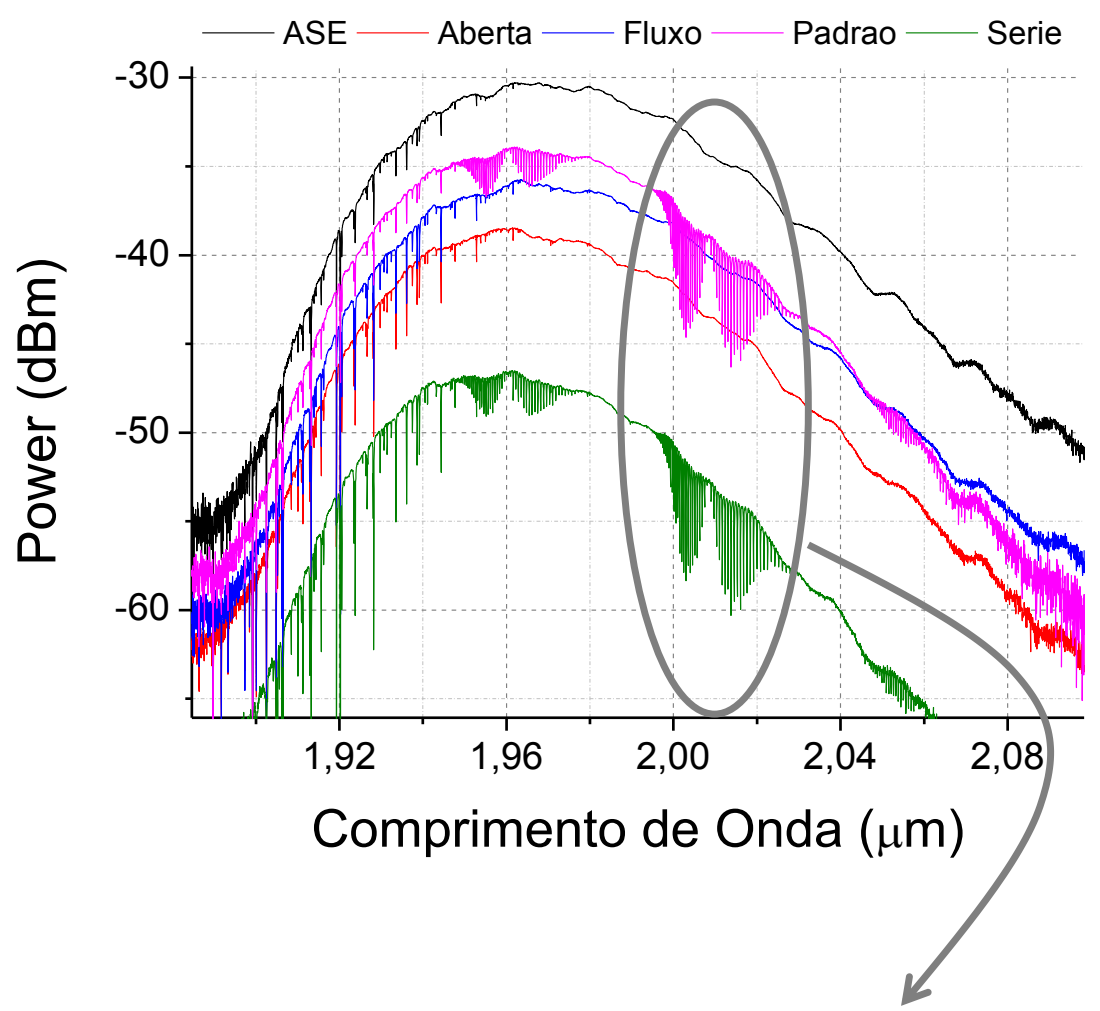


Figura 48 - Transmissão do sinal da fonte ASE pelas células de gás individualmente e quando conectadas em série.

\subsection{Caracterização da FBG no LSFO/DEM/PUC-Rio}

O ambiente utilizado para desenvolvimento dos testes experimentais é novamente o LSFO. O laboratório possui quase todos os recursos necessários para a realização das atividades, de acordo com os itens listados a seguir:

1. Fonte ASE - $2000 \mathrm{~nm}$ Fiber Amplifier AdValue Photonics

2. OSA THORLABS 203B $1000-2600 \mathrm{~nm}$

3. Cilindros de gases $\mathrm{CO}_{2}$ e N (nitrogênoo) a serem aplicados na câmara de testes

4. Células ópticas de gás - serão aplicadas dois tipos de células: uma de referência e uma segunda chamada célula de fluxo, vez que possibilita a entrada e saída do gás em análise. Esta última mencionada, permite que sejam identificados diferentes percentuais de concentração de gás ambiente

5. Equipamento medidor de concentração de $\mathrm{CO}_{2}$ ambiente 
De acordo com o esquema ilustrado anteriormente na Figura 44, quando esta fonte ASE ilumina a FBG construída, a excitação desta rede permite a seleção adequada do comprimento de onda de emissão desejado, uma faixa estreita centrada no comprimento de onda Bragg ( $\lambda_{\text {Bragg }}$ em torno de $\left.2 \mu \mathrm{m}\right)$. Esta parcela de sinal é refletida em um dos terminais do acoplador. Em seguida, este sinal é utilizado para realimentar a fonte ASE. Como consequência do processo, esse sinal óptico é amplificado e entregue novamente ao sistema.

No experimento desenvolvido, a ASE apresenta inicialmente potência de entrada igual a -34 dBm entre 1900 e $2100 \mathrm{~nm}$. O comprimento de onda refletido da FBG está centrado em $1955 \mathrm{~nm}$, com potência de pico próxima a -45 $\mathrm{dBm}$. Entretanto, quando este sinal realimenta a ASE, a detecção na saída mostra uma amplificação em torno de $50 \mathrm{~dB}$ deste sinal. Esta primeira medida foi realizada com o analisador de espectro óptico Thorlabs. Estes dados descritos estão apresentados na Figura 49, onde é possível observar a amplificação do sinal óptico quando realimentado.

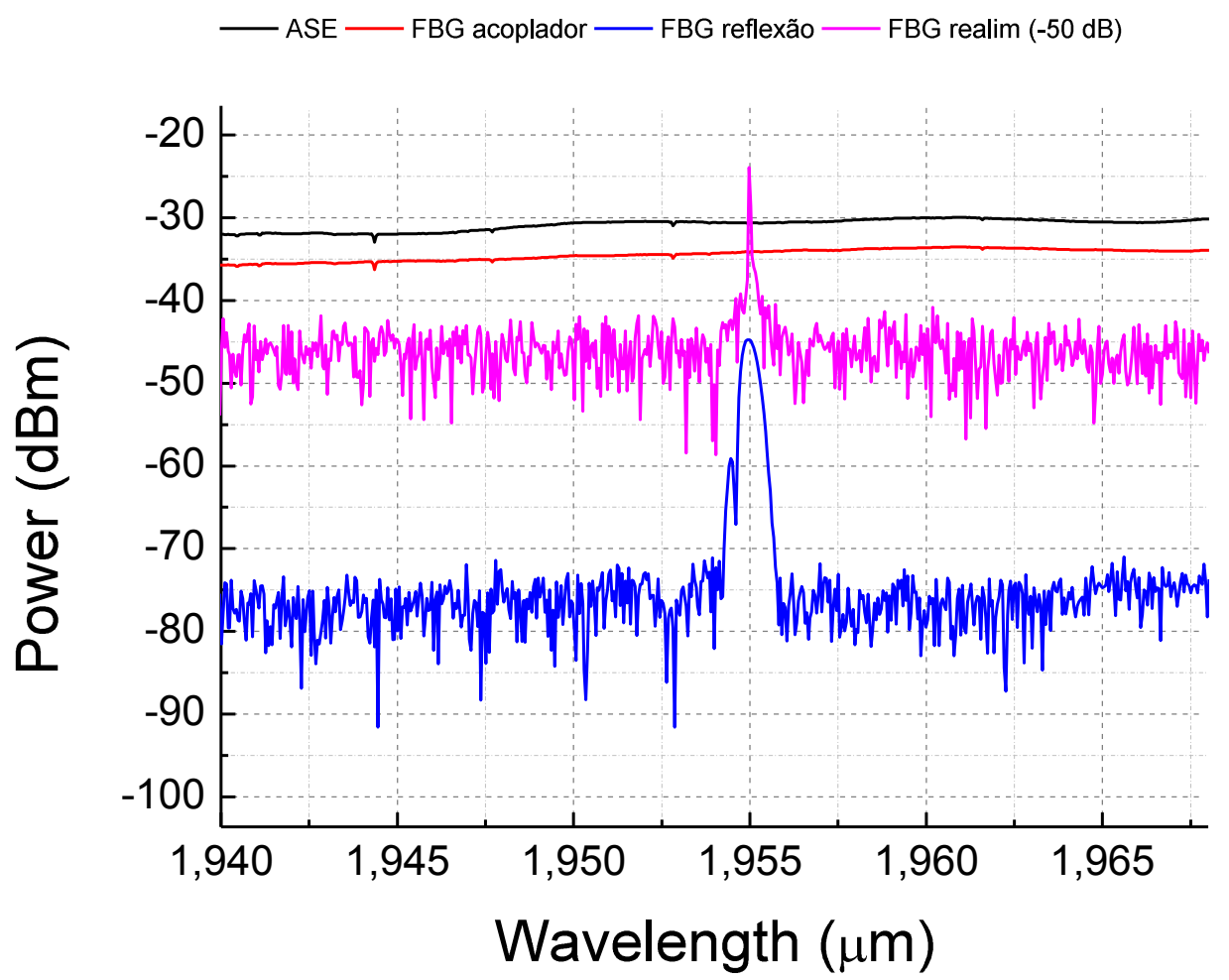

Figura 49 - FBG realimentando fonte ASE. Atenuação de 50 dB é necessária para evitar danificar o OSA na aquisição dos dados. 
O comprimento de onda Bragg refletido do sistema é apresentado dentro das linhas de absorção do $\mathrm{CO}_{2}$ na Figura 50 a seguir. A linha em azul representa o $\lambda_{\text {Bragg }}$ e a linha em preto mostra as linhas de absorção de $\mathrm{CO}_{2}$ nesta região, de acordo com os parâmetros do HITRAN. Conforme está indicado, é possível observar que as linhas de absorção têm largura igual a $0,5 \mathrm{~nm}$. A FHWM (full width at half maximum - largura à meia altura ou ou largura $\mathrm{a} 3 \mathrm{~dB}$ ) do $\lambda_{\mathrm{Bragg}}$ também é de 0,5 nm. Estes resultados foram obtidos com o OSA Thorlabs.

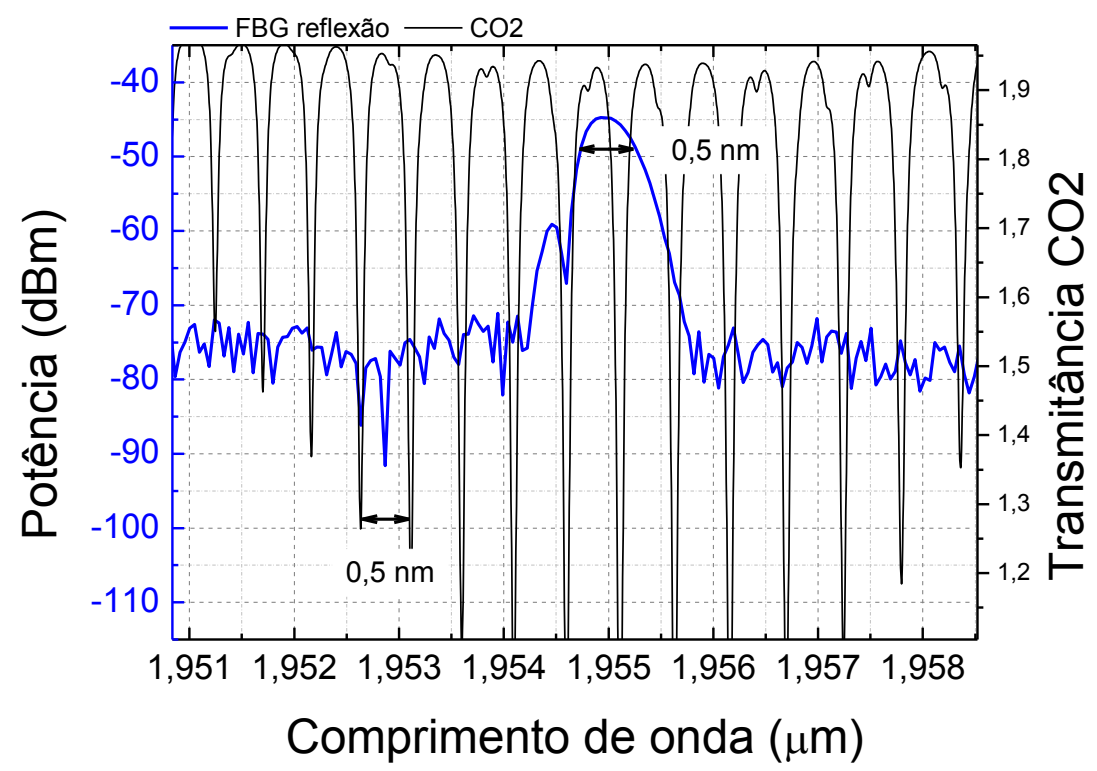

Figura 50 - Gráfico indicando a FWHM do $\lambda_{\text {Bragg }}$ dentro das linhas de absorção de $\mathrm{CO}_{2}$ pela base de dados do HITRAN.

Após a realimentação, o nível medido atenuado $50 \mathrm{~dB}$ mostra-se próximo a $-24 \mathrm{dBm}$. A FHWM deste sinal neste caso é igual a $0,1 \mathrm{~nm}$, conforme pode ser verificado a seguir na Figura 51. Para a rede ainda sem deformação, o comprimento de onda permanece centrado em 1,955 $\mu \mathrm{m}$, sendo este, portanto, a referência do laser em anel construído. 


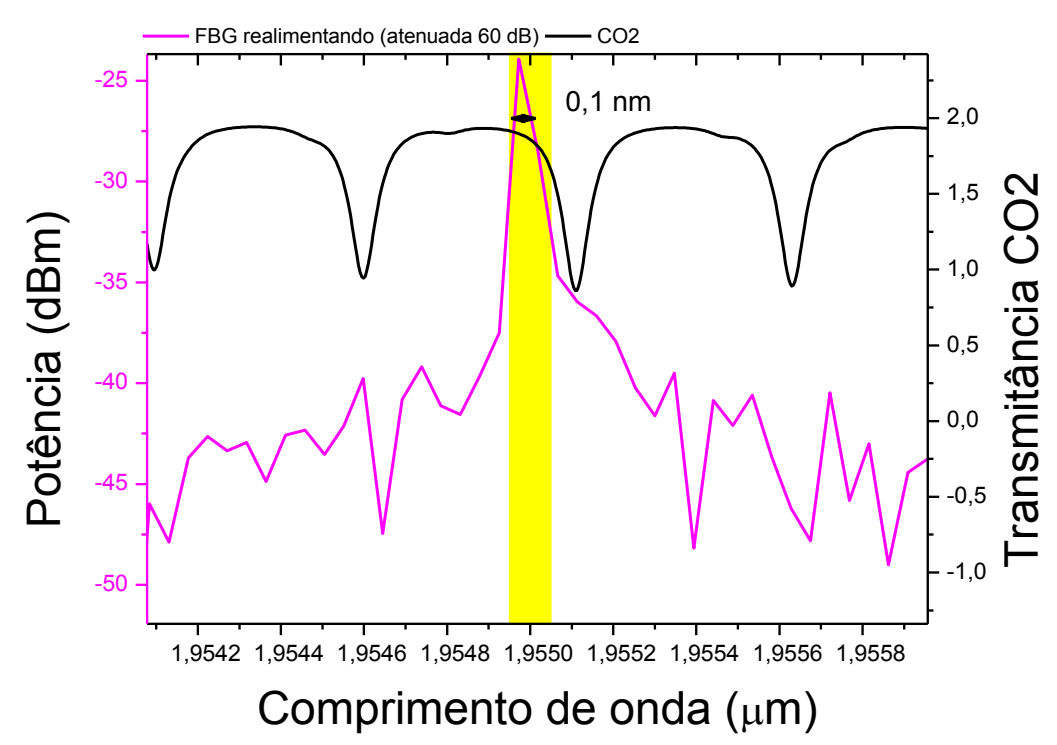

Figura 51 - Sinal resultante da fonte ASE e entregue ao sistema, a partir da realimentação pelo $\lambda_{\text {Bragg. }}$

Conforme a rede é deformada pelo parafuso micrométrico (no sentido vertical para baixo), este comprimento de onda pode deslocar-se e caminhar numa janela de aproximadamente $1 \mathrm{~nm}$. Sendo a largura das linhas de absorção de $\mathrm{CO}_{2}$ de $0,5 \mathrm{~nm}$, logo, é possível percorrer até duas linhas com a deformação causada. Esta distância está demonstrada no gráfico da Figura 52.

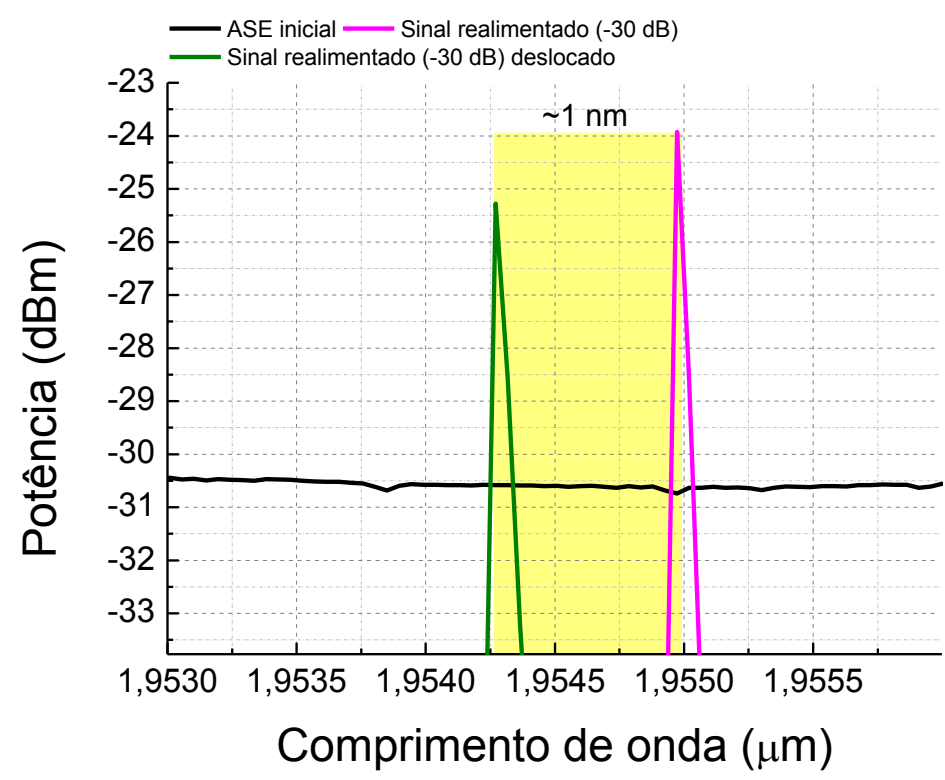

Figura 52 - Deslocamento do comprimento de onda a partir da deformação causada na FBG. 
- Segunda montagem da viga com sistema controlado por motor elétrico:

Para aprimorar a parte do sistema onde é feita a deformação da FBG fabricada, um segundo sistema contendo um motor elétrico é desenvolvido pelo grupo do LSFO e posteriormente implementado, de acordo com a montagem experimental na imagem da Figura 53 abaixo.
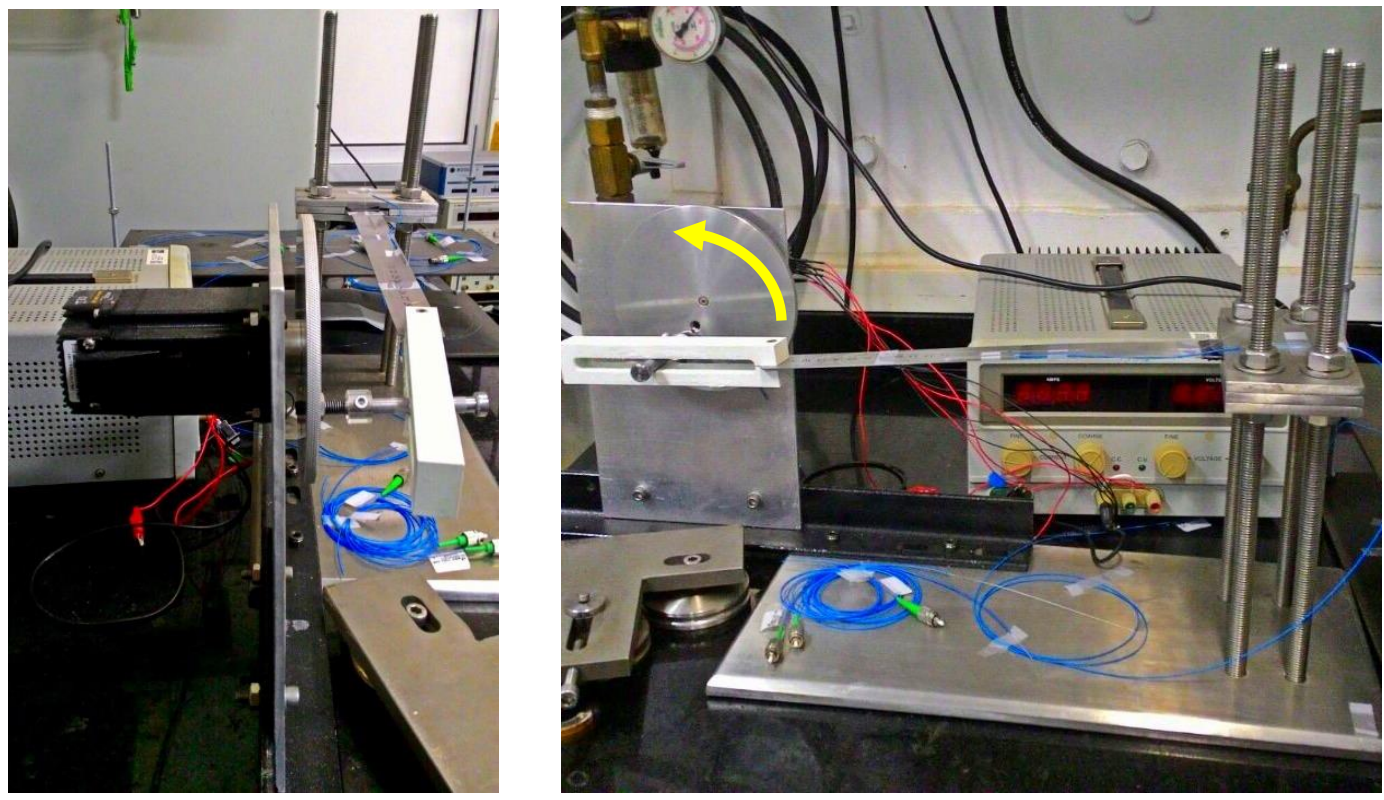

Figura 53 - Motor montado no LSFO para deformação da viga onde está colada a FBG. O motor realiza a rotação do disco permitindo que a viga seja deformada na vertical para cima e para baixo.

Como pode ser visualizado, o novo sistema motorizado permite que a FBG seja deformada tanto na vertical para cima quanto para baixo. O raio do disco é ajustável, permitindo que a deformação possa ocorrer com menor ou maior curvatura. Este raio irá corresponder a quantas linhas de absorção do gás em análise podem ser observadas. Com esta montagem, foi possível observar com o analisador de espectro até três linhas de absorção do $\mathrm{CO}_{2}$ em tempo real.

$\mathrm{Na}$ etapa de aquisição de medidas desse segundo método, ocorre a inserção de um novo conjunto contendo um fotodetector (THORLABS PDA10D 1,2 $\mu \mathrm{m}-2,6 \mu \mathrm{m})$ para substituição do equipamento OSA. O dispositivo faz a conversão óptica-elétrica do sinal que, em seguida, é processado por filtragem elétrica. Por último, a leitura é finalmente realizada com o módulo Mixed Signal 
Oscilloscope (National Instruments Virtual Bench), que realiza o armazenamento dos dados e possui um software que possibilita visualização e aquisição destes. A bancada de montagem descrita é mostrada na Figura 54. Da esquerda para a direita, têm-se os elementos: uma caixa plástica de dimensões $30 \mathrm{~cm}$ x $50 \mathrm{~cm}$ x $20 \mathrm{~cm}$, simulando o ambiente contendo o gás analisado, um filtro elétrico, o módulo NI e o monitor exibindo as linhas de absorção do $\mathrm{CO}_{2}$. A caixa indicada pela seta verde, possui um orifício onde é injetada uma mangueira com $\mathrm{CO}_{2}$ e um outro onde é inserida a mangueira do equipamento medidor de concentração 410i Thermo Scientific. Este equipamento é utilizado durante o experimento como medida de segurança e para verificação das concentrações de $\mathrm{CO}_{2}$ que saem do cilindro. Dentro da caixa, estão posicionadas as células de $\mathrm{CO}_{2}$ (referência e de fluxo) descritas anteriormente.

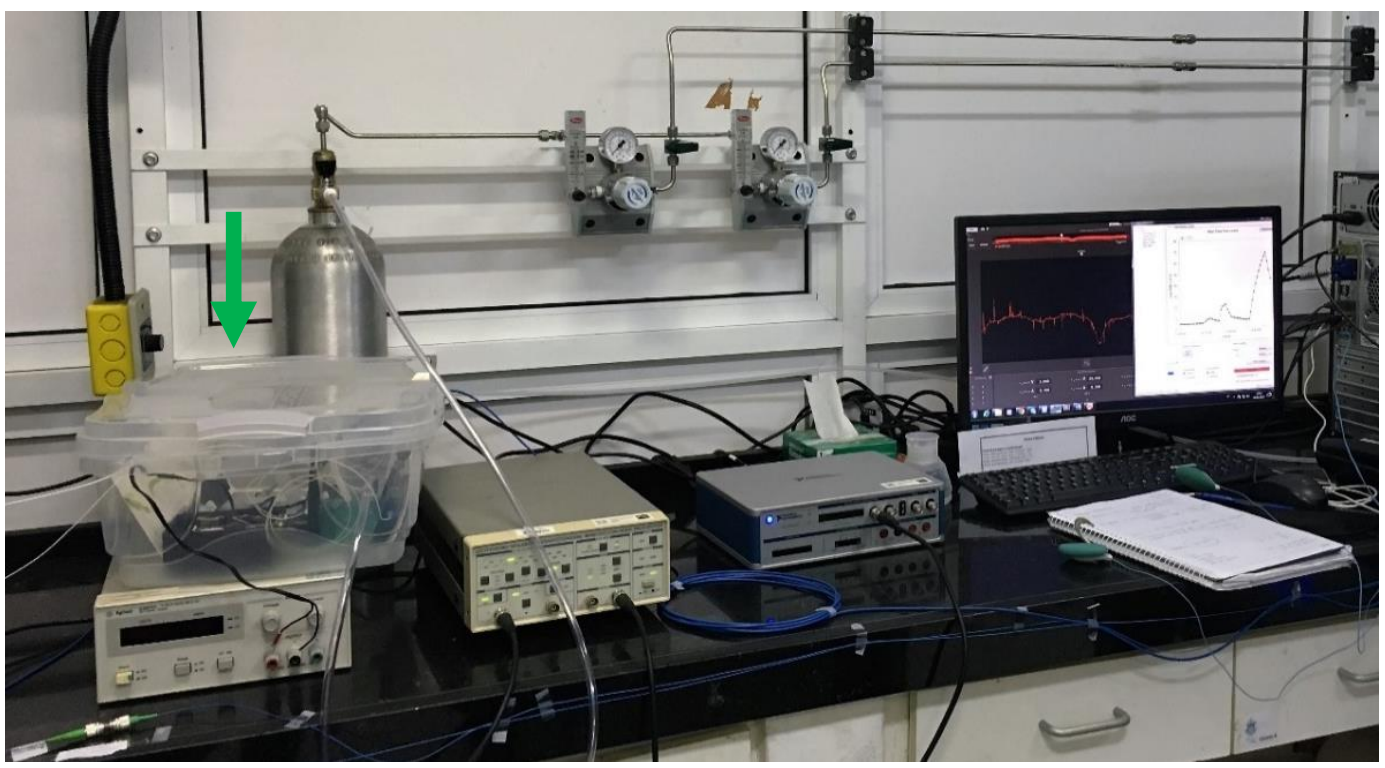

Figura 54 - Bancada de teste do sistema de detecção de $\mathrm{CO}_{2}$ montado no LSFO.

O teste com a FBG foi refeito com o sistema a motor. A linha se deslocando é apresentada na Figura 55 a seguir. Novamente o sinal teve que ser atenuado por limitação do OSA, mas o resultado similar esperado foi obtido. Isso mostra que ambos sistemas são eficientes, porém, do ponto de vista experimental, o segundo torna-se mais prático por ser automatizado. Para o comprimento de onda em $1955 \mathrm{~nm}$, a distância entre os picos antes e após o deslocamento (giro do disco causando subida e descida da régua onde está colada a FBG) é na ordem de $1 \mathrm{~nm}$. 
Figura 55 - Deslocamento do comprimento de onda a partir da deformação causada na FBG.

Nessa segunda etapa, o OSA é substituído pelo sistema de aquisição elétrico formado pelo conjunto: fotodetector para conversão óptica-elétrica, filtro elétrico e módulo de aquisição de dados osciloscópio. O resultado obtido é mostrado no gráfico adquirido na Figura 56 que segue abaixo.

O sinal inicial medido, em preto, trata-se do sistema antes da inserção das células de gás. O nível do sinal está em 1,85 V, para o sinal de entrada $-24 \mathrm{dBm}$ antes da conversão óptica-elétrica. É importante comentar que a mesma atenuação aplicada na entrada do OSA teve que ser repetida no fotodetector, também por limitações tanto do dispositivo como do filtro de sinal.

A linha em azul mostra o resultado obtido quando a célula padrão com $33 \%$ de $\mathrm{CO}_{2}$ é inserida no sistema. A diminuição do nível de tensão de $1,85 \mathrm{~V}$ para $1 \mathrm{~V}$ é devido à perda de inserção destas. Os vales indicados pelas setinhas em vermelho indicam os pontos onde a rede passa pelas linhas de absorção do gás e há absorção do sinal óptico. Considerando o nível médio sem atenuação em 1 V, podese observar que a atenuação é de pouco mais de $300 \mathrm{mV}$. 


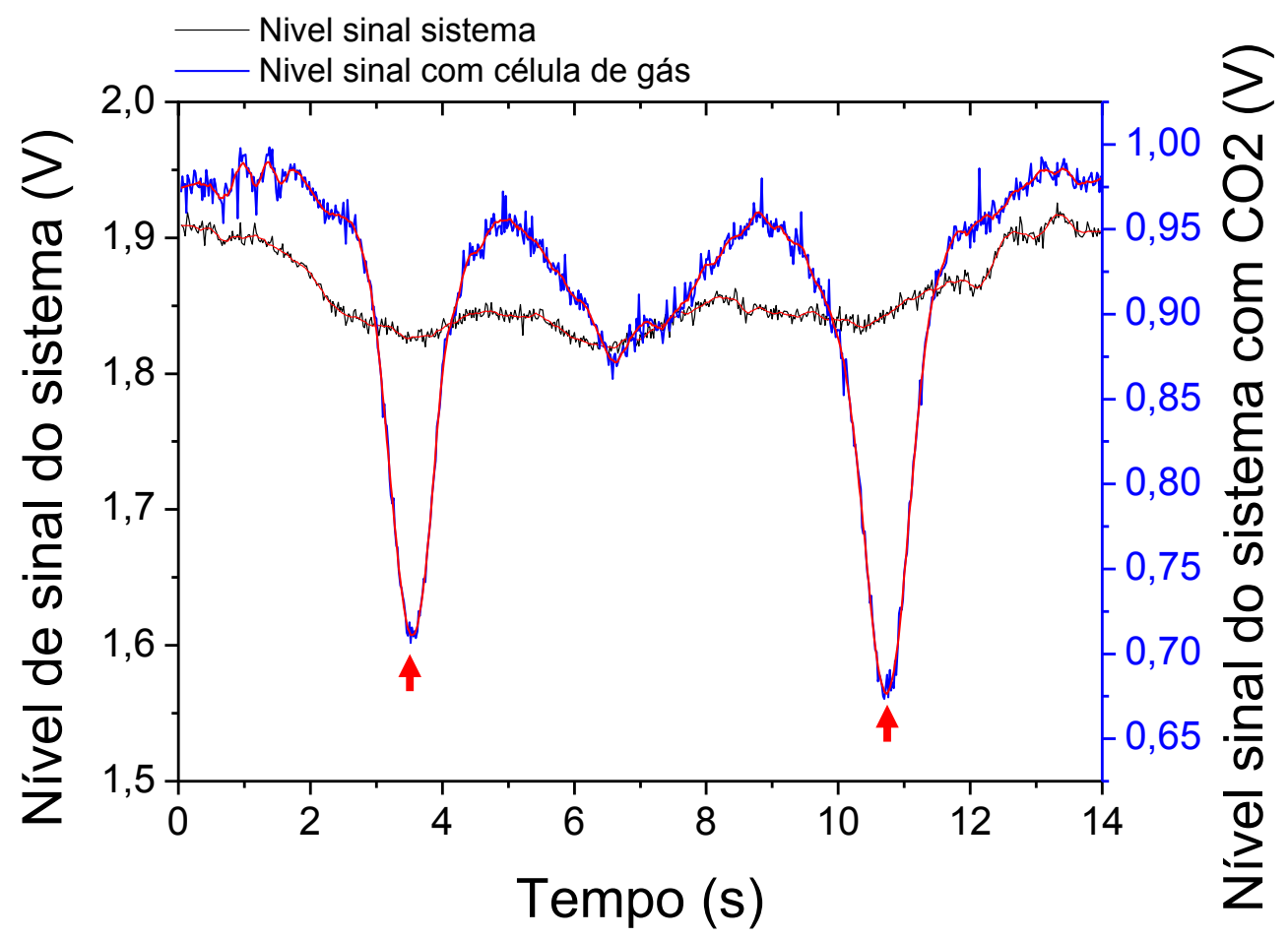

Figura 56 - Resultados obtidos com osciloscópio. Os vales na curva em azul indicam os pontos em que a FBG passou pelas linhas de absorção de $\mathrm{CO}_{2}$.Para o instante em $7 \mathrm{~s}, \lambda$ $=1955 \mathrm{~nm}, \Delta \lambda=2 \mathrm{~nm}$.

O sinal do sistema sem a célula de gás foi plotado com 16 médias, enquanto que com a célula inserida foi plotado com 8 médias. A média móvel (linha indicada em vermelho) foi plotado com aplicação de 20 médias.

O resultado obtido mostra a sensibilidade do sistema para a detecção das linhas de absorção do gás $\mathrm{CO}_{2}$. Caso a FBG fosse construída para outro comprimento de onda correspondente a linha de absorção de outros gases, a detecção seria possível dentro dos parâmetros do sistema.

\subsection{Comentários e conclusões do Capítulo}

No início do presente Capítulo são apresentadas simulações de fibras ópticas padrão SMF-28 realizadas considerando os coeficientes de atenuação e também simulações baseadas em fibras ópticas multimodos sem casca utilizando 
núcleos com vários diâmetros e fatores de absorção. Os resultados obtidos permitem avaliar o comportamento destas estruturas como sensores. Adicionalmente, o comportamento destas fibras é avaliado associadas ao índice de refração da água e do ar. Apesar de experimentalmente não ter sido possível observar a interação luz propagante e gás, a análise dos resultados permite destacar a possibilidade de aplicar tais fibras em sensoriamento distribuído de gases, apresentando diferentes coeficientes de absorção ambiente para camadas micrométricas em alta concentração do gás em estudo.

As células ópticas de $\mathrm{CO}_{2}$ utilizadas como um elemento sensor de gás podem ser substituídos por outros sensores ópticos. Um dispositivo com esta finalidade pode ser obtido a partir da fibra óptica microestruturada HC-2000, vez que este dispositivo apresentou, conforme descrito, resultados com elevada interação entre o gás e o sinal propagante. Deve ser destacado que, apesar da verificação da injeção de $\mathrm{CO}_{2}$ com o sinal propagante na fibra $\mathrm{HC}-2000$, não foi possível alterar a concentração deste gás, isto é, não foi possível obter-se a sensibilidade da fibra micro estruturada em função do percentual de $\mathrm{CO}_{2}$.

Um segundo protótipo inicial começou a ser desenvolvido e está em etapa de concretização. A fonte óptica a ser aplicada neste caso é a ASE em 2000 $\mathrm{nm}$.

O sistema de interrogação baseado no laser em anel apresentou resultados satisfatórios quando associado a medições utilizando células de gás, conforme esperado. Este mesmo sistema cuja FBG apresenta comprimento de onda em $1950 \mathrm{~nm}$ pode ser reproduzido para outros comprimentos de onda, possibilitando assim a detecção de outros tipos de gases de acordo com as especificações do projeto em desenvolvimento. Os experimentos deste Capítulo, destacando a utilização da fibra micro estruturada HC-2000, constituem as principais contribuições praticas do presente trabalho. 


\section{Ampliação da sensibilidade na detecção de gases}

De acordo com objetivos iniciais descritos, no presente Capítulo são apresentados modelos de detecção simplificados desenvolvidos para finalidade de testar a sensibilidade destes sistemas a variações do nível de potência óptica que pode significar a presença de gás no ambiente. A ideia de um sistema de detecção de variações extremamente reduzidas do índice de refração devido a presença de algum gás utilizando cavidades de Fabry-Perot é ilustrada e descrita.

\subsection{Sensores utilizando detecção simplificada de intensidade}

Um método de detecção óptica simplificado pode ser descrito inicialmente utilizando um trecho de fibra óptica, um laser semicondutor operando em um determinado comprimento de onda $\left(\lambda_{s}\right)$ e um fotodiodo. A responsividade desse dispositivo é definida como: $\mathrm{R}=\frac{\eta \mathrm{q}}{\mathrm{h} v}$, sendo os termos $\eta$ a eficiência quântica do fotodetector, $\mathrm{h} v$ a energia do fóton incidente (Joules) e q a carga o elétron $\left(1,60217657 \times 10^{-19}\right.$ Coulombs). Este esquema está configurado segundo a Figura 57 indicada abaixo, onde a corrente verificada no fotodetector é indicada pela equação: $\mathrm{I}_{\mathrm{pd}}=$ R.P. $\mathrm{P}_{\mathrm{s}}$.

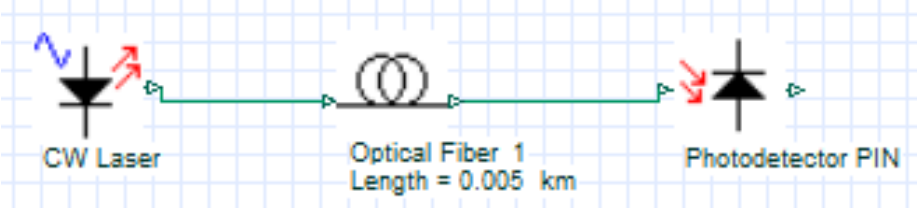

Figura 57 - Sistema simples de uma fonte laser operando em um determinado $\lambda$ s entregando uma potência Ps para um fotodetector.

Caso um sensor seja introduzido em série com a fibra, qualquer variação de potência óptica associada ao sensor resultará em: $\Delta \mathrm{I}_{\mathrm{pd}}=\mathrm{R} \cdot \Delta \mathrm{P}_{\mathrm{s}}$. 
Usualmente, muitas medições utilizam uma fonte óptica e um detector de envoltória [41]. Este procedimento pode ser associado a técnica de modulação em intensidade e detecção direta (IMDD: intensity modulation direct detection) [16]. Essa técnica é muito sensível aos ruídos e quando operada corretamente apresenta uma variação reduzida do sinal recebido.

Uma primeira alternativa interessante consiste na modulação da fonte óptica com uma portadora de RF. Nesta situação, a variação do sinal é multiplicada pelo dobro e o nível de ruído do sinal medido é reduzido de forma significativa.

Um método adicional é a utilização da técnica de detecção coerente, que envolve a utilização de um oscilador local óptico e o batimento do sinal que está sendo avaliado com este oscilador, utilizando o comportamento não linear de um fotodetector. Para a utilização deste método na detecção de gases, a fonte óptica deve ser dividida por duas vias: uma das vias utiliza modulação em RF e a outra conduz o sinal óptico sem modulação. Os dois sinais são combinados em um fotodiodo. O comportamento não linear deste fotodiodo permite que o sinal a ser medido seja amplificado em muitas vezes.

O arranjo indicado na Figura 58 ilustra este comportamento.

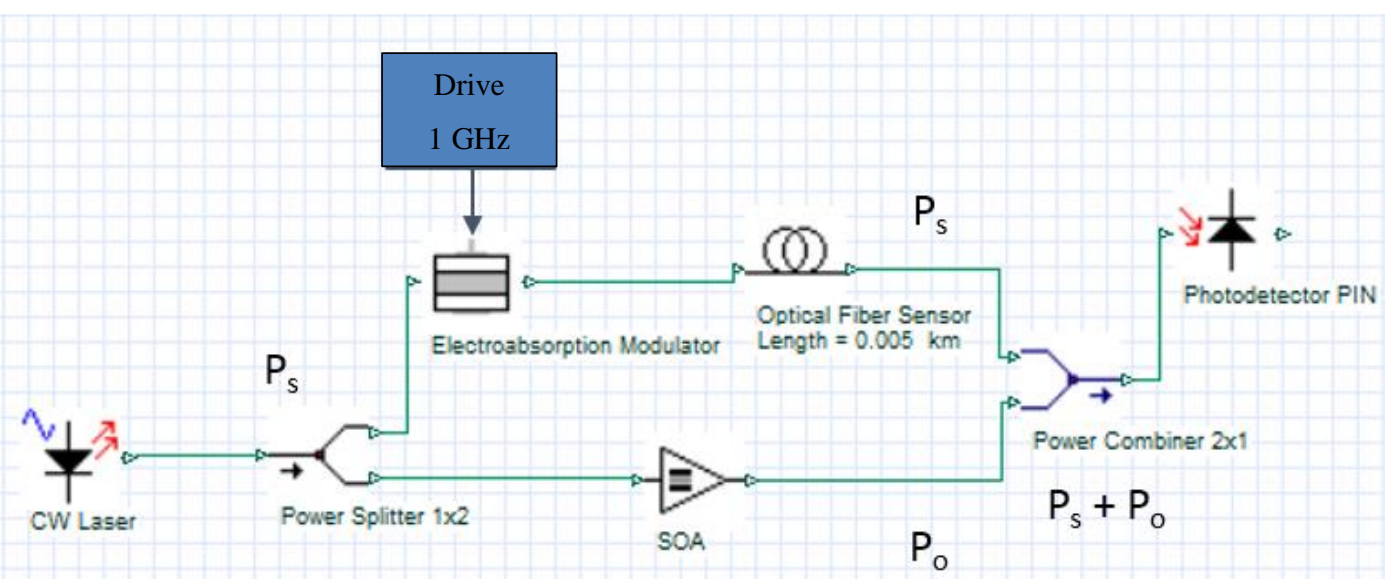

Figura 58 - Sistema sensor utilizando detecção coerente e modulação.

Em uma das saídas do divisor óptico é adicionado um sensor e um modulador de eletroabsorção excitado por um sinal de $1 \mathrm{GHz}$. Na outra saída é adicionado um amplificador tipo SOA (semiconductor optical amplifier). Obtêmse então os sinais $\mathrm{P}_{\mathrm{s}}$ e $\mathrm{P}_{\mathrm{o}}$ adicionados através de um combinador óptico e entregues 
a um fotodetector. Devido à amplificação proporcionada pelo $\mathrm{SOA}, \mathrm{P}_{\mathrm{o}} \gg \mathrm{P}_{\mathrm{s}}$. $\mathrm{O}$ fotodetector é então excitado por dois campos de intensidade óptica $E_{s}$ e $E_{o}$, expressos por (16):

$$
E_{s}=A_{s} e^{-j\left(\omega_{s} t+\phi_{s}\right)} e \quad E_{o}=A_{o} e^{-j\left(\omega_{o} t+\phi_{o}\right)}
$$

Entretanto, a resposta de um fotodetector a sinais de intensidade óptica $E_{s}$ e $E_{o}$ pode ser expressa como: $P=c\left|E_{s}+E_{o}\right|^{2}=c\left|A_{s}^{2}+A_{o}^{2}\right|$, sendo $c$ uma constante, e ainda: $c A_{\mathrm{s}}^{2}=\mathrm{P}_{\mathrm{s}}, \mathrm{cA}_{\mathrm{o}}^{2}=\mathrm{P}_{\mathrm{o}}$. Consequentemente, a potência óptica resultante é dada por (17):

$$
\mathrm{P}(\mathrm{t})=\mathrm{P}_{\mathrm{s}}+\mathrm{P}_{\mathrm{o}}+2 \sqrt{\mathrm{P}_{\mathrm{s}} \mathrm{P}_{\mathrm{o}}} \cos \left[\phi_{\mathrm{s}}-\phi_{\mathrm{o}}\right]
$$

A Figura 58 indica que as potências $\mathrm{P}_{\mathrm{s}}$ e $\mathrm{P}_{\mathrm{o}}$ possuem o mesmo comprimento de onda (frequência óptica). A diferença de fase pode ser ajustada para zero. O ramo óptico associado a Ps possui um modulador óptico de eletroabsorção modulado em $1 \mathrm{GHz}$.

A corrente do fotodetector é então dada por (18):

$$
\mathrm{I}(\mathrm{t})=\mathrm{R}\left[\left(\mathrm{P}_{\mathrm{s}}+\mathrm{P}_{\mathrm{o}}\right)+2 \sqrt{\mathrm{P}_{\mathrm{s}} \mathrm{P}_{\mathrm{o}}}\right]
$$

Onde o termo: $\mathrm{R}\left(\mathrm{P}_{\mathrm{s}}+\mathrm{P}_{\mathrm{o}}\right) \approx \mathrm{P}_{\mathrm{o}}>\mathrm{P}_{\mathrm{s}}$, com $\mathrm{R} \approx 1$

Um capacitor na saída do fotodetector bloqueia o termo soma $\left(\mathrm{P}_{\mathrm{s}}+\right.$ $\mathrm{P}_{\mathrm{o}}$ ) da equação (18) e a resposta $\mathrm{I}(\mathrm{t})$ é então expressa por: $\mathrm{I}(\mathrm{t})=2 \mathrm{R} \sqrt{\mathrm{P}_{\mathrm{s}} \mathrm{P}_{\mathrm{o}}}$. Verifica-se então que a potência $\mathrm{P}_{\mathrm{s}}$ associada so sensor, está multiplicada por $\mathrm{P}_{\mathrm{o}}$. Caso um amplificador EDFA (erbium doped fibre amplifier) com ganho de $20 \mathrm{~dB}$ seja utilizado, obtém-se que: $\mathrm{I}(\mathrm{t})=2 \mathrm{R} \sqrt{100 \mathrm{P}_{\mathrm{s}}}$. Consequentemente, a potência elétrica associada a $\mathrm{I}(\mathrm{t})$ é expressa por: $\mathrm{P}(\mathrm{t})=\mathrm{R}_{\mathrm{L}} \mathrm{I}^{2}(\mathrm{t})=\mathrm{R}_{\mathrm{L}}\left(4 \mathrm{R}^{2} 100 \mathrm{P}_{\mathrm{S}}\right)$, isto é, uma variação $\Delta \mathrm{P}_{\mathrm{S}}$ provocada por qualquer material que esteja sendo testado (DUT) está associada a uma variação de potência multiplicada por 100. Desta forma, 
qualquer variação produzida pelo sensor $\left(\Delta \mathrm{P}_{\mathrm{s}}\right)$ pode ser facilmente verificada quando a configuração da Figura 58 é utilizada.

Esta técnica foi testada em laboratório segundo a montagem apresentada na Figura 59. O aparato para prova de conceito foi desenvolvido no Laboratório GSOM/CETUC/PUC-Rio (Grupo de Sistemas Ópticos e Microondas do Centro de Estudos em Telecomunicações da PUC-Rio). Possui os seguintes elementos para a realização dos testes: um gerador de sinais (modelo HP 83752B 0,01 - $20 \mathrm{GHz}$ ) que fornece a frequência de RF para o modulador; um laser com comprimento de onda em $1550 \mathrm{~nm}$ como fonte de luz; atenuador óptico (a ser substituído pelo sensor de gás); um módulo HP 83420A Lightwave test set conjunto este que possui modulador e conversor óptico elétrico; analisador de espectro elétrico manual N9344C.

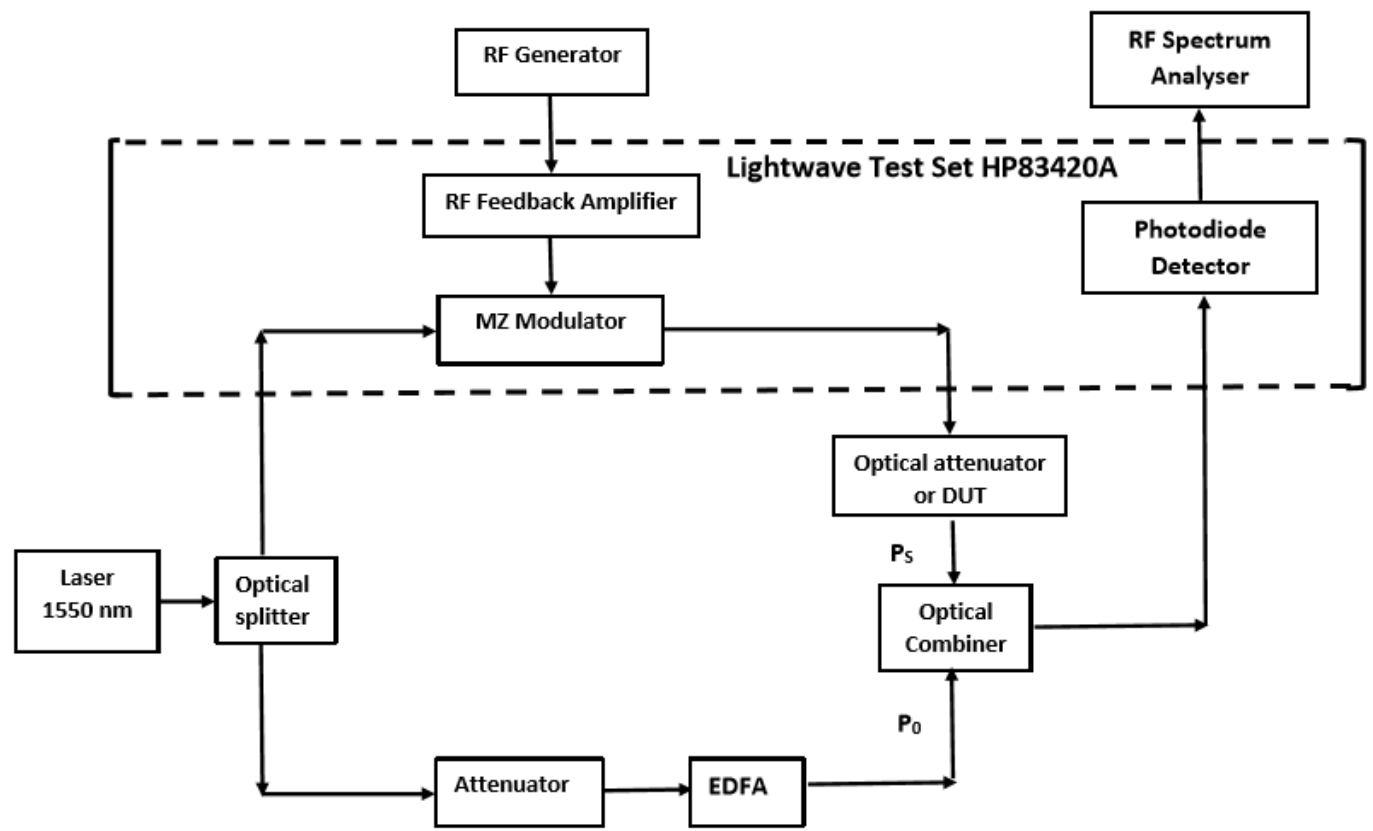




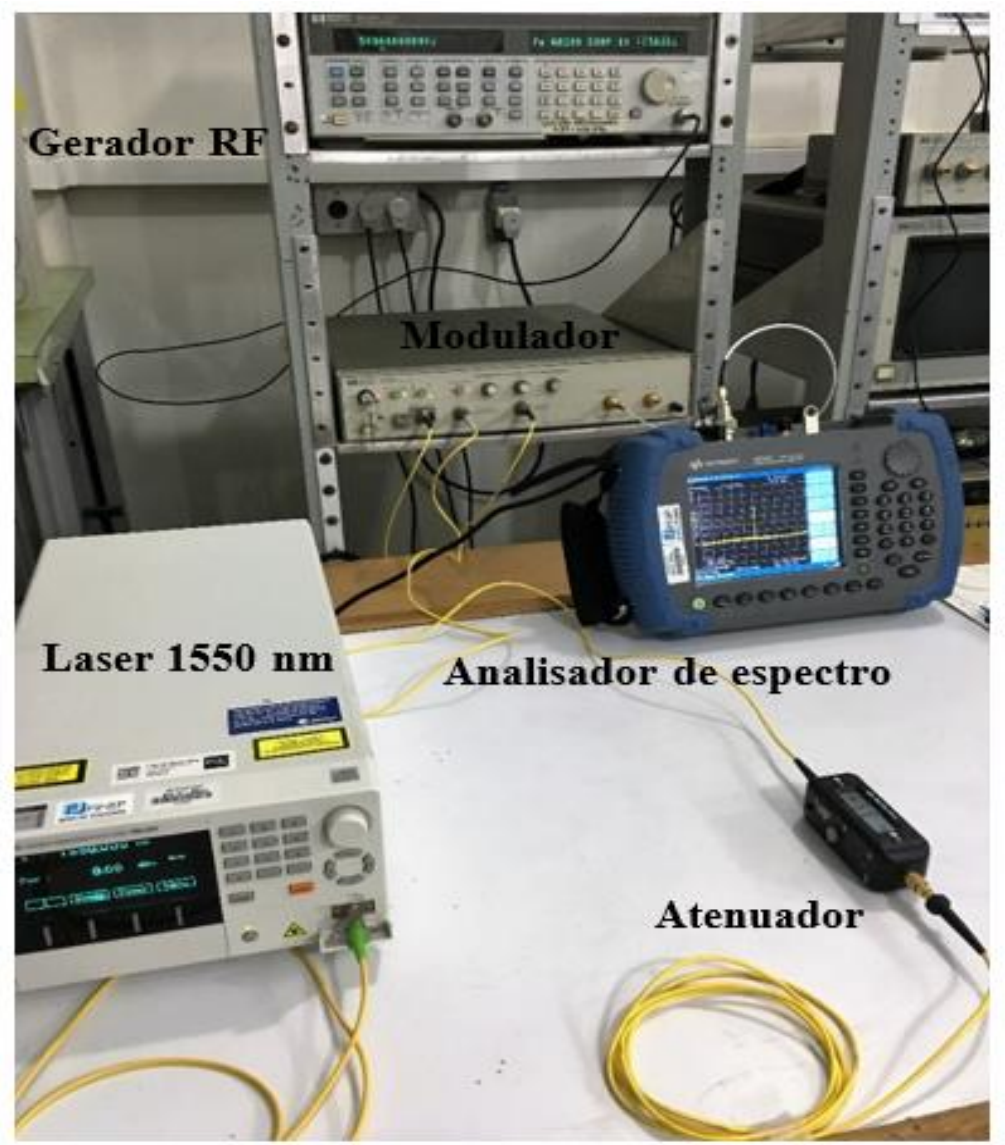

Figura 59 - Diagrama em bloco do sistema de de detecção coerente homodina e foto da montagem.

$\mathrm{O}$ atenuador óptico (atuando como DUT - device under test) é inserido no sistema para ativar as variações de potência similares às produzidas por um sensor de gás. O sinal de um laser operando em $1550 \mathrm{~nm}$ é dividido por um "splitter" passivo. O sinal de uma das saídas deste dispositivo é entregue a um trecho em fibra monomodo contendo um atenuador, um EDFA formando o sinal óptico $\mathrm{P}_{\mathrm{o}}$ que excita a entrada de um combinador óptico.

O sinal da outra saída do divisor é entregue ao módulo HP 83420A e excita o modulador Mach-Zender contido no interior deste. Um sinal externo de RF é introduzido na porta elétrica deste módulo. Este sinal é amplificado e ativa o modulador Mach-Zhender. O sinal óptico modulado em intensidade é conectado a uma porta de saída deste módulo. Em seguida, este sinal é conectado a um trecho de fibra monomodo contendo um atenuador ou um dispositivo sensor de gás, formando na saída destes o sinal $\mathrm{P}_{\mathrm{S}}$. Os sinais $\mathrm{P}_{\mathrm{o}}$ e $\mathrm{P}_{\mathrm{S}}$ são conectados às portas de 
um combinador óptico. O sinal combinado é entregue a um fotodetector. Através de efeitos não lineares descritos pela relação $\mathrm{P}=\mathrm{c}|\mathrm{Es}+\mathrm{Eo}|^{2}$ produzidos pelo fotodetector, o sinal de RF é recuperado ampliado pelo ganho do amplificador óptico. Quando o nível de potência do atenuador óptico é alterado, verifica-se então que para cada $1 \mathrm{~dB}$ desta variação, o sinal monitorado apresenta uma variação de pelo menos 2 a $3 \mathrm{~dB}$ de potência elétrica - observada via o analisador de espectro elétrico N9344C. Logo, uma variação de 5 dB óptica equivale a no mínimo $10 \mathrm{~dB}$ elétrica. Um dos resultados obtidos é apresentado a seguir na Figura 60. Entretanto, destaca-se que em alguns casos foram obtidas para os mesmos $10 \mathrm{~dB}$ cerca de 40 dB.

Nos equipamentos que constituem o esquema montado e medido foram selecionados os seguintes parâmetros:

- Gerador de RF em 1 GHz e -20 dBm

- Laser de comprimento de onda $1550 \mathrm{~nm}$ e $0 \mathrm{dBm}$

- Atenuador óptico com variação de até $20 \mathrm{~dB}$

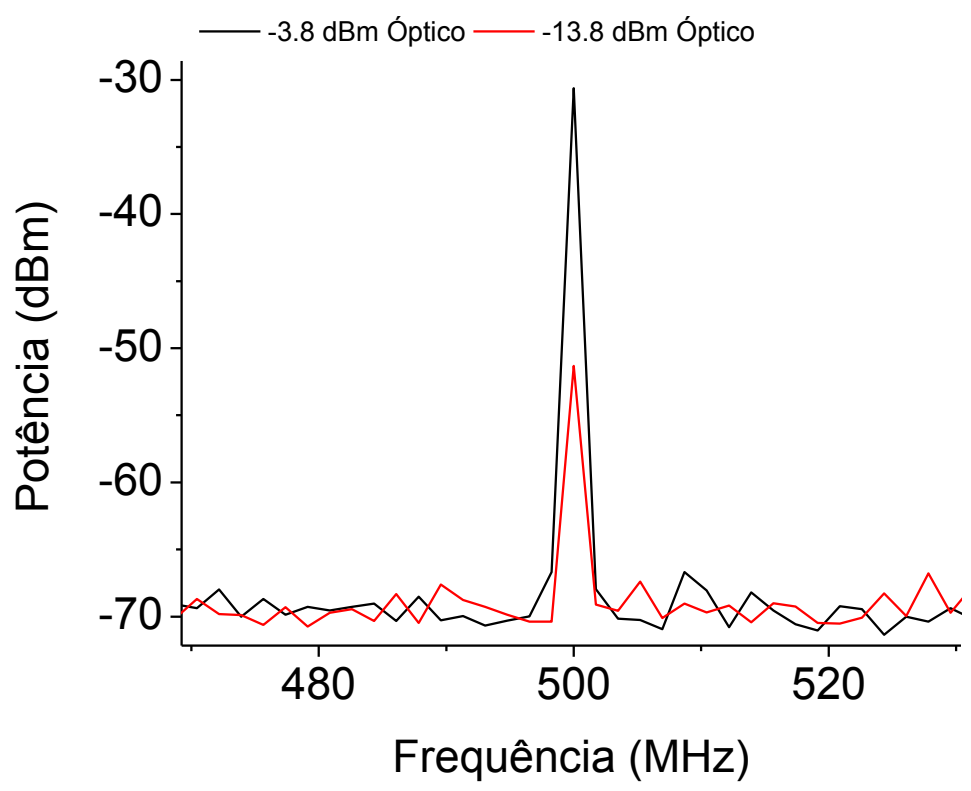

Figura 60 - Potência elétrica associada às potências ópticas de $-3,8$ e $-13,8 \mathrm{dBm}$ (modulado em $500 \mathrm{MHz}$ ). 
Medidas subsequentes foram realizadas aumentando a potência óptica durante a realização do experimento. Os resultados obtidos podem ser melhor observados na Figura 61 abaixo.

Os componentes e dispositivos utilizados não permitiram o controle dos níveis de potência óptica na entrada do modulador Mach-Zender e também dos níveis de RF na entrada elétrica deste modulador. Desta forma, o EDFA utilizado não pôde ser ajustado para produzir o máximo ganho desejado.

Nas medições, foram obtidas variações de até $20 \mathrm{~dB}$ na saída elétrica, para variações iniciais de potência óptica em torno de $5 \mathrm{~dB}$. Entretanto, o sinal elétrico analisado apresentou-se instável. Esta instabilidade verificada pode ser associada ao termo $\left[\cos \left(\phi_{\mathrm{s}}-\phi_{\mathrm{o}}\right)\right]$ mostrado na (17). Para correção desta limitação, seria necessário substituir o fotodetector indicado no diagrama da Figura 59 por um receptor óptico com recuperação de sincronismo. Um outro procedimento alternativo poderia ser a utilização de ferramentas de processamento de sinais na saída do fotodetector.

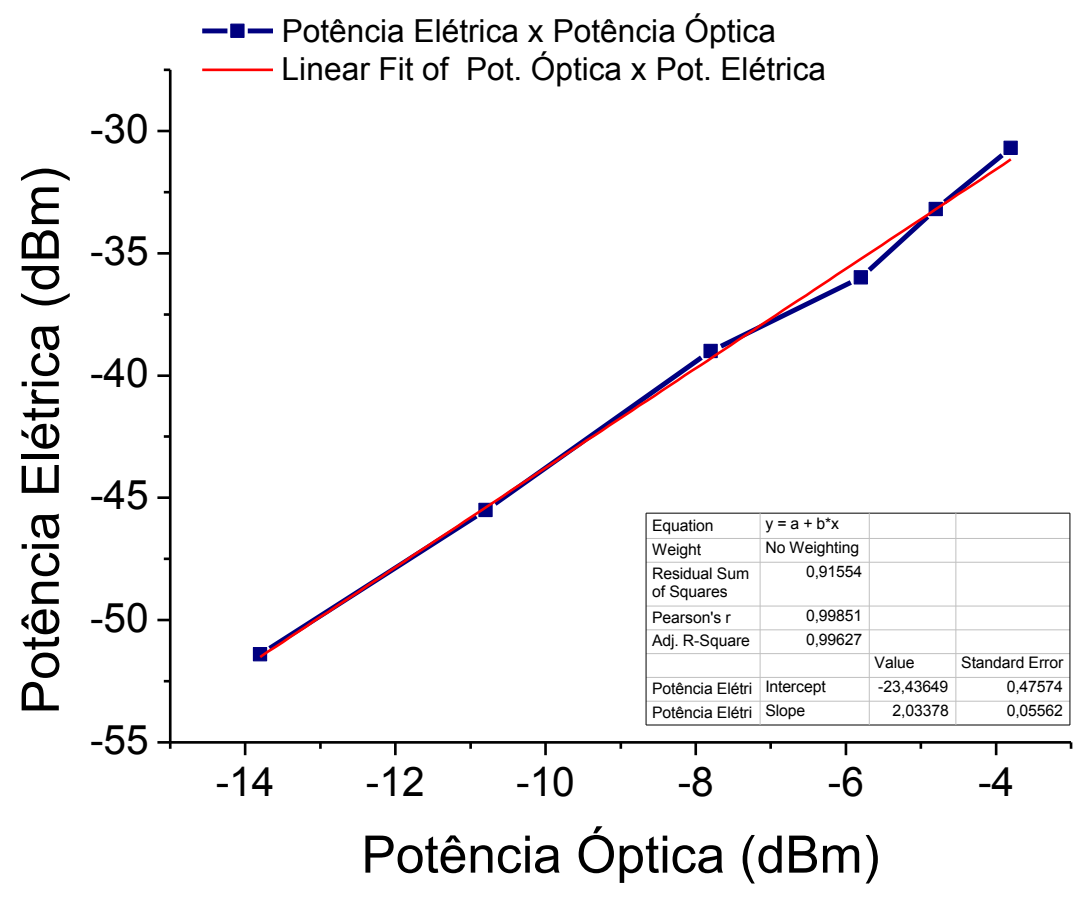

Figura 61 - Gráfico demonstrativo da relação de aumento da potência elétrica em $5 \mathrm{~dB}$ para cada $2 \mathrm{~dB}$ óptico.

O gráfico acima permite concluir que para uma variação de $10 \mathrm{~dB}$ óptica, tem-se uma sensibilidade de pelo menos $20 \mathrm{~dB}$ elétrico no sistema 
desenvolvido. Esse resultado ilustra o conceito descrito acima, e ainda mostra a possibilidade da construção de um sistema de detecção a partir da aplicação de um sistema de RF com modulação de um sistema óptico. Quando ocorrer atenuação (ou absorção do sinal óptico por linhas de gás no comprimento de onda de transmissão), as pequenas variações ocorrentes nos níveis de potência óptica podem ser detectados ampliadas na saída elétrica do sistema.

O analisador de espectro utilizado para observar os resultados pode ser substituído por um sistema de detecção que indique o valor medido em volts.

Caso o atenuador óptico aplicado seja substituído por uma célula óptica de gás como elemento sensor, a absorção da luz pelo gás pode ser identificada de modo análogo à atenuação do dispositivo.

No conjunto desenvolvido, o laser utilizado tem comprimento de onda $1550 \mathrm{~nm}$. Os equipamentos, dispositivos e fibras ópticas disponíveis para a montagem proposta e desenvolvida são de aplicação em sistemas de telecomunicações, cujos comprimentos de onda de operação são na ordem de 1310 e $1550 \mathrm{~nm}$. Portanto, utilizando gases cujas absorções sejam nessas linhas, torna-se possível detectar gás a partir do sistema óptico com modulação em RF realizado e aqui apresentado.

$\mathrm{O}$ acetileno $\left(\mathrm{C}_{2} \mathrm{H}_{2}\right)$ é um gás que apresenta linhas de absorção molecular na banda de 1510 a $1540 \mathrm{~nm}$. Um exemplo de uma célula óptica de referência deste gás conectorizada por fibra é mostrado na Figura 62 (este dispositivo está melhor detalhado no Capítulo 3). Em (a) está o dispositivo que possui com comprimento físico de $5,5 \mathrm{~cm}$, perda de inserção de 1 a $3 \mathrm{~dB}$, e em (b) o gráfico de transmitância desta quando há absorção de luz.

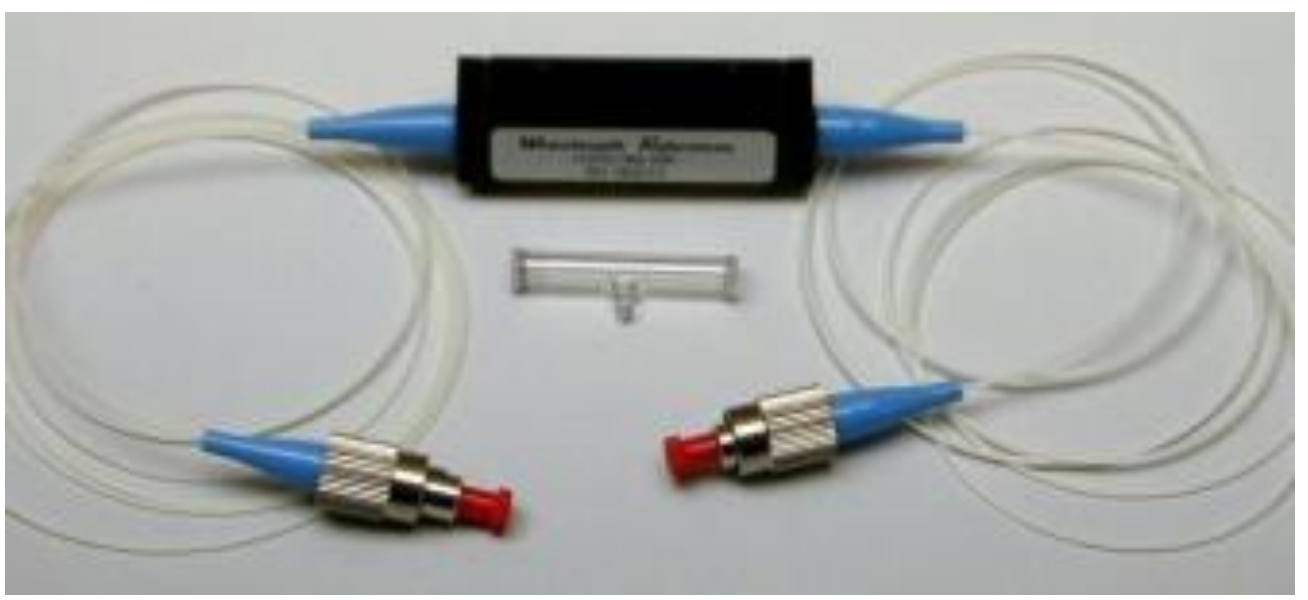




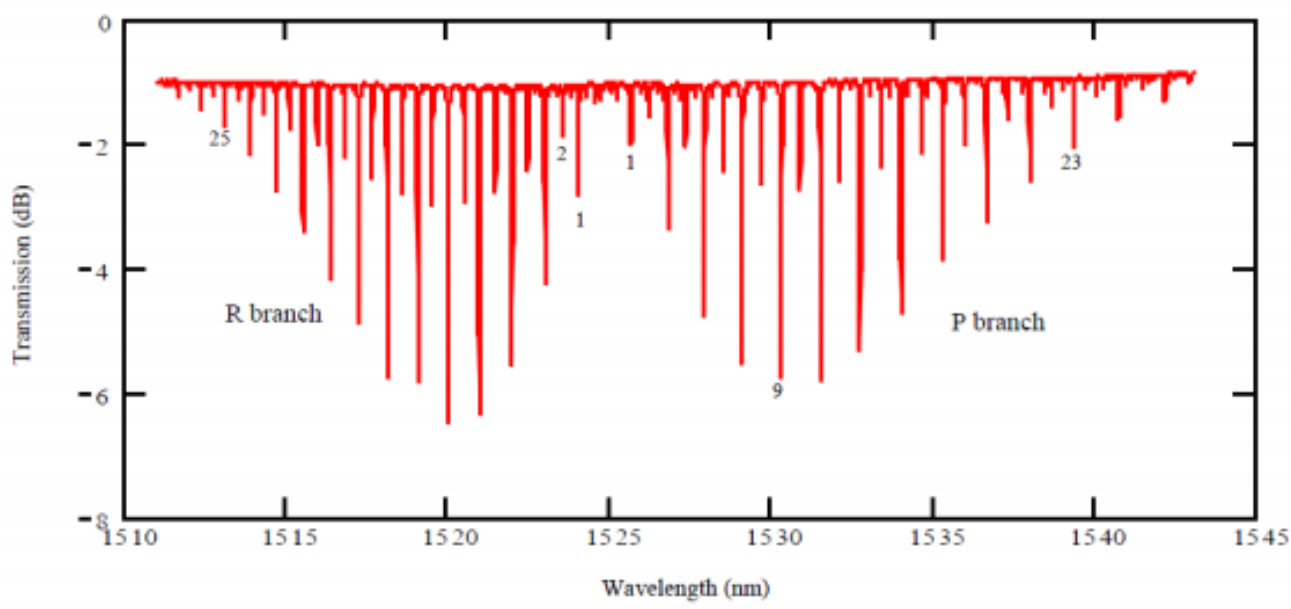

(b)

Figura 62 - Célula de referência de $\mathrm{C}_{2} \mathrm{H}_{2}$ : (a) Imagem do dispositivo, (b) espectro de transmissão - linhas de absorção em função do comprimento de onda.

Caso os elementos do sistema sejam substituídos por dispositivos que apresentam operação na janela de um comprimento de onda distinto, torna-se possível realizar a detecção de outros gases.

As linhas de absorção dos gases podem ser verificadas tendo como referência um analisador de espectro óptico (OSA - THORLABS 203B 1000 $2600 \mathrm{~nm}$ ). Este equipamento usa a base de dados do Hitran (HIgh resolution TRANSmission molecular absorption database), que foi originalmente criada para simulações e análise de observações na atmosfera terrestre. Assim, pode ser feita comparação entre o resultado medido e o espectro correspondente a partir dos parâmetros inseridos: percentual de concentração de gás, pressão atmosférica, região do espectro, comprimento do caminho óptico, resolução.

Como exemplo deste comentário, a Figura 63 a seguir apresenta o gráfico de transmitância de uma célula de gás com caminho óptico de comprimento $78 \mathrm{~cm}$, contendo a concentração de $0.1 \%$ (1000 ppm) para os gases dióxido de carbono $\left(\mathrm{CO}_{2}\right)$ e acetileno $\left(\mathrm{C}_{2} \mathrm{H}_{2}\right)$. 


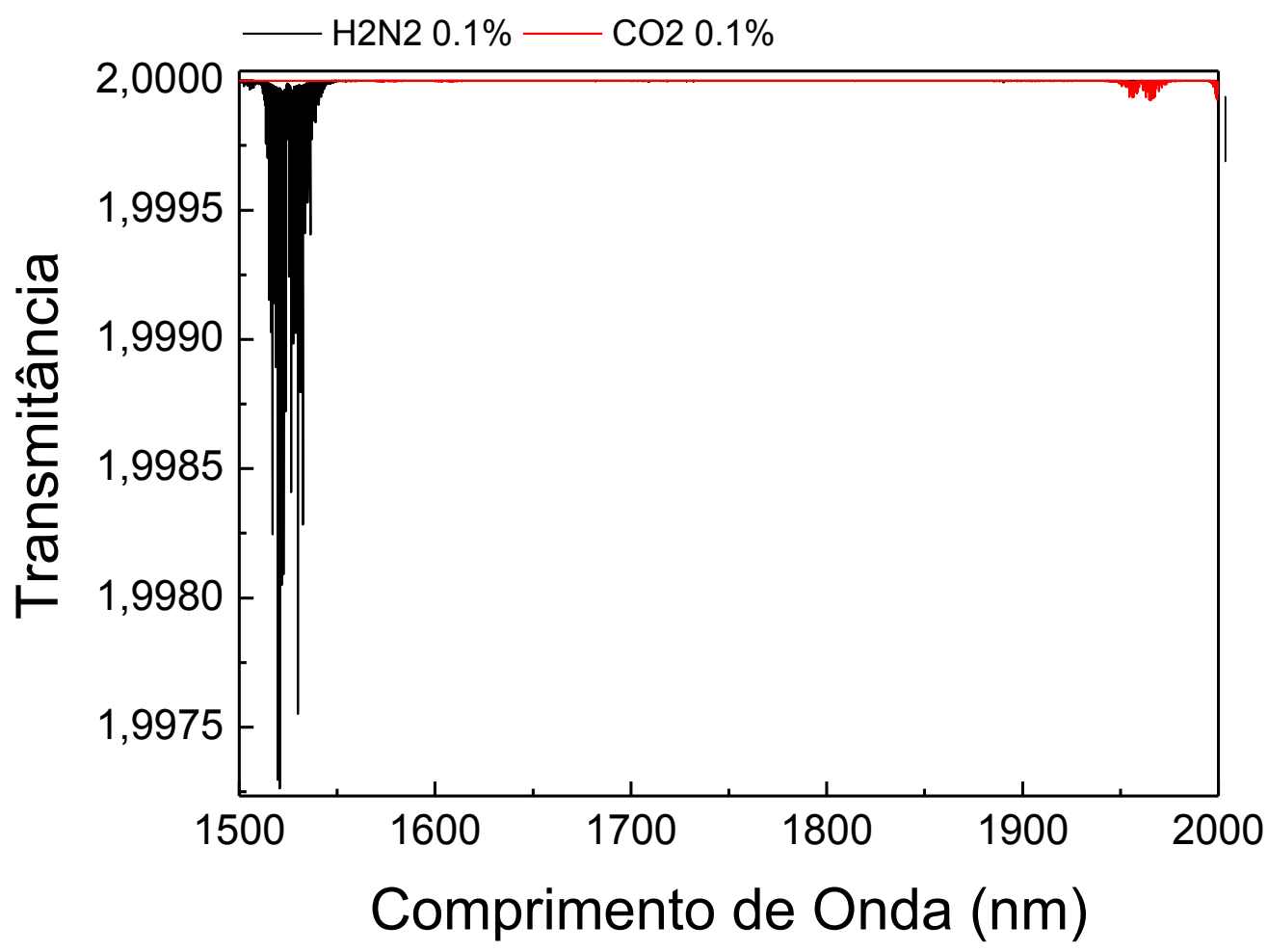

Figura 63 - Gráfico da transmitância dos gases $\mathrm{C}_{2} \mathrm{H}_{2}$ e $\mathrm{CO}_{2}$ na região de comprimento de onda referente a 1500 a $2000 \mathrm{~nm}$, para um mesmo percentual de concentração igual a $0,1 \%$.

Analisando o gráfico apresentado, é possível observar que para um mesmo percentual de concentração, os gases apresentam diferentes absorções e transmitâncias no espectro; $\mathrm{O} \mathrm{C}_{2} \mathrm{H}_{2}$ mostra maiores linhas de absorção e mais profundas em $1500 \mathrm{~nm}$ enquanto que o $\mathrm{CO}_{2}$ indica absorção na região de $2000 \mathrm{~nm}$. Logo, o $\mathrm{C}_{2} \mathrm{H}_{2}$ é mais simples de identificar que o $\mathrm{CO}_{2}$.

Pode ser observado que a variação da transmitância, mesmo no $\mathrm{C}_{2} \mathrm{H}_{2}$, apresenta-se extremamente reduzida e indica a conveniência de utilização de um sistema capaz de ampliar a sensibilidade de detecção. 


\subsection{Detecção de variações extremamente reduzidas do índice de refração}

A estrutura básica de um oscilador senoidal elétrico em realimentação é descrita pela Figura 64 abaixo, onde A pode representar um elemento de ganho, $\beta$ uma estrutura de realimentação, $V_{i}$ a tensão de ruído na entrada e $V_{o}$ o sinal de saída. A relação $\left(\frac{V_{i}}{V_{o}}\right)$ é expressa por (19):

$$
\frac{\mathrm{V}_{\mathrm{i}}}{\mathrm{V}_{\mathrm{o}}}=\frac{\mathrm{A}}{1-\beta \mathrm{A}}
$$

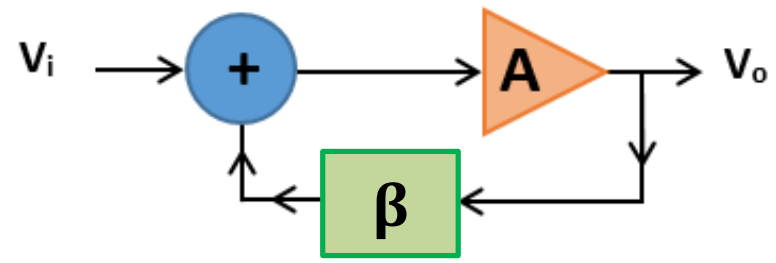

Figura 64 - Configuração básica de um oscilador.

Quando o termo $(1-\beta A)=0$, a malha realimentada pode oscilar. Para tal, a fase da malha deve ser igual a $2 n \pi$, sendo $n=1,2,3, \ldots$. Esta condição é conhecida como critério de Barkhausen.

Um circuito óptico pode ser desenvolvido atendendo o critério de Barkhausen em um determinado comprimento de onda $\lambda_{1}$. Para tal, considere a Figura 65 abaixo:

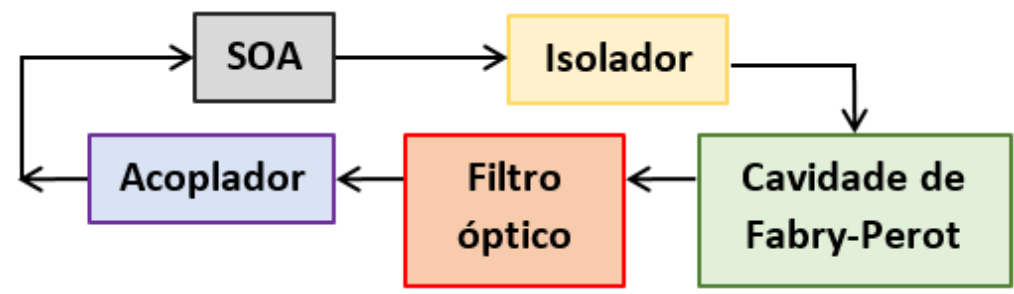

Figura 65 - Malha de realimentação óptica.

A cavidade de Fabry-Perot deve ter o comprimento ajustado para que o oscilador opere em determinado modo no comprimento de onda $\lambda_{1}$. O filtro 
óptico é selecionado para evitar que outros modos da cavidade atuem realimentando a malha. Esta seleção é ilustrada na Figura 66.

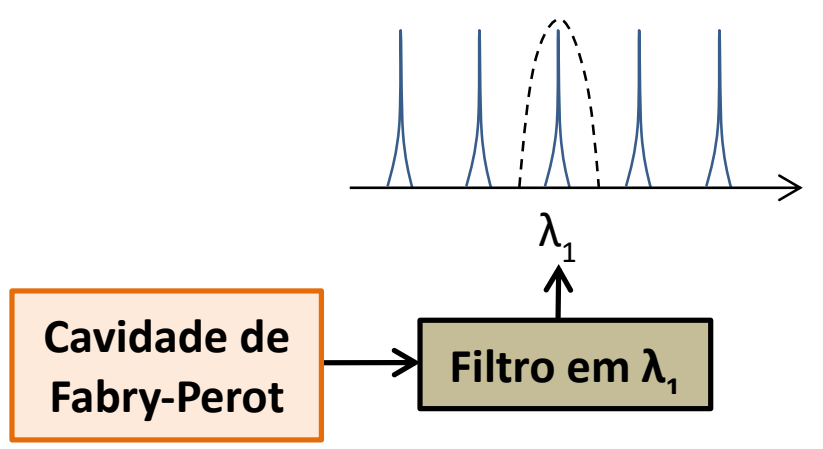

Figura 66 - Associação da cavidade Fabry-Perot com um filtro óptico para selecionar o modo próximo a $\lambda_{1}$.

Como o SOA (Semiconductor Optical Amplifiers) pode amplificar nos dois sentidos, um isolador óptico é utilizado. Desta forma, somente um sentido de circulação será ativado na malha. Ajustando-se a polarização do SOA, o critério de Barkhausen pode ser ativado no comprimento $\lambda_{1}$.

Dois osciladores idênticos podem ser realizados tendo seus sinais adicionados através de um combinador óptico e entregues a um fotodetector. O batimento destes dois sinais pode ser ajustado através das duas polarizações dos seus respectivos SOA para obter-se uma frequência de RF muito reduzida. Cada oscilador realimentado pode apresentar nesta configuração uma largura de linha inferior a $1 \mathrm{MHz}$. A Figura 67 a seguir ilustra o sistema montado.

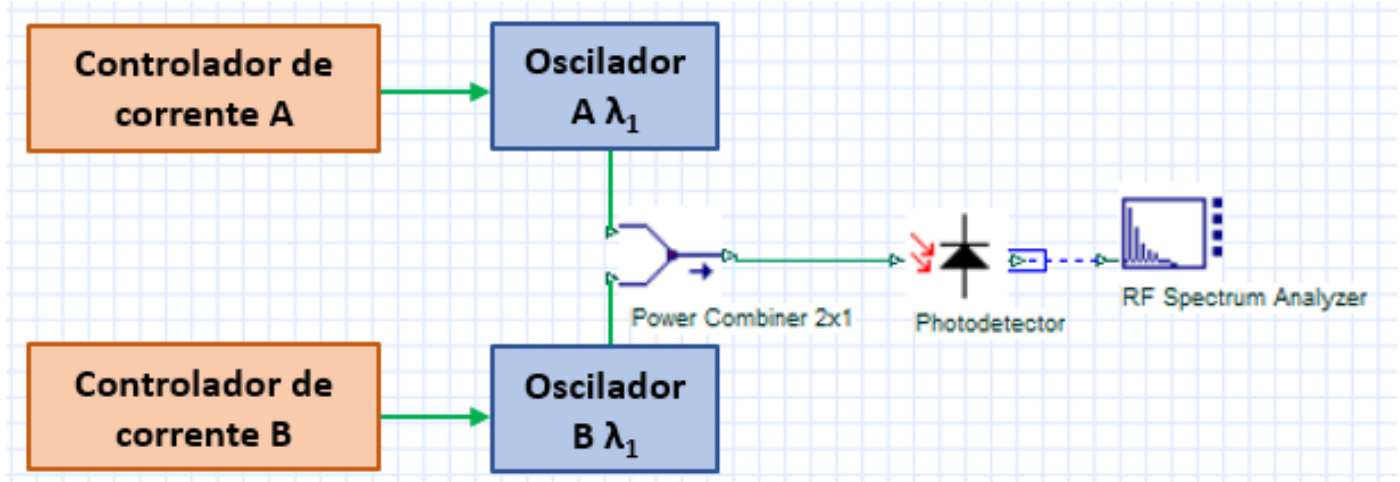

Figura 67 - Sistema para detecção e calibração $\left(\lambda_{1 \mathrm{~A}}-\lambda_{1 \mathrm{~B}} \approx 0\right)$. 
Se for então considerada uma calibração inicial com as cavidades Fabry-Perot no vácuo, obtém-se desta forma: $\lambda_{1 \mathrm{~A}}-\lambda_{1 \mathrm{~B}}<2 \mathrm{MHz}$.

Caso uma das cavidades seja preenchida com um gás que posua uma constante dielétrica $\mathcal{E}=1,00001 \varepsilon_{0}$, de acordo com a teoria, o comprimento de onda $(\lambda)$ de uma onda eletromagnética num meio dielétrico é dado pela expressão (20):

$$
\begin{gathered}
\lambda^{\prime}=\frac{\lambda_{\mathrm{o}}}{\sqrt{\varepsilon_{\mathrm{r}}}}, \text { sendo } \varepsilon_{\mathrm{r}}=\frac{\varepsilon}{\varepsilon_{\mathrm{o}}} \\
\text { Logo, em } \lambda_{1}=1550 \mathrm{~nm} \text {, obtém-se: } \\
\lambda_{1}^{\prime}=\frac{\lambda_{1}}{\sqrt{1,00001}}=0,999995 \lambda_{1}=0,999995(1550 \mathrm{~nm})=1549,99225 \mathrm{~nm}
\end{gathered}
$$

Observa-se então que um dos osciladores permanece operando na cavidade com constante igual à do vácuo $\left(\mathcal{E}=\varepsilon_{0}\right)$ e o comprimento de onda de oscilação $\lambda_{1}=1550 \mathrm{~nm}$ correspondente permaneceu inalterado. $O$ segundo oscilador, cuja cavidade foi preenchida com um gás onde $\varepsilon=1,00001 \varepsilon_{0}$ teve o comprimento de onda de oscilação alterado para $\lambda_{1}^{\prime}=1549,99225 \mathrm{~nm}$.

O batimento no fotodetector destes sinais provenientes dos dois osciladores ativa a diferença de frequência: $\lambda_{1}-\lambda_{1}^{\prime}=\Delta \lambda=0,0075 \mathrm{~nm}$ e então $\Delta f=775 \mathrm{MHz}$. Um analisador de espectro elétrico pode indicar esta frequência e o sistema apresentado pode ser calibrado para identificação de gases que apresentem constantes dielétricas muito próximas da constante $\varepsilon_{0}$ do espaço livre com grande precisão.

\subsection{Comentários e conclusões do Capítulo}

As propostas de trabalho demonstradas neste Capítulo comtemplam atividades de pesquisa sobre dois sistemas de medição capazes de ampliar de forma significativa a sensibilidade quando da detecção de gases. $\mathrm{O}$ primeiro sistema, utilizando um procedimento de detecção coerente homodina, caso ajustado corretamente, pode permitir que uma absorção de $1 \mathrm{~dB}$ de um determinado gás 
provoque uma variação do sinal elétrico detectado de $30 \mathrm{~dB}$. O segundo sistema utiliza a realimentação óptica de um SOA através de cavidades de Fabry-Perot na geração de dois sinais ópticos. Variações do índice de refração na quarta ou quinta casas decimais podem ser detectadas, permitindo a identificação de vários gases. $\mathrm{O}$ primeiro sistema foi testado com os dispositivos disponíveis no laboratório do CETUC e, em alguns casos apresentou variações de $5 \mathrm{~dB}$ para cada $1 \mathrm{~dB}$ produzido pelo DUT. O segundo sistema não foi montado devido a não disponibilidade dos dispositivos indicados nas montagens. Deve ser destacado, entretanto que, até o presente, nenhum dos dois sistemas apresentados foram verificados na literatura associada a detecção de gases. Entretanto, fica como sugestão de contribuição para futuros trabalhos que a serem desenvolvidos. 


\section{Comentários finais e conclusões}

$\mathrm{Na}$ introdução da presente tese, fica evidenciada a importância de serem desenvolvidos sistemas de detecção de gases utilizando meios ópticos. Os vários tipos de fibras ópticas foram estudados de acordo com os objetivos propostos. Entretanto, para que estes objetivos propostos fossem atingidos podem ser destacadas as seguintes dificuldades:

Os índices de refração dos gases apresentarem valores muito próximos do espaço livre;

$>$ Quando são separadas as cascas das fibras ópticas, o campo eletromagnético propagante no núcleo tende a ficar mais concentrado nesta região. Esse efeito torna muito difícil a interação deste campo com os diversos gases presentes no ambiente e, no caso em estudo, particularmente com o $\mathrm{CO}_{2}$;

Os comprimentos de onda de absorção dos diversos gases ocorrem muitas vezes em regiões nos quais as fontes ópticas não estão disponíveis. $\mathrm{O} \mathrm{CO}_{2}$ possui absorção óptica próximo a $2000 \mathrm{~nm}$, comprimento de onda associado a fontes óticas de difícil aquisição;

As fibras ópticas microestruturadas, devido ao foco de desenvolvimento para aplicação destas, priorizam a faixa de operação nos comprimentos de onda utilizados em telecomunicações, que corresponde ao range de 750 a $1700 \mathrm{~nm}$. Desta forma, nem sempre apresentam absorção de gases nos comprimentos de onda desejados. As medições que indicavam as linhas de absorção de gases na faixa do $\mathrm{CO}_{2}$ utilizando tais fibras só foram realizadas com êxito quando o sistema foi excitado por uma fonte ASE em $2000 \mathrm{~nm}$;

A maior parcela dos componentes e dispositivos ópticos são dedicados a faixa de operação em telecomunicações. Neste contexto, a seleção e aquisição de componentes e dispositivos na janela de $2000 \mathrm{~nm}$ apresentou-se extremamente difícil e dispendiosa, ocasionando consequentemente em atrasos em várias etapas da presente tese; 
A utilização de um laser em anel operando em $1950 \mathrm{~nm}$ não apresentou resultados positivos na medição da absorção de diversos gases quando da utilização das fibras micro estruturadas mencionadas.

Entretanto, pode-se concluir que os principais resultados obtidos neste trabalho estão abaixo listados:

1. A medição do nível de absorção do $\mathrm{C}_{2} \mathrm{H}_{2}$ foi possível com a aplicação da FOM3 - fibra micro estruturada da ACREO, utilizando um laser em $1550 \mathrm{~nm}$ (resultado apresentado na Figura 35);

2. Os níveis de absorção do $\mathrm{CO}_{2}$ foram medidos utilizando tipos diferentes de células ópticas de gás aplicando diferentes concentrações (dispositivos mostrados na Figura 47);

3. A medição do nível de absorção do $\mathrm{CO}_{2}$ através da fibra óptica microestruturada HC-2000 Thorlabs (resultado apresentado na Figura 38) foi realizada utilizando-se a ASE como fonte óptica;

4. Desenvolvimento de um sistema laser em anel utilizando uma FBG (montagem pode ser vista nas Figura 43 e Figura 53 e resultados na Figura 56);

5. Apresentação de um método capaz de medir a absorção de gases com sensibilidade ampliada utilizando detecção coerente homodina, cujas medidas iniciais realizadas estão apresentadas nas Figuas 60 e 61);

6. Por fim, a sugestão de um método utilizando variações da constante dielétrica dos gases com precisão até a quarta casa decimal (ilustração na Figura 67).

Deve ser observado que os resultados indicados nos itens $1,3,4,5$, e 6 descritos acima não estão reportados na literatura consultada até a presente data. 
- Sugestões de trabalhos futuros:

A partir da primeira medida obtida na Figura 38, concretizar da construção de um sensor de $\mathrm{CO}_{2}$ utilizando a fibra micro estruturada HC-2000 mostrada em Figura 36.

$>$ Montagem de um ambiente de medida utilizando detecção coerente homodina a partir da sincronização dos sinais inseridos no sistema.

Construção de um sensor de $\mathrm{CO}_{2}$ utilizando a diferença entre os índices de refração, segundo o conjunto apresentado em Figura 67.

Avaliação e comparação da sensibilidade em função do percentual de $\mathrm{CO}_{2}$ das técnicas de detecção direta, deteção homodina, espectroscopia de correlação, espectrofotometria, cavity ringdown spectroscopy (CRDS), detecção fotoacústica, e sistemas com fibras microestruturadas. 


\section{Referências bibliográficas}

[1] 2016. [Online]. Available:

http://www.suapesquisa.com/efeitoestufa/gases_do_efeito_estufa.htm

[2] R. Garcia, "Concentração de $\mathrm{CO}_{2}$ sofreu maior aumento anual dos últimos 30 anos," 2014. [Online]. Available:

http://www.publico.pt/ecosfera.

[3] A. M. S. S. M. F. P. K. M. G. L. e. I. M. R. Jr, "Sensores Ópticos com detecção no infravermelho próximo e médio," Química Nova, vol. 32, 2009.

[4] E. C. d. Moraes, "Fundamentos de Sensoriamento Remoto," Instituto Nacional de Pesquisas Espaciais, São José dos Campos, 2002.

[5] "Wikipedia," [Online]. Available: https://en.wiki2.org/wiki/File:MODIS_ATM_solar_irradiance_svg.

[6] "Centro Estadual de Pesquisas em Sensoriamento Remoto e Meteorologia," [Online]. Available:

http://www.ufrgs.br/engcart/PDASR/rem.html. [Acesso em 2016].

[7] "Microsoft," [Online]. Available: https://technet.microsoft.com/ptbr/library/cc756996(v=ws.10).aspx. [Acesso em 2016].

[8] M. F. Moreira, "Desenvolvimento e caracterização de um sistema laser de cristal líquido colestérico acoplado à fibra óptica," Rio de Janeiro, PUC-Rio , 2004.

[9] M. S. d. P. Gomes, "Desenvolvimento de Sensores Ópticos para Monitoramento de $\mathrm{CO}_{2}$," Petrobrás, Rio de Janeiro, 2013.

[10] "JAMES CLERK MAXWELL - Eletromagnetismo e Luz," [Online]. Available:

http://www.ghtc.usp.br/Biografias/Maxwell/Maxwelleletreluz.html. [Acesso em 2016].

[11] J. C. Maxwell, The theory of molecularvortices applied to magnetic phenomena, Phil. Mag. XXIII., 1862. 
[12] P. D. R. L. Viana, "Eletromagnetismo II - As Equações de Maxwell," Universidade Federal do Paraná, Curitiba , 2015.

[13] J. C. Maxwell, A Dynamical Theory of the Electromagnetic Field, Roy. Soc.Proc. XIII. , 1864.

[14] J. C. Maxwell, A Treatise on Electricity and Magnetism, 1873.

[15] G. de Freitas Guimarães, “Amplificador e conversor de comprimento de onda híbrido TDFA/FOPA para comunicações ópticas”.

[16] G. P. Agrawal, Fiber-Optic Communication Systems, John Wiley \& Sons, Inc. , 2002.

[17] J. B. Carvalho, "Controle de Estado de Polarização da Luz em Sistemas Ópticos,” Rio de Janeiro, PUC-Rio, 2012.

[18] [Online]. Available:

http://coral.ufsm.br/gpscom/professores/ComDados14_novo_Renato.pdf.

[19] "Wavelength References," [Online]. Available:

http://www.wavelengthreferences.com/products/single-mode-flowcells/

[20] R. P. T. Jane Hodgkinson, "Optical gas sensing: a review," Measurement Science and Technology, 2013.

[21] "Optical gas sensing: a review," Sci. Technology, [Online]. Available: http://iopscience.iop.org/0957-0233/24/1/012004.

[22] T. M. J. C. K. C. a. Y. J. Adler F, “Cavity-enhanced direct frequency comb spectroscopy: technology and applications," Rev. Anal. Chem., 2010.

[23] R. P. S. J, "Photonic crystal fibers," Journal of Lightwave Technology, 2006.

[24] P. A. S. R. W. L. B. D. A. F. G. J, “ Tunable diode laser absorption spectroscopy in coiled hollow optical waveguides," Appl. Opt., vol. 41, n 2002.

[25] P. C. J. S. d. Matos, "Fibras de cristal fotônico: novas plataformas para estudos deóptica não-linear, sensoriamento e dispositivos fotônicos," [Online]. Available: Grupo de Fotônica - Universidade Presbiteriana Mackenzie.

[26] K. K. K. I. a. T. T. Yoshino, "Fiber Optic Pressure Sensor," The Journal os the Acoustical Society of America, 1980. 
[27] B. D. H. S. C. B. G. A. L. H. C. J, “ Photonic band-gap fiber gas cell fabricated using femtosecond micromachining," Opt. Express, 2007.

[28] F. C. Fávero, "Sensores a Fibra Óptica Microestruturadas," Pontificia Univerdade Católica do Rio de Janeiro, Rio de Janeiro, 2012.

[29] L. J. C. A. H. B. J. A. L. H. P. W. H, “Chemical sensing using fiber cavity ring-down spectroscopy," Sensors, vol. 10, nº 2010.

[30] A. I. d. S. J. A. M. F. B. R. J. Casella, “ ABSORÇÃO ATÔMICA,” IFRJ.

[31] E. E. e. M. P. Souza, "A Lei de Beer Aplicada na Atmosfera Terrestre," [Online]. Available: Instituto Nacional de Pesquisas Espaciais.

[32] A. M. G, "Diode laser absorption sensors for gas-dynamic and combustion," Measurement Science and Technology, 1998.

[33] T. F. S. A. Q. Instruments, Instruction Manual Optical Filter $\mathrm{CO}_{2}$ Analyzer Model 410i, Thermo Scientific, 2010.

[34] “Optiwave,” [Online]. Available: http://optiwave.com/.

[35] “HITRAN," [Online]. Available: http://hitran.org/.

[36] A. C. N. B. J. Y. Xu, “A theoretical evaluation of fibre-optic evanescent wave absorption in spectroscopy and sensors," Optics and Lasers Engineering, pp. 93-101, 2006.

[37] C. Russell, Optofluidics, Sensors and Actuators in Microstructured Optical Fibers, 2006.

[38] R. T. J. M. Dudley, Supercontinuum Generation in Optical Fibers, 2010.

[39] A. G. M. I. C. a. M. B. G. C. Righini, Fiber and Integrated Optics Sensors: Fundamentals and Applications.

[40] “ACREO,” [Online]. Available: https://www.acreo.se/.

[41] M. M. M. V. P. R. F. F. I. L. Carvalho J. B., "Detectores de Sinais de Microondas," UFJF, Juiz de Fora, 2012.

[42] “Optiwave,” 2014. [Online]. Available: http://optiwave.com/.

[43] W. S. S. S. E. P. F. A. H. S. E.-H. H. A. V. S. M. T. M, "Sensing with suspended-core optical fibers," Opt. Fiber Technology, vol. 16, 2010.

[44] R. G. T. J. H. P. B. L. V. I. C. Q. T. N. S. F. A. J. L. D. F, “Chalcogenide glas hollow core photonic crystal fibers," Opt. Mater, vol. 32, no 2010. 
[45] “THORLABS,”. Available:

https://www.thorlabs.com/thorproduct.cfm?partnumber=HC-2000.

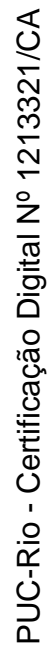

